\title{
Development and Environmental Applications of Activated Carbon Cloths
}

\author{
Ana Lea Cukierman ${ }^{1,2,3}$ \\ ${ }^{1}$ Programa de Investigación y Desarrollo de Fuentes Alternativas de Materias Primas y Energía (PINMATE), \\ Depto. de Industrias, Facultad de Ciencias Exactas y Naturales, Universidad de Buenos Aires, Intendente Güiraldes 2620, \\ Ciudad Universitaria, (C1428BGA) Buenos Aires, Argentina \\ ${ }^{2}$ Consejo Nacional de Investigaciones Científicas y Técnicas (CONICET), Av. Rivadavia 1917, (C1033AAJ) Buenos Aires, Argentina \\ ${ }^{3}$ Cátedra de Tecnología Farmacéutica II, Depto. de Tecnología Farmacéutica, Facultad de Farmacia y Bioquímica, \\ Universidad de Buenos Aires, Junín 956, (C1113AAD) Buenos Aires, Argentina
}

Correspondence should be addressed to Ana Lea Cukierman; analea@di.fcen.uba.ar

Received 23 December 2012; Accepted 13 January 2013

Academic Editors: P. V. Bonnesen, C. Chen, C. B. Coldeira, and C. Perego

Copyright (c) 2013 Ana Lea Cukierman. This is an open access article distributed under the Creative Commons Attribution License, which permits unrestricted use, distribution, and reproduction in any medium, provided the original work is properly cited.

\begin{abstract}
Activated carbon cloths have received growing attention because they offer comparative advantages over the traditional powdered or granular forms of this well-known adsorbent, providing further potential uses for technological innovations in several fields. The present article provides an overview of research studies and advances concerned with the development of activated carbon cloths and their use as adsorbent in environmental applications, mostly reported in the last years. The influence of some fabrics and textile wastes used as precursors, and of main activation process variables on the development and physicochemical, mechanical and/or electrical properties of the resulting activated carbon cloths are first reviewed. Then, investigations dealing with the removal of water and air pollutants by adsorption onto activated carbon cloths, including advances toward optimizing their regeneration after organic vapors saturation, are presented.
\end{abstract}

\section{Introduction}

Activated carbon in powdered and granular forms is a wellknown, versatile adsorbent of widespread use in a broad spectrum of applications, including purification, remediation of polluted aquatic environments, treatment of liquid and gaseous effluents generated in industry, gas storage and delivery, metal recovery, catalysis, and biomedical applications, among various others [1-12]. Growing concern and stricter regulations pertaining to environmental pollution have led to the increase of the activated carbon demand, which is forecasted to continue raising in the near future $[13,14]$.

In the last years, activated carbon cloths (ACCs) have gained increasing interest because they offer comparative advantages over the traditional forms and potentialities for technological innovation in different fields, including their potential use in cell therapy, as a support for stem cell growth [15]. Main advantages arise from the small diameter of the fibers constituting ACC [16]. They include faster adsorption kinetics, higher efficiency, and larger capacity for adsorption due to the higher surface area and pore volume of the ACC. In particular, micropores $(<2 \mathrm{~nm})$ of ACC are directly connected to the external surface area, thus diminishing heat and mass transfer resistances and lowering pressure drops in flow units [3, 17-20]. Besides, activated carbon cloths are light materials that can be arranged in different stable configurations and provide a contiguous carbon form suited for electrical and electrochemical applications [2124]. Moreover, Joule effect heating of ACC offers additional benefits in terms of desorption for their in situ regeneration in volatile organic compounds (VOCs) treatment processes and for vapors recovery $[19,20,25-29]$.

Owing to their technological advantages, ACCs are promoting a new conception in equipment design [30], favoring the development of novel devices, that is, microstructured reactors for improving chemical process safety and intensification [31]. A growing numbers of studies for potential novel applications have been investigated in the last years 
[32], involving commercial samples in most cases. Either untreated or modified ACCs have been explored as catalyst or catalyst/biocatalyst support in several processes [33-44], as electrode materials [21, 22, 45-56], and as potential substrate for nanotube growth [57]. They have also been examined intensively for abatement of gaseous and liquid pollutants $[19,20,28,58-65]$, as well as for separation and purification of biomolecules [66]. Other applications investigated have included gas storage and separation, recovery, purification and/or sensing of $\mathrm{H}_{2}$, and sour gas sweetening [67-72].

As for the conventional forms, the two main processes applied for the development of activated carbon cloths are the so-called physical or thermal activation and chemical activation $[3,17,19]$. Briefly, physical activation generally involves pyrolysis of the fabric used as a precursor, subsequently followed by gasification with an oxidizing gas, often steam or $\mathrm{CO}_{2}$, under strictly controlled conditions. In some recent studies, the preparation of activated carbon fibers using supercritical fluids, water, and $\mathrm{CO}_{2}$, has been investigated [73-75]. On the other hand, chemical activation involves impregnation of the precursor frequently with a Lewis acid, such as zinc chloride and phosphoric acid, followed by pyrolysis of the impregnated precursor. Washing of the soobtained product to eliminate the remaining impregnating agent leads to a complete porous structure development. In particular, the use of cellulose-based precursors and alkalis as impregnating agents, that is, $\mathrm{KOH}$, requires carbonization of the precursor prior to the impregnation stage due to the important reactivity of cellulose at low temperatures, which might even lead to the destruction of the fibrous nature of the samples [11, 76]. Advantages and drawbacks of these processes have been reported in detail elsewhere [3, 17, 19]. Properties of the resulting activated carbon cloths are highly dependent on the precursor, the activation process, and process parameters used. Development of activated carbon cloths is more complex in comparison with that of the traditional forms since the ACCs require a highly developed porous structure whilst preserving integrity of the constituent fibers, namely, they must possess an adequate strength to prevent break-up and dusting [3].

The aim of the present paper is to provide an overview of research studies dealing with the development of activated carbon cloths and their use in environmental applications, mostly reported in the last years. A selection of studies concerned with the effect of the precursor and of main process variables on the development and characteristics of the resulting activated carbon cloths is first presented. Then, some environmental applications exploring the use of ACC, limited to their role as adsorbent, for the removal of pollutants from water and air are summarized.

\section{Development of Activated Carbon Cloths: Effect of the Precursor and Activation Process Variables}

Different natural and synthetic polymeric precursors have been investigated for the development of activated carbon fibers and activated carbon cloths. The precursors mostly examined have included cellulose and regenerated cellulose (mainly, viscous rayon), polyacrylonitrile (PAN), pitch, polyimides, aramids, polyvinyl alcohol, and phenolicbased materials [19, 75, 77-92]. Recently, the preparation of microporous activated carbon fibers from poly (p-phenylene benzobisoxazole) has also been reported $[93,94]$.

For physical activation of a given precursor, experimental variables involved in the pyrolysis and gasification stages, such as heating rate, temperature, activating gas, gas flow rate, and degree of burn-off, have been examined. Among the variables involved in chemical activation, the chemical reagent used as impregnating agent and its concentration, impregnating agent to precursor ratio, soaking time, and pyrolysis temperature have been primarily studied. Their influence on process yield and on different characteristics of the resulting activated carbon cloths, that is, chemical composition, morphology, texture, mechanical and electrical properties, and behavior in some specific applications, has been explored. Some selected studies exploring the aforementioned aspects and mainly involving cellulose-based or relatively low-cost precursors are summarized below.

For instance, Rodríguez Reinoso and coworkers reported a series of comprehensive studies concerned with preparation of activated carbon cloths from viscous rayon fabric by both the physical and chemical activation processes, examining the effect of process variables on the development of porous structures and mechanical properties of the resulting ACC [77-80]. For physical activation, slower carbonization rates were found to induce increases in yield, strength and micropore volume of the resulting char, lower reactivity in gasification, and micropores with narrower entrances. Air preoxidation of the precursor led to the increase of the carbonization yield and breaking load. Among other investigated aspects concerned with the char gasification stage, the effects of the activation temperature $\left(750-850^{\circ} \mathrm{C}\right)$ and of the activating gas $\left(\mathrm{CO}_{2}\right.$ or steam) on porosity development and breaking load of the ACC were examined. For $\mathrm{CO}_{2}$ activation, lower temperatures were found to enhance the adsorption capacity and micropore volumes of the ACC, with slightly lower volumes of mesopores. The trend was explained by the slower, more uniform gasification taking place at lower temperatures and the lower gradient of the reacting gas concentration through the pores. Whereas $\mathrm{CO}_{2}$ led to a continuous development of narrow microporosity and slight widening from $30 \mathrm{wt} \%$ burn-off, steam was found to induce ACC with smaller micropores volumes. The latter was attributed to the widening of wider microporosity from the process onset. Higher loss in strength was determined for the ACC obtained by $\mathrm{CO}_{2}$ activation as a result of narrow pores deepening. The breaking loads were found to depend on the initial carbonization conditions, and to decrease with the extent of activation and increasing rates of activation, among other findings $[3,78,79]$. On the other hand, the effect of the chemical activating agent and the concentration used in the impregnation stage of the chemical activation process on yield, porosity, and breaking load of the viscous rayon-based ACC at preestablished operating conditions was studied [80]. Aqueous solutions of $\mathrm{AlCl}_{3}, \mathrm{ZnCl}_{2}, \mathrm{NH}_{4} \mathrm{Cl}$, $\mathrm{FeCl}_{3}, \mathrm{CuCl}_{2}, \mathrm{H}_{3} \mathrm{PO}_{4}$, and $\mathrm{Na}_{2} \mathrm{HPO}_{4}$ of concentrations in the 
range of $1-12 \mathrm{wt} \%$ were employed. Higher yields found for the fabric impregnated with the different chemicals compared to that for the precursor without impregnation were explained accounting for modifications in the precursor's pyrolysis occasioned by the impregnating agent, favoring dehydration over depolymerization. Porosity development was found to be markedly dependent on the reagent used. All chlorides led to ACC with narrow microporosity and constrictions, whereas $\mathrm{H}_{3} \mathrm{PO}_{4}$ promoted wider microporosity, especially at the higher concentrations, and $\mathrm{Na}_{2} \mathrm{HPO}_{4}$ led to a significant mesoporosity. The highest yields (36\%) were achieved using $5 \mathrm{wt} \%$ of $\mathrm{AlCl}_{3}$ and $\mathrm{H}_{3} \mathrm{PO}_{4}$. Besides, it was found that $\mathrm{AlCl}_{3}$ led to the most pronounced increase of the breaking load, from 10 to $32 \mathrm{~N}$ for $\sim 5 \mathrm{wt} \%$ concentration $[3,80]$.

Changes in the porous structure during fast heating $\left(100^{\circ} \mathrm{C} \mathrm{min}{ }^{-1}\right)$ to the activation temperature $\left(850^{\circ} \mathrm{C}\right)$ for viscose fibers pyrolyzed to different final temperatures (400, 600 , and $850^{\circ} \mathrm{C}$ ) were examined [95]. The results showed the existence of a level of internal ordering during pyrolysis and a range of temperature differences of pyrolysis and activation, where fast increase of carbon fiber temperature before activation was found to be advantageous for porous structure development. Furthermore, the development of activated carbon cloths from viscous fabrics by chemical activation with aqueous potassium hydroxide solution was investigated [46]. Their potentialities as electrode materials for electrochemical capacitors were also assessed. The fabrics were pyrolyzed at $400^{\circ} \mathrm{C}$ and $600^{\circ} \mathrm{C}$ in $\mathrm{Ar}$ atmosphere for $1 \mathrm{~h}$, prior to impregnation with $12-25 \mathrm{wt} \% \mathrm{KOH}$ solutions. Different alkali/carbon ratios were used, from $3.5: 1$ to $5: 1$, depending on the concentration of the impregnating solution. For the activation stage, the samples were thermally treated from 680 to $800^{\circ} \mathrm{C}$ in $\mathrm{Ar}$ atmosphere during $30-120 \mathrm{~min}$. Depending on the experimental conditions used, the resulting ACC were characterized by surface areas ranging between 1300 and $2000 \mathrm{~m}^{2} \mathrm{~g}^{-1}$ and predominance of micropores in most cases. The results demonstrated that appropriate activated carbon cloths for positive and negative capacitor electrodes both in acidic and alkaline media could be obtained by a careful selection of process parameters.

The role of carbon fibers crystallinity in chemical activation with alkali hydroxides was examined [96]. For this purpose, carbon fibers of different structural order, as precursors, and either $\mathrm{KOH}$ or $\mathrm{NaOH}$ as impregnating agents, were used. Increase in structural order of the fibers was found to make the activation more difficult. The results also confirmed that the hydroxide used had an important role in porosity development, in turn depending on the precursor. $\mathrm{NaOH}$ was found more effective than $\mathrm{KOH}$ in porosity development for pitch-based carbon fibers, possessing the lowest crystallinity. Instead, $\mathrm{KOH}$ generated a greater pore volume than $\mathrm{NaOH}$ for PAN-based carbon fibers and nanofibers with high crystallinity. As pointed out in this study, the results support the formation of intercalation compounds during the activation process of the carbon fibers, especially for $\mathrm{KOH}$ and the high structural order PAN-based carbon fiber.

Precursors with high nitrogen content, such as those based on PAN and aramids, have received attention since an appreciable quantity of the heteroatom remaining in the final structure of the ACC favors the removal of sulfur containing compounds [87], avoiding further posttreatments. Among other $\mathrm{N}$-containing precursors investigated, studies involving commercial acrylic textile fibers, obtained by polymerization from acrylonitrile $(\sim 90 \mathrm{wt} \%)$ and vinyl acetate $(\sim 10 \mathrm{wt} \%)$ monomers, and physical activation with $\mathrm{CO}_{2}$ [67, 97-99] showed that these fibers could be used to produce activated carbon fibers with properties which compared favorably with those derived from nontextile PAN, Kevlar and Nomex. Microstructural characteristics of the product were found to depend on the precise nature of the precursor and the conditions involved in both stages of the activation process. The fiber processing could also affect the structure development during activation. In particular, for fibers activated at $900^{\circ} \mathrm{C}$, pronounced changes in the micropore volume, mean pore width, mean stack height, and reactivity were found over a very limited range of burn-off between 40 and $50 \%$. They were explained by a change in the mechanism of activation, from one mainly involving gasification of amorphous carbon at low burn-off to other principally associated with attack of individual crystallites and their reorganization at higher burn-off. A detailed examination of chemical transformations taking place in the acrylic textile fibers during the activation course indicated that thermal degradation of the precursor polymeric chain started with the cyclisation of the structure with acetate ion from vinyl acetate acting as a catalyst, and continued with both cyclisation and dehydrogenation reactions resulting in the formation of several functional groups [99]. The development of microand mesoporous ACC from a commercial acrylic textile cloth by physical activation with $\mathrm{CO}_{2}$ and the addition of boric acid and sodium hydrogen phosphate, as impregnating agents, were further investigated [100]. The use of the latter was found to yield ACC with greater mesopore volume than other conditions examined, which mainly resulted in microporous samples. The samples were found to be formed from layers of aromatic sheets that in a nanoscale resembled graphite. Xray diffraction results indicated microcrystallites with width between 5.9 and $7.6 \mathrm{~nm}$ and height between 2.4 and $2.7 \mathrm{~nm}$, corresponding to 7 to 8 parallel graphene layers. In addition, other results [101] showed that microwave treatment could be used as an effective method for modifying the surface chemistry of activated carbon fibers, leading to very basic carbons, with points of zero charge of around 11, as a result of the production of pyrone groups.

Within the growing scenario toward recycling and environmentally sustainable processes to produce useful products from wastes and in the search of lowering ACC cost, some proposals explored the use of wastes from the textile industry $[76,102-106]$ and also carpet wastes [107] as potential starting materials for ACC manufacture by physical and chemical activations. High quality ACC (specific surface area of $2400 \mathrm{~m}^{2} \mathrm{~g}^{-1}$; total pore volume of $1.15 \mathrm{~cm}^{3} \mathrm{~g}^{-1}$ ) were successfully developed from acrylic fabric wastes, by adopting sequential multistage carbonization subsequently followed by steam activation at $900^{\circ} \mathrm{C}$ for $5 \mathrm{~min}$. Prior to carbonization, stabilization of the precursor at $250^{\circ} \mathrm{C}$ for $5 \mathrm{~h}$ was carried out. 
The stabilization mechanism was found to be influenced by both the heating rate and environmental gases. The ACCs derived from the acrylic textile wastes were found superior to conventional commercial PAN-based ACC [102]. Recently, the effect of the pyrolysis temperature $\left(700-900^{\circ} \mathrm{C}\right)$ and of the activation time (up to $4 \mathrm{~h}$ ) for the steam gasification stage at $900^{\circ} \mathrm{C}$ was examined also using acrylic textile waste [106]. A maximum surface area of $750 \mathrm{~m}^{2} \mathrm{~g}^{-1}$ was attained for the sample produced from the char generated at $700^{\circ} \mathrm{C}$ and steam activated for $2 \mathrm{~h}$. The porosity was mainly microporous with an increase in mesopore fraction at higher degrees of burn-off. For all the samples, concentrations of basic groups were found to be pronouncedly higher than those of acidic groups. Differences in textural characteristics with those earlier reported could be due to differences in composition of the wastes used as precursor and in the experimental conditions employed in the activation process.

Furthermore, natural fibers generated as textile byproduct and processed via traditional textile manufacturing methods in the form of biomass fibrous nonwoven matting materials were examined $[76,103,104]$. Textile wastes of flax and hemp natural fibers as nonwoven, preformed matting materials were employed. Chemical activation using either solutions of $\mathrm{ZnCl}_{2}$ or $\mathrm{H}_{3} \mathrm{PO}_{4}$ acid was applied. The influences of the solutions concentration (20-200 wt\%) and of the temperature of the subsequent pyrolysis $\left(450-650^{\circ} \mathrm{C}\right)$ were investigated. The results showed that activated carbon matting with high surface area of over $2000 \mathrm{~m}^{2} \mathrm{~g}^{-1}$ could be produced. Final yield and surface area were found to be significantly influenced by the concentration of the activating agent and the pyrolysis temperature. Higher concentrations led to lower carbon yield. The flax generally produced higher yields compared to the hemp when $\mathrm{ZnCl}_{2}$ was used. Higher surface areas were attained with higher concentrations of the activating agent and lower temperatures of pyrolysis. Zinc chloride was found to produce significantly higher surface areas compared to phosphoric acid. The pore size distribution of the carbons could also be modified depending on the process conditions, although they were mainly microporous. Instead, it was found that physical activation of the flax textile waste at $800^{\circ} \mathrm{C}$ using steam led to samples predominantly mesoporous with surface area up to $840 \mathrm{~m}^{2} \mathrm{~g}^{-1}$. Mesoporous and microporous structures in the physically and chemically activated samples, respectively, were identified. More recently, hemp cloth-derived carbon fibers by chemical activation with $\mathrm{ZnCl}_{2}$ were also prepared [108]. In this case, maximum BET surface area of $915 \mathrm{~m}^{2} \mathrm{~g}^{-1}$ was attained at $800^{\circ} \mathrm{C}$. All the samples were microporous, with pore size distribution mainly within the $2 \mathrm{~nm}$ micropore region. Furthermore, use of different carpet wastes, as alternative low-cost, abundant precursors, through chemical activation with $\mathrm{KOH}$, by varying the activation temperature (600$900^{\circ} \mathrm{C}$ ) and $\mathrm{KOH}$ : char impregnation ratios (from 0.5:1 to $4: 1$ ), was examined in an attempt to produce economic adsorbents for the capture of $\mathrm{CO}_{2}$ emissions and also to contribute to reduce wastes disposal [107]. Both the type of precursor and the activation conditions were found to have a pronounced influence on the microporosity and $\mathrm{CO}_{2}$ capture capacities of the resulting samples. Maximum $\mathrm{CO}_{2}$ capacities were attained for the sample derived from a preconsumer carpet waste activated at $700^{\circ} \mathrm{C}$ for a $\mathrm{KOH}$ : char impregnation ratio of $1: 1$. It was found that this sample had the highest narrow microporosity $\left(\sim 0.5 \mathrm{~cm}^{3} \mathrm{~g}^{-1}\right)$, indicating that only those pores that are smaller than $1 \mathrm{~nm}$, were effective for $\mathrm{CO}_{2}$ adsorption at atmospheric pressure.

The feasibility of using some other nonconventional fabrics as novel ACC precursors, such as denim, lyocell, kenaf, indigo, and drill, has been explored in the last years, examining the effect of the activation process variables [28, 72, 109-113]. Ramos et al. [109] investigated the development of activated carbon cloths from denim fabric of widespread use and popularity due to its strength and durability, by $\mathrm{H}_{3} \mathrm{PO}_{4}$ acid activation in inert atmosphere. The effects of acid concentration (5-15wt\%) and final thermal treatment temperature $\left(600-950^{\circ} \mathrm{C}\right)$ on yield, chemical characteristics (elemental composition, ash, and total acidity), porosity development, morphology, and electrical properties of the resulting ACC were examined. In particular, it should be highlighted that only a few studies have been devoted to examine the effect of process variables on electrical properties of lab-prepared ACC on a macroscopic scale. Activated carbon cloths with well-preserved fibers integrity were achieved using denim as a precursor. As judged by thermogravimetric analysis, impregnation of the denim fabric with $\mathrm{H}_{3} \mathrm{PO}_{4}$ acid solutions induced noticeable changes in its thermal behavior, increasing the carbonization yield with respect to the nonimpregnated precursor as a result of reduction in volatile matter release. Likewise, $\mathrm{H}_{3} \mathrm{PO}_{4}$ acid activation modified the surface chemistry of the precursor, promoting formation of acidic functional groups on the surface of the resulting ACC; this was evidenced in the enhancement of total acidity and oxygen content of the samples. Surface properties of the denimderived ACC were dependent on a combined effect of the temperature and acid concentration, even though the former exerted a stronger influence. As for conventional activated carbon forms, progressive development of porosity took place as more acid was incorporated into the precursor, presumably due to dilation of the cross-linked structure, up to a limit above which reduction in porosity development occurred. It was explained by possible pores collapse occasioned by the larger excess of acid, presumably as a consequence of intensified dilation. Increasing the final thermal treatment temperature led to a pronounced increase of the BET surface area of the resulting ACC, although it was at the expense of decreases in yield. A maximum BET surface area of $1055 \mathrm{~m}^{2} \mathrm{~g}^{-1}$ and total pore volume of $0.53 \mathrm{~cm}^{3} \mathrm{~g}^{-1}$ were reached for $10 \mathrm{wt} \%$ acid concentration at $950^{\circ} \mathrm{C}$. Prolongation of the thermal treatment stage from $1 \mathrm{~h}$ to $3 \mathrm{~h}$ at this final temperature led to pronounced increases in BET area and total pore volume, attaining values of $\sim 2500 \mathrm{~m}^{2} \mathrm{~g}^{-1}$ and $1.9 \mathrm{~cm}^{3} \mathrm{~g}^{-1}$, respectively, at the expense of lower yields. Besides, almost all the denim-based ACCs were found electrically conductive, following ohmic behavior. Increasing the final temperature from 600 to $800^{\circ} \mathrm{C}$ led to a substantial change in the electrical conductivity, which was found to depend on the extent of porosity development. The ACCs were heated by Joule effect, 
attaining surface temperatures in the range of $300-500 \mathrm{~K}$, suggesting that they could be regenerated after saturation by electrothermal desorption.

The effect of the characteristics inherent to the fabric precursor on yield, physicochemical, and electrical properties of the resulting activated carbon cloths was also examined [110]. For this purpose, five different cellulose-based fabrics and $\mathrm{H}_{3} \mathrm{PO}_{4}$ acid activation at preestablished experimental conditions were used. The precursors included two pure cellulosic samples, denim, regenerated cellulose, and a fabric composed of a mixture of cellulose (37\%) and polyester (73\%) fibers. As evidenced by scanning electronic microscopy (SEM), all the ACC showed a well-preserved integrity of the fibers, except those obtained from one of the pure cellulosic precursors. For the investigated conditions, the ACC derived from denim showed BET surface area $\left(784 \mathrm{~m}^{2} \mathrm{~g}^{-1}\right)$ and total pore volume $\left(0.40 \mathrm{~cm}^{3} \mathrm{~g}^{-1}\right)$ lower than those obtained from the four other precursors $\left(1058-1183 \mathrm{~m}^{2} \mathrm{~g}^{-1}\right.$; $0.55-$ $\left.0.67 \mathrm{~cm}^{3} \mathrm{~g}^{-1}\right)$, whereas the carbon content and yield for the former (36\%) were higher. Electrical properties of the developed ACC were investigated to examine the possibility of regeneration by direct electrical heating. Electrical resistivity of the developed ACC was properly correlated with their elemental carbon content and total pore volume, the denimderived ACC showing the lowest electrical resistivity $(\sim 8 \times$ $10^{-3} \Omega \mathrm{m}$ ).

In another study, the feasibility of using Tencel fabric as a precursor for the manufacture of ACC by $\mathrm{H}_{3} \mathrm{PO}_{4}$ acid activation was investigated [111]. Tencel is the brand name for a recently improved fabric from a fiber generically called lyocell. Lyocell is a natural man-made fiber, produced in an environmentally friendly process from wood pulp, that has become popular in clothing. As a result of the controlled and regular structure of its nanofibrils, new functional properties can be introduced to Tencel fabrics. Compared to cotton and viscose fibers, higher strength (especially when wet) and higher modulus are considered two of the major physical benefits of lyocell fibers. In particular, the influence of the final thermal treatment temperature $\left(660-970^{\circ} \mathrm{C}\right)$ and the temperature programme (temperature of the isothermal step and heating rate) on yield, elemental composition, porosity development, and mechanical strength of the resulting ACC were examined. Acid solutions of $10 \mathrm{wt} \%$ concentration and impregnation ratio (mass of phosphoric acid/mass of dried precursor) of 0.21 were used for all the samples. The impregnated samples were heated up to the different final temperatures at a heating rate of $5^{\circ} \mathrm{Cmin}^{-1}$. To improve the mechanical resistance of the ACC, an isothermal step of $40 \mathrm{~min}$ was included in the thermal programme. The temperature of the isothermal step was varied in the range of $170-270^{\circ} \mathrm{C}$ for the ACC prepared at $864^{\circ} \mathrm{C}$. For the sake of comparison, ACC were also obtained at $864^{\circ} \mathrm{C}$ with a heating rate of $15^{\circ} \mathrm{C} \mathrm{min}^{-1}$. The activated carbon cloths developed from lyocell showed a well-developed pore structure and good mechanical strength. A predominance of fairly narrow micropores and good physical appearance were found using the different strategies for the thermal treatment stage. The textural characteristics of the derived ACC were mainly dependent on the final treatment temperature with the precise thermal programme having little effect. A maximum BET surface area of $1705 \mathrm{~m}^{2} \mathrm{~g}^{-1}$ and total pore volume of $0.67 \mathrm{~cm}^{3} \mathrm{~g}^{-1}$ were reached at $963^{\circ} \mathrm{C}$. For the ACC obtained at lower temperatures, there was a development of very narrow microporosity and constrictions in the entrance of the micropores. Comparison of micropore volume as a function of micropore width for the Tencel-based ACC along with some other common types of activated carbon fibers and cloths, enabled to demonstrate their excellent properties. For a given narrow pore width, they had higher micropore volumes than viscose or PAN-derived samples and, over the approximate range of $0.7-1.1 \mathrm{~nm}$, showed a micropore volume/width relationship very similar to phenolic fibers. On the other hand, the isothermal step and the slower heating rate were found to produce more resistant lyocell-based ACC, likely because these conditions induced a slower evolution of volatile matter, resulting in a more ordered structure and higher breaking load. The highest values of breaking strength $(0.47 \mathrm{MPa})$ and Young's modulus ( 74 MPa) in the weft direction were achieved for the ACC obtained at $864^{\circ} \mathrm{C}$, whereas a further increase in temperature to $963^{\circ} \mathrm{C}$ resulted in samples with the lowest values. For low activation degree, the increase in temperature led to better mechanical properties likely due to the predominant development of more ordered structures. In contrast, the deterioration in mechanical strength for the highest degree of activation could be due to the presence of higher and wider porosity, which considerably reduced the real cross-section of the fibers. More recently, the influence of different activating agents (ammonium citrate, boric acid, phosphoric acid, sodium dihydrogen phosphate, potassium dihydrogen phosphate, disodium hydrogen phosphate, and trisodium phosphate) on the development of activated carbon cloths by chemical activation of the lyocell precursor was further studied at pre-established conditions [113]. Their effect on main physicochemical characteristics and electrical behavior of the resulting ACC was explored. Solutions of $5 \mathrm{wt} \%$ concentration of the different chemical reagents were used. The impregnated samples were thermally treated under flowing nitrogen at $5^{\circ} \mathrm{C} \mathrm{min}^{-1}$ up to a temperature of $864^{\circ} \mathrm{C}$, which was maintained for $1 \mathrm{~h}$. The activating agent markedly influenced yield, elemental composition, and textural properties of the ACC. Phosphoric and boric acid-derived samples presented the highest yields (29\%), whereas the ACC developed with trisodium phosphate showed the lowest value. The highest carbon content ( 89\%) was obtained for the samples impregnated with sodium and potassium dihydrogen phosphate, while the ACC obtained with ammonium citrate showed the highest nitrogen content $(\sim 1 \%)$. Hydrogen content increased and yield decreased as the phosphorous compound employed for impregnation was more basic. This was explained by a more intense reaction between the precursor and the activating agent during impregnation, leading to the hydrolysis of the cellulose. The ACC obtained with phosphoric and boric acids were essentially microporous, while those developed with the other reagents presented mesoporosity. Phosphoric acid-derived samples showed the highest specific surface area $\left(\sim 980 \mathrm{~m}^{2} \mathrm{~g}^{-1}\right)$, whereas the ACC 
obtained with ammonium citrate showed the lowest value $\left(\sim 520 \mathrm{~m}^{2} \mathrm{~g}^{-1}\right)$. All the ACCs were electrically conductive, their resistivity being also strongly dependent on the nature of the activating agent. The ACC prepared with boric acid and ammonium citrate showed the highest $\left(21 \times 10^{-3} \Omega \mathrm{m}\right)$ and the lowest $\left(8 \times 10^{-3} \Omega \mathrm{m}\right)$ values of electrical resistivity, respectively. The electrical resistivity of the lyocell-based ACC obtained with all the phosphorous compounds was properly correlated with their $\mathrm{C} / \mathrm{H}$ ratio and micropore volume. The results indicated that by a proper selection of the activating agent, properties of the ACC derived from this novel precursor may be conveniently tailored depending on the desired application [113].

The preparation of activated carbon cloths from a precursor fabric of kenaf natural fibers was investigated by chemical activation using $\mathrm{K}_{2} \mathrm{HPO}_{4}$ solution as an activating reagent [112]. The effect of the carbonization temperature $\left(300-500^{\circ} \mathrm{C}\right)$, concentration of $\mathrm{K}_{2} \mathrm{HPO}_{4}$ solution (5$50 \% \mathrm{w} / \mathrm{v})$, heating rate to achieve the activation temperature $\left(2-30^{\circ} \mathrm{C} \mathrm{min}{ }^{-1}\right)$, activation temperature $\left(500-800^{\circ} \mathrm{C}\right)$, and activation time $(0.5-4 \mathrm{~h})$ on the adsorption ability of the derived samples, as determined from iodine number, was investigated. By applying an experimental design method based on orthogonal arrays, the optimal process conditions determined were carbonization temperature of $300^{\circ} \mathrm{C}$, solution concentration of $30 \% \mathrm{w} / \mathrm{v}$, heating rate of $2^{\circ} \mathrm{C} \mathrm{min}{ }^{-1}$, and temperature of $700^{\circ} \mathrm{C}$ for $2 \mathrm{~h}$. Increasing the activation temperature up to $700^{\circ} \mathrm{C}$, enhanced adsorption characteristics of the ACC due to formation of micropores in the resulting ACC. Further increase in activation temperature up to $800^{\circ} \mathrm{C}$ was found to decrease their adsorption ability. This was explained by the probable destruction of micropores and their transformation into larger pores reducing the adsorption ability. A relative low specific surface area $\left(\sim 500 \mathrm{~m}^{2} \mathrm{~g}^{-1}\right)$ with predominant contribution of micropores characterized the ACC samples obtained at optimized conditions. The performances of kenaf-derived ACC in the adsorption of phenol and p-nitrophenol from aqueous solutions were further investigated. On the other hand, two other nonconventional fabrics composed of $100 \%$ cotton (indigo and drill) as ACC precursors were explored [72]. The effect of the activating agent on microporosity, formation of oxygen surface groups, and behavior as molecular sieves for gas separation for the ACCs obtained by chemical activation was examined. As chemical reagents, solutions of $\mathrm{AlCl}_{3}, \mathrm{ZnCl}_{2}$, and $\mathrm{H}_{3} \mathrm{PO}_{4}$ of $2 \mathrm{wt} \%$ concentration were used. The impregnated and dried samples were thermally treated under a flow of $\mathrm{CO}_{2}$ at a heating rate of $5^{\circ} \mathrm{C} \mathrm{min}^{-1}$ up to a final treatment temperature of $850^{\circ} \mathrm{C}$ kept for $1 \mathrm{~h}$. All the samples exhibited microporosity and low contents of oxygen surface groups.

\section{Environmental Applications of Activated Carbon Cloths}

3.1. Adsorption of Water Pollutants onto Activated Carbon Cloths. The effectiveness of activated carbon cloths in the removal of different kinds of pollutant species from aqueous solutions, mimicking wastewater, or industrial liquid effluents has been investigated in the last years. Most studies involve experiments using commercial activated carbon cloths, batch mode, and single solute solutions. Only a few have been performed under dynamic conditions or using lab-prepared ACC or multisolute solutions. Some other publications include comparison of the adsorption capacity of the activated carbon cloths for particular pollutants with conventional forms and/or research on the adsorption mechanisms involved. Besides, in order to enhance the uptake of the pollutant species under investigation, different treatments of the activated carbon cloths, basically intended to tune their surface chemistry, have also been explored. The majority of the results show improvement in the removal of targeted pollutants for the ACC samples due to surface chemistry modifications. Major factors influencing liquid-phase adsorption of pollutants onto activated carbons have been examined, mainly including porous structure characteristics and surface chemistry of the ACC samples, the shape, size, charge, solubility, hydrophobicity and/or aromaticity of the adsorbate, and the $\mathrm{pH}$ and ionic strength of the liquid medium employed in adsorption assays.

3.1.1. Adsorption of Inorganic Pollutants onto Activated Carbon Cloths. The discharge of effluents containing pollutants generated from different anthropogenic activities, such as heavy metals, nitrates, phosphates, into water courses constitutes a serious environmental problem which affects water quality. It is well recognized that concentrations of these species above the admissible threshold in aquatic environments cause harmful effects on humans and a variety of other living species because of their toxicity, persistence, and accumulation in living tissues throughout the food chain $[7,12]$. Heavy and/or toxic metals are present in raw wastewater streams from several industries such as plating plants, batteries, welding, and alloys manufacturing, nonferrous metals mineral processing, dye industries, porcelain enameling, and steamelectric power plants [114-117]. Different methods have been proposed to remove low concentrations of heavy metals from waste streams or drinking water, including precipitation, membrane processes (nanofiltration or reverse osmosis), oxidation, biotreatments, ion exchange, and adsorption, each one having merits and limitations. Among them, adsorption has demonstrated to be economically favorable and technically easy compared, for instance, with reverse osmosis or ion exchange [118].

Effect of Characteristics and/or of Posttreatments of Activated Carbon Cloths on Metal Ions Removal. Research on adsorption of toxic metals onto ACC has mainly focused on $\mathrm{Cd}(\mathrm{II}), \mathrm{Pb}(\mathrm{II}), \mathrm{Co}(\mathrm{II}), \mathrm{Cu}(\mathrm{II}), \mathrm{Ni}(\mathrm{II}), \mathrm{Cr}(\mathrm{III}), \mathrm{Cr}(\mathrm{VI})$, and $\mathrm{Zn}$ (II) ions. Selected studies involving lab-developed and commercial activated carbon cloths, either pristine or modified by different posttreatments, are summarized below. Some representative examples are shown in Table 1. In most of these studies adsorption kinetics and equilibrium isotherms were determined. Kinetics was in general represented by either a pseudofirst- or pseudosecond-order rate model, whereas 
the isotherms were mainly fitted to the conventional twoparameter Freundlich or Langmuir models.

For instance, the effect of porous texture of two different commercial rayon-based activated carbon cloths (Actitex Co., Levallois, France), on the adsorption of $\mathrm{Cu}(\mathrm{II}), \mathrm{Ni}(\mathrm{II})$, and $\mathrm{Pb}$ (II) ions was examined [119]. The ACC samples were obtained by activation using $\mathrm{CO}_{2}$ at $1200^{\circ} \mathrm{C}$ (CS 1501) or steam at $900^{\circ} \mathrm{C}$ (RS 1301). The former possessed more than $96 \%$ of micropore volume, while the latter was characterized by $32 \%$ of mesopore volume (Table 1 ). The results showed the dependency of adsorption on the metal ion size and ACC porosity. Among the investigated species, the largest cation $\mathrm{Pb}$ (II) was found to be more adsorbed onto the sample with greater presence of mesopores. An adsorption mechanism by ion exchange between the metal cations and $\mathrm{H}^{+}$ions at the surface of the ACC was proposed. Seemingly, carboxylic groups were especially involved in the mechanism, and precipitation between metal ions could also take place.

One of the scarce publications involving lab-prepared activated carbon cloths [109] explored the effect of the porous characteristics and surface chemistry of ACC, obtained by phosphoric acid activation ( $10 \mathrm{wt} \%$ acid concentration) of denim fabric at two different final thermal treatment temperatures $\left(600^{\circ} \mathrm{C}\right.$ and $\left.950^{\circ} \mathrm{C}\right)$, on the adsorption of $\mathrm{Zn}[\mathrm{II}]$ ions at preestablished equilibrium conditions (Table 1). Blank samples obtained by using distilled water instead of the acid in the impregnation stage were also employed for comparison. The ACC obtained at $600^{\circ} \mathrm{C}$ possessing maximum total acidity $\left(1 \mathrm{mmol} \mathrm{g}^{-1}\right)$ presented the highest zinc adsorption (90\%). This sample, however, showed the poorest porosity development $\left(510 \mathrm{~m}^{2} \mathrm{~g}^{-1}\right.$ and $\left.0.26 \mathrm{~cm}^{3} \mathrm{~g}^{-1}\right)$, similar to that determined for the blank with a total acidity of $0.15 \mathrm{mmol} \mathrm{g}^{-1}$, which in turn exhibited the lowest $\mathrm{Zn}$ (II) ion uptake (7\%). The ACC prepared at $950^{\circ} \mathrm{C}$ with a relatively low total acidity $(0.48 \mathrm{mmol} / \mathrm{g})$ and the best surface properties $\left(1055 \mathrm{~m}^{2} \mathrm{~g}^{-1}\right.$, $0.53 \mathrm{~cm}^{3} \mathrm{~g}^{-1}$ ) demonstrated a poor effectiveness in $\mathrm{Zn}$ (II) ion capture, only attaining $17 \%$. The trend agrees with results reported for the adsorption of different metal ions on conventional activated carbons and on some commercial ACC $[7,63,114]$. Total acidity of carbon sorbents is important in relation to their potentiality for liquid-phase adsorption of inorganic and organic polar molecules, particularly for wastewater treatment $[2,4,6-8]$. The results highlighted the relevance of acidic oxygen surface groups on the denimbased ACC in connection with their behavior as cationic exchangers, in line with results for conventional activated carbons. Dissociation or polarization of these groups, involving carboxyls, carbonyls, phenols, and lactones, provides anionic characteristics to the surface of the carbons immersed in aqueous solutions, thus favoring their behavior as cationic exchangers.

In the same direction, several studies using commercial ACC samples have applied different kinds of treatments in order to modify the surface chemistry and examine its influence on metal ion adsorption (Table 1). For instance, the effect of applying different oxidation treatments to a commercial activated carbon cloth based on PAN fiber
(KoTHmex TC-66 C, Taiwan) on adsorption of Cd(II) ions was investigated [120], comparatively using pristine and oxidized samples (Table 1). The surface of the ACC was modified by oxidation with nitric acid solution, ozone and electrochemical oxidation. From comparative adsorption experiments, a pronounced increase in cadmium uptake, 13 times greater, was found for the electrochemically oxidized ACC, in agreement with an increase in the total exchange capacity for the oxidized samples with respect to the pristine samples. Equilibrium sorption isotherms at different $\mathrm{pH}$ values, between 4 and 6, were determined. The results showed that cadmium uptake increased with the increasing $\mathrm{pH}$. Although oxidation with ozone occasioned physical damage to the ACC, the acid and electrochemically oxidized samples were found stable. Leyva-Ramos et al. [130] also investigated $\mathrm{Cd}[\mathrm{II}]$ ion adsorption onto a PAN-based ACC oxidized with $\mathrm{HNO}_{3}$ solution. Due to the greater concentration of acidic sites generated upon oxidation, the adsorption capacity of the oxidized ACC was higher than that of the untreated ACC, in agreement with other results for systems involving activated carbons and metal ions. In addition, the results also attested the pronounced influence of the solution $\mathrm{pH}$ and, to a lesser extent, of the temperature. The maximum adsorption of cadmium was found to take place at $\mathrm{pH} 8$, increasing near 22 times for $\mathrm{pH}$ increases from 2 to 8 , whereas a twofold decrease in the adsorption capacity was attained when the temperature increased from 15 to $35^{\circ} \mathrm{C}$.

As may be seen in Table 1, treatments with other chemical reagents were also investigated. A commercial ACC (Spectracarb 2225 from Spectra Corp., specific surface area $=2500 \mathrm{~m}^{2} \mathrm{~g}^{-1}$ ) was treated with $\mathrm{NaOH}$ solution and with the chelating agent ethylenediaminetetraacetic acid (EDTA) to examine the effect of these treatments on its adsorption capacity of monovalent, divalent, trivalent, and tetravalent metal ions from single solute solutions $[121,122]$. The metal ions investigated included: $\mathrm{Ag}[\mathrm{I}], \mathrm{Bi}[\mathrm{II}], \mathrm{Cd}[\mathrm{II}], \mathrm{Cu}[\mathrm{II}]$, $\mathrm{Co}[\mathrm{II}], \mathrm{Fe}[\mathrm{III}], \mathrm{Ni}[\mathrm{II}], \mathrm{Pb}[\mathrm{II}], \mathrm{Sb}[\mathrm{III}], \mathrm{Sn}[\mathrm{IV}], \mathrm{Sr}[\mathrm{II}], \mathrm{Ti}[\mathrm{I}]$, and $\mathrm{Zn}[\mathrm{II}]$. Adsorption isotherms for each cation onto the unmodified and treated samples were determined at room temperature and nearly neutral $\mathrm{pH}$ values. Both treatments led to the enhancement of the adsorption of the majority of the metal cations onto the ACC in the range of 1.26.6, as reflected in the estimated Langmuir and Freundlich model parameters. Adsorption on the unmodified ACC was attributed to surface complex formation and exchange between metal ions and acidic functional groups, with these groups only covering a small fraction of the carbon surface area. The applied treatments were found to increase the number of active sites, probably due to the surface reaction occurring to lactone groups in the case of the $\mathrm{NaOH}$ treatment and to the additional chelation of metal ions via nitrogen and carboxyl groups for the EDTA treatment. The same commercial ACC (Spectracarb 2225) was further modified by attachment of some monobenzo- and dibenzocrown ethers to enhance the adsorption of $\mathrm{Cr}$ [III], $\mathrm{Co}$ [II], and $\mathrm{Ni}[\mathrm{II}]$ ions [123]. The effects of the type and cavity size of the crown ethers and the size and form of the ions on the extent of adsorption were analyzed in terms of interactions of the adsorbate species with the ACC surface. The adsorption 
TABLE 1: Some selected studies involving activated carbon cloths (ACCs) for metal species removal.

\begin{tabular}{|c|c|c|c|c|}
\hline Sample & ACC characteristics & $\begin{array}{c}\text { Metal species } \\
\text { investigated }\end{array}$ & Adsorption assays & Reference \\
\hline $\begin{array}{l}\text { Commercial ACC } \\
\text { Kynol Europe }\end{array}$ & $\begin{array}{l}\text { As-received ACC: } \\
A_{\mathrm{BET}}=2128 \mathrm{~m}^{2} \mathrm{~g}^{-1} ; V_{m}=0.913 \mathrm{~cm}^{3} \mathrm{~g}^{-1} ; \\
V_{M}=0.028 \mathrm{~cm}^{3} \mathrm{~g}^{-1} ; \\
L_{0}=1.69 \mathrm{~nm} ; \mathrm{pH}_{\mathrm{PZC}}=8.0 \\
\text { Oxidized ACC: } \\
A_{\mathrm{BET}}=1636 \mathrm{~m}^{2} \mathrm{~g}^{-1} ; V_{m}=0.716 \mathrm{~cm}^{3} \mathrm{~g}^{-1} ; \\
V_{M}=0.030 \mathrm{~cm}^{3} \mathrm{~g}^{-1} ; \\
L_{0}=1.80 \mathrm{~nm} ; \mathrm{pH}_{\mathrm{PZC}}=3.3\end{array}$ & $\begin{array}{l}\mathrm{Cr}[\mathrm{III}] \\
\mathrm{Mn}[\mathrm{II}] \\
\mathrm{Cu}[\mathrm{II}] \\
\mathrm{Zn}[\mathrm{II}]\end{array}$ & $\begin{array}{l}\text { Batch mode } \\
\text { Single solute sol. } \\
T=15^{\circ} \mathrm{C}, 35^{\circ} \mathrm{C} \\
C_{0}=0.05-2.9 \mathrm{mM} \\
\mathrm{pH}=3.5-6.1\end{array}$ & {$[63]$} \\
\hline $\begin{array}{l}\text { Lab-prepared } \\
\text { denim-based ACC by } \\
\mathrm{H}_{3} \mathrm{PO}_{4} \text { activation at } \\
\text { different conditions }\end{array}$ & $\begin{array}{l}\text { ACC }\left(T=600^{\circ} \mathrm{C}, 10 \mathrm{wt} \% \text { acid conc. }\right): \\
A_{\mathrm{BET}}=510 \mathrm{~m}^{2} \mathrm{~g}^{-1} ; V_{T}=0.26 \mathrm{~cm}^{3} \mathrm{~g}^{-1} \\
\text { Total acidity }=1 \mathrm{mmol} \mathrm{g}^{-1} \\
\text { ACC }\left(T=950^{\circ} \mathrm{C}, 10 \mathrm{wt} \% \text { acid conc. }\right): \\
A_{\text {BET }}=1055 \mathrm{~m}^{2} \mathrm{~g}^{-1} ; V_{T}=0.53 \mathrm{~cm}^{3} \mathrm{~g}^{-1} \\
\text { Total acidity }=0.48 \mathrm{mmol} \mathrm{g}^{-1}\end{array}$ & $\mathrm{Zn}[\mathrm{II}]$ & $\begin{array}{l}\text { Batch mode } \\
T=25^{\circ} \mathrm{C} \\
\mathrm{pH}=3 \\
C_{0}=0.30 \mathrm{mM}\end{array}$ & [109] \\
\hline $\begin{array}{l}\text { Commercial } \\
\text { rayon-based ACC: } \\
\text { CS 1501; RS } 1301 \\
\text { Actitex Co., France }\end{array}$ & $\begin{array}{l}\text { CS 1501: } \\
A_{\mathrm{BET}}=1689 \mathrm{~m}^{2} \mathrm{~g}^{-1} ; V_{T}=0.665 \mathrm{~cm}^{3} \mathrm{~g}^{-1} ; \\
V_{m}=0.6384 \mathrm{~cm}^{3} \mathrm{~g}^{-1} ; \mathrm{pH}_{\mathrm{PZC}}=7.6 \\
\text { RS 1301: } \\
A_{\mathrm{BET}}=1460 \mathrm{~m}^{2} \mathrm{~g}^{-1} ; V_{T}=0.506 \mathrm{~cm}^{3} \mathrm{~g}^{-1} ; \\
V_{m}=0.345 \mathrm{~cm}^{3} \mathrm{~g}^{-1} ; \mathrm{pH}_{\mathrm{PZC}}=9.5\end{array}$ & $\begin{array}{l}\mathrm{Cu}[\mathrm{II}] \\
\mathrm{Pb}[\mathrm{II}] \\
\mathrm{Ni}[\mathrm{II}]\end{array}$ & $\begin{array}{l}\text { Batch mode } \\
\text { Single solute sol. } \\
T=20^{\circ} \mathrm{C} \\
\mathrm{pH}=2-10 \\
C_{0}=0.1-1.4 \mathrm{mM}\end{array}$ & [119] \\
\hline $\begin{array}{l}\text { Commercial PAN-based } \\
\text { ACC } \\
\text { TC-66 C KoTHmex, } \\
\text { Taiwan }\end{array}$ & $\begin{array}{l}\text { As-received ACC: } \\
A_{\mathrm{BET}}=973 \mathrm{~m}^{2} \mathrm{~g}^{-1} ; \mathrm{Dp}=1.79 \mathrm{~nm} ; \\
\mathrm{pH}_{\mathrm{PZC}}=4.2 \\
\text { ACC oxidized with } \mathrm{HNO}_{3}: \\
A_{\mathrm{BET}}=730 \mathrm{~m}^{2} \mathrm{~g}^{-1} ; \mathrm{Dp}=1.83 \mathrm{~nm} ; \\
\mathrm{pH} \\
\text { Electrochemically oxidized ACC: } \\
A_{\mathrm{BET}}=730 \mathrm{~m}^{2} \mathrm{~g}^{-1} ; \mathrm{Dp}=1.83 \mathrm{~nm} ; \\
\mathrm{pH}_{\mathrm{PZC}}=2.25\end{array}$ & $\mathrm{Cd}[\mathrm{II}]$ & $\begin{array}{l}\text { Batch mode } \\
T=25^{\circ} \mathrm{C} \\
\mathrm{pH}=4-6 \\
C_{0}=0.05-1.0 \mathrm{mM}\end{array}$ & {$[120]$} \\
\hline $\begin{array}{l}\text { Commercial ACC } \\
\text { Spectracarb 2225, } \\
\text { Spectra Corp., USA }\end{array}$ & $\begin{array}{l}\text { ACC washed: } \\
A_{\mathrm{BET}}=1870 \mathrm{~m}^{2} \mathrm{~g}^{-1} ; V_{T}=0.827 \mathrm{~cm}^{3} \mathrm{~g}^{-1} ; \\
V_{m}=0.709 \mathrm{~cm}^{3} \mathrm{~g}^{-1} ; \\
V_{M}=0.082 \mathrm{~cm}^{3} \mathrm{~g}^{-1} ; \\
\mathrm{pH} \text { PZC }=7.4 \\
\text { Treated with } \mathrm{NaOH} \text { and } \\
\text { with chelating agent EDTA }\end{array}$ & $\begin{array}{c}\mathrm{Co}[\mathrm{II}], \mathrm{Cu}[\mathrm{II}] \\
\mathrm{Bi}[\mathrm{II}], \mathrm{Cd}[\mathrm{II}] \\
\mathrm{Ni}[\mathrm{II}], \mathrm{Sr}[\mathrm{II}] \\
\mathrm{Fe}[\mathrm{III}], \mathrm{Pb}[\mathrm{II}] \\
\mathrm{Sb}[\mathrm{III}], \mathrm{Sn}[\mathrm{IV}] \\
\mathrm{Zn}[\mathrm{II}], \mathrm{Ag}[\mathrm{I}] \\
\text { and } \mathrm{Ti}[\mathrm{I}]\end{array}$ & $\begin{array}{l}\text { Batch mode } \\
\text { Single solute sol. } \\
T=25^{\circ} \mathrm{C} \\
\mathrm{pH} \sim 7 \\
C_{0}=0.47-2 \mathrm{mM}\end{array}$ & {$[121,122]$} \\
\hline $\begin{array}{l}\text { Commercial ACC } \\
\text { Spectracarb 2225, } \\
\text { Spectra Corp., USA }\end{array}$ & $\begin{array}{l}\text { ACC washed: } \\
A_{\mathrm{BET}}=1870 \mathrm{~m}^{2} \mathrm{~g}^{-1} ; V_{T}=0.827 \mathrm{~cm}^{3} \mathrm{~g}^{-1} ; \\
V_{m}=0.709 \mathrm{~cm}^{3} \mathrm{~g}^{-1} ; \\
V_{M}=0.082 \mathrm{~cm}^{3} \mathrm{~g}^{-1} ; \\
\text { pH } \\
\text { Modified by benzo-crown ethers attachment }\end{array}$ & $\begin{array}{l}\mathrm{Cr}[\mathrm{III}] \\
\mathrm{Co}[\mathrm{II}] \\
\mathrm{Ni}[\mathrm{II}]\end{array}$ & $\begin{array}{l}\text { Batch mode } \\
\text { Single solute sol. } \\
T=30^{\circ} \mathrm{C} \\
\mathrm{pH}=6 \\
C_{0}=0.06 \mathrm{mM} \mathrm{Cr}(\mathrm{III}) \\
C_{0}=0.01 \mathrm{mM} \mathrm{Co}[\mathrm{II}] \\
C_{0}=0.02 \mathrm{mM} \mathrm{Ni}[\mathrm{II}]\end{array}$ & {$[123]$} \\
\hline $\begin{array}{l}\text { Commercial viscose } \\
\text { rayon-based ACC } \\
\text { Zorflex FM } 10 \\
\text { Charcoal Cloth } \\
\text { International }\end{array}$ & $\begin{array}{l}\text { As-received ACC: } \\
A_{\mathrm{BET}}=1378 \mathrm{~m}^{2} \mathrm{~g}^{-1} ; \\
\mathrm{dp}=20.5 \mathrm{~nm} ; \mathrm{pH}_{\mathrm{PZC}}=6.8 \\
\text { Electrochemically reduced ACC: } \\
A_{\mathrm{BET}}=998 \mathrm{~m}^{2} \mathrm{~g}^{-1} ; \mathrm{dp}=19.7 \mathrm{~nm} ; \\
\mathrm{pH} \\
\text { Electrochemically oxidized ACC: } \\
A_{\mathrm{BET}}=533 \mathrm{~m}^{2} \mathrm{~g}^{-1} ; \mathrm{dp}=18.7 \mathrm{~nm} ; \\
\mathrm{pH}_{\mathrm{PZC}}=2.8\end{array}$ & $\mathrm{Cr}[\mathrm{VI}]$ & $\begin{array}{l}\text { Batch mode } \\
T=25^{\circ} \mathrm{C} \\
\mathrm{pH}=4,6 \text {, and } 8 \\
C_{0}=0.19-9.62 \mathrm{mM}\end{array}$ & {$[124]$} \\
\hline
\end{tabular}


TABle 1: Continued.

\begin{tabular}{|c|c|c|c|c|}
\hline Sample & ACC characteristics & $\begin{array}{c}\text { Metal species } \\
\text { investigated }\end{array}$ & Adsorption assays & Reference \\
\hline $\begin{array}{l}\text { Commercial ACC } \\
\text { HEG Ltd., India }\end{array}$ & $\begin{array}{l}A_{\mathrm{BET}}=1565 \mathrm{~m}^{2} \mathrm{~g}^{-1} \\
V_{T}=0.65 \mathrm{~cm}^{3} \mathrm{~g}^{-1}\end{array}$ & $\mathrm{Cr}[\mathrm{VI}]$ & $\begin{array}{l}\text { Batch mode } \\
T=10,25, \text { and } 40^{\circ} \mathrm{C} \\
\mathrm{pH}=2-10 \\
C_{0}=0.02-1.92 \mathrm{mM}\end{array}$ & {$[125]$} \\
\hline $\begin{array}{l}\text { Commercial } \\
\text { rayon-based ACC: CS } \\
\text { 1501; RS } 1301 \\
\text { Actitex Co. }\end{array}$ & $\begin{array}{l}\text { CS 1501: } \\
A_{\text {BET }}=1689 \mathrm{~m}^{2} \mathrm{~g}^{-1} ; V_{T}=0.665 \mathrm{~cm}^{3} \mathrm{~g}^{-1} \\
V_{m}=96 \% ; \mathrm{pH}_{\text {PZC }}=7.6 \\
\text { RS 1301: } \\
A_{\text {BET }}=1460 \mathrm{~m}^{2} \mathrm{~g}^{-1} ; V_{T}=0.506 \mathrm{~cm}^{3} \mathrm{~g}^{-1} \\
V_{m}=68.2 \% ; \mathrm{pH}_{\text {PZC }}=9.5\end{array}$ & $\begin{array}{l}\mathrm{Cu}[\mathrm{II}] \\
\mathrm{Pb}[\mathrm{II}]\end{array}$ & $\begin{array}{l}\text { Batch mode } \\
T=20^{\circ} \mathrm{C} ; \mathrm{pH}=5 \\
\text { Single solute sol. } \\
C_{0}=0.1-1.4 \mathrm{mM} \\
\mathrm{Cu}[\mathrm{II}] \text { or } \mathrm{Pb}[\mathrm{II}] \\
\text { Binary solutions: } \\
\mathrm{Cu}[\mathrm{II}]+\mathrm{Pb}[\mathrm{II}]: \\
C_{0}=0.1-0.7 \mathrm{mM} \\
\mathrm{Cu}[\mathrm{II}] \text { or } \mathrm{Pb}[\mathrm{II}]+\text { Benzoic } \\
\text { acid }(\mathrm{BA}): \\
C_{0}=0.1-0.7 \mathrm{mM} \text { metal ions; } \\
C_{0}=10 \mathrm{mM} \mathrm{BA}\end{array}$ & [126] \\
\hline $\begin{array}{l}\text { Commercial ACC } \\
\text { Kynol Europe }\end{array}$ & $\begin{array}{l}\text { As-received ACC: } \\
A_{\mathrm{BET}}=2128 \mathrm{~m}^{2} \mathrm{~g}^{-1} ; V_{m}=0.905 \mathrm{~cm}^{3} \mathrm{~g}^{-1} \\
V_{M}=0.028 \mathrm{~cm}^{3} \mathrm{~g}^{-1} ; L_{0}=1.69 \mathrm{~nm} ; \\
\text { pH } H_{\text {PZC }}=8.0 \\
\text { Oxidized ACC: } \\
A_{\mathrm{BET}}=1636 \mathrm{~m}^{2} \mathrm{~g}^{-1} ; V_{m}=0.715 \mathrm{~cm}^{3} \mathrm{~g}^{-1} \\
V_{M}=0.030 \mathrm{~cm}^{3} \mathrm{~g}^{-1} ; L_{0}=1.80 \mathrm{~nm} ; \\
\mathrm{pH}_{\mathrm{PZC}}=3.3\end{array}$ & $\mathrm{Cd}[\mathrm{II}]$ & $\begin{array}{l}\text { Batch mode } \\
T=25^{\circ} \mathrm{C} \\
\mathrm{pH}=5 \\
C_{0}=0.03-1.33 \mathrm{mM} \\
\text { Binary solutions: } \\
\mathrm{Cd}[\mathrm{II}]\left(C_{0}=0.09 \mathrm{mM}\right)+ \\
\text { tannic acid (variable conc.) }\end{array}$ & [127] \\
\hline $\begin{array}{l}\text { Commercial viscose } \\
\text { rayon-based-ACC } \\
\text { HEG Ltd., India }\end{array}$ & $\begin{array}{l}V_{m}=0.25 \mathrm{~cm}^{3} \mathrm{~g}^{-1} \\
\text { Acidic surface groups }=2 \mathrm{mmol} \mathrm{g}^{-1}\end{array}$ & $\mathrm{Hg}[\mathrm{II}]$ & $\begin{array}{l}\text { Continuous mode column } \\
(25 \mathrm{~mm} \text { ID) } \\
\text { Bed depth }=80-150 \mathrm{~mm} \\
\mathrm{HLR}=3-7 \mathrm{~m}^{3} / \mathrm{h} / \mathrm{m}^{2} \\
\mathrm{pH}=6 \\
C_{0}=0.25-0.75 \mathrm{mM}\end{array}$ & [128] \\
\hline $\begin{array}{l}\text { Commercial ACC } \\
\text { Kynol Europe }\end{array}$ & $\begin{array}{l}\text { As-received ACC: } \\
A_{\mathrm{BET}}=2128 \mathrm{~m}^{2} \mathrm{~g}^{-1} ; V_{M}=0.028 \mathrm{~cm}^{3} \mathrm{~g}^{-1} ; \\
V_{m}=0.913 \mathrm{~cm}^{3} \mathrm{~g}^{-1} ; \\
L_{0}=1.69 \mathrm{~nm} ; \mathrm{pH}_{\mathrm{PZC}}=8.0 \\
\text { Oxidized ACC: } \\
A_{\mathrm{BET}}=1636 \mathrm{~m}^{2} \mathrm{~g}^{-1} ; V_{M}=0.030 \mathrm{~cm}^{3} \mathrm{~g}^{-1} ; \\
V_{m}=0.716 \mathrm{~cm}^{3} \mathrm{~g}^{-1} ; \\
L_{0}=1.80 \mathrm{~nm} ; \mathrm{pH}_{\mathrm{PZC}}=3.3\end{array}$ & $\mathrm{Zn}[\mathrm{II}]$ & $\begin{array}{l}\text { Batch and continuous modes } \\
T=25^{\circ} \mathrm{C} ; \mathrm{pH}=5.8-6.2 ; \\
C_{0}=0.05-2.29 \mathrm{mM} \\
\text { Column }(9 \mathrm{~mm} \text { ID) packed } \\
\text { with ACC wafers: } \\
C_{0}=0.30 \mathrm{mM} ; \mathrm{pH}=6 \\
\text { Flow rate }=2 \mathrm{~mL} \mathrm{m^{-1 }}\end{array}$ & [129] \\
\hline
\end{tabular}

$A_{\mathrm{BET}}$ : BET surface area; $V_{T}$ : total pore volume; $V_{M}$ : mesopore volume; $V_{m}$ : micropore volume; $L_{0}$ : mean micropore width; dp: average pore diameter $\left(4 V_{T} / A_{\mathrm{BET}}\right)$; Dp: average pore size according to density functional theory; $\mathrm{pH}_{\mathrm{PZC}}: \mathrm{pH}$ at the point of zero charge; $C_{0}$ : initial concentration; HLR: hydraulic loading rate. 
capacity of the ACC was found to be greater for $\mathrm{Cr}$ (III) ions than for $\mathrm{Co}$ (II) and $\mathrm{Ni}$ (II) ions for both the untreated and modified samples. The trend was attributed to the $\mathrm{H}$ bonding interactions between the ACC surface functional groups and $\mathrm{Cr}(\mathrm{III})$ ions that were found to exist in $\mathrm{Cr}(\mathrm{OH})^{2+}$ or $\mathrm{Cr}(\mathrm{OH})_{2}{ }^{+}$forms in the solution at the $\mathrm{pH}$ used $(\mathrm{pH}=$ 6 ), in addition to the normal ionic interactions. The extent of metal ions adsorption onto the ACC was enhanced by modification of the surface with monobenzo-crown ethers. Among the benzo-crown ethers studied, those leading to the best adsorption capacity of each of the metal species investigated were identified.

The effect of modifying a commercial viscose-rayonbased activated carbon cloth (Zorflex FM 10, Charcoal Cloth Int.) by electrochemical reduction and electrochemical oxidation on the adsorption of $\mathrm{Cr}(\mathrm{VI})$ ions was examined by Harry et al. [124] (Table 1). This study demonstrated that the electrochemically reduced ACC could be effectively used for treating acidic aqueous solutions polluted with $\mathrm{Cr}(\mathrm{VI})$, whereas the electrochemically oxidized sample was effective for treating basic or neutral aqueous solutions of $\mathrm{Cr}(\mathrm{VI})$ ion. The sorption capacity of the ACC was almost duplicated at $\mathrm{pH} 4$ due to electrochemical reduction, while it was found to increase by a factor of $\sim 11$ times at $\mathrm{pH} 8$ for the electrochemically oxidized ACC. The highest $\mathrm{Cr}(\mathrm{VI})$ sorption capacity (i.e., $3.8 \mathrm{mmol} \mathrm{g}^{-1}$ ) was determined for the electrochemically reduced $\mathrm{ACC}$ at $\mathrm{pH} 4$. It was approximately 4 times higher than $\mathrm{Cr}(\mathrm{VI})$ sorption capacity of electrochemically oxidized ACC at pH 8 (i.e., $0.84 \mathrm{mmolg}^{-1}$ ). As pointed out in the study, since most industrial wastewaters containing $\mathrm{Cr}(\mathrm{VI})$ ions are highly acidic, electrochemical reduction of ACC could be an efficient alternative for enhancing $\mathrm{Cr}(\mathrm{VI})$ sorptive capacity for wastewater treatment. The solution $\mathrm{pH}$ played a key role on the sorption of $\mathrm{Cr}(\mathrm{VI})$ ions onto the electrochemically reduced and oxidized ACC. The uptake of $\mathrm{Cr}(\mathrm{VI})$ ions decreased with an increase in the solution $\mathrm{pH}$ for the electrochemically reduced ACC, while the opposite occurred for the electrochemically oxidized ACC. Ion exchange mechanisms were ascribed as responsible for $\mathrm{Cr}(\mathrm{VI})$ ions sorption onto all ACC. However, $\mathrm{Cr}(\mathrm{VI})$ ion was sorbed in anionic form onto the electrochemically reduced ACC, and as a cation onto the electrochemically oxidized sample due to the reduction of $\mathrm{Cr}(\mathrm{VI})$ ion to $\mathrm{Cr}$ (III) ion by hydroxyl functional groups present on the ACC. Thus, these results indicated that electrochemical reduction of the viscose rayon-based ACC markedly enhanced the removal of $\mathrm{Cr}(\mathrm{VI})$ ions from aqueous solutions. In the frame of another study devoted to remove $\mathrm{Cr}[\mathrm{VI}]$ ion using conventional activated carbons developed from low-cost wastes, adsorption of $\mathrm{Cr}[\mathrm{VI}]$ ions onto a commercial activated carbon cloth employed for comparative purposes was examined [125]. The results showed that the activated carbon cloth performed better than the other tested adsorbents.

More recently, Moreno-Castilla et al. [63] investigated the effect of the number, amount, and strength of the surface acid functionalities on the adsorption mechanism of divalent and trivalent cations onto a commercial ACC (Kynol Europe) oxidized with a saturated solution of $\left(\mathrm{NH}_{4}\right)_{2} \mathrm{~S}_{2} \mathrm{O}_{8}$ in $1 \mathrm{M}$
$\mathrm{H}_{2} \mathrm{SO}_{4}$ (Table 1). Batch experiments for the adsorption of $\mathrm{Cr}(\mathrm{III}), \mathrm{Mn}$ (II), $\mathrm{Cu}(\mathrm{II})$, and $\mathrm{Zn}$ (II) ions were performed at $15^{\circ} \mathrm{C}$ and $35^{\circ} \mathrm{C}$. The amounts of surface oxygen functionalities and their acidity constant distribution were determined by potentiometric titration. Metal cation adsorption was considered to take place by a proton exchange mechanism, in turn involving inner sphere or outer sphere surface metal complex formation depending on whether the cations were divalent or trivalent and on the adsorption temperature. Two and three surface carboxyl groups were involved in the adsorption of divalent and trivalent cations, respectively, although not all surface carboxyl groups with the appropriate $\mathrm{pKa}$ to adsorb metal cations took part in the adsorption. The strength of the groups involved in the adsorption was found to increase in the order $\mathrm{Cr}$ (III) $<\mathrm{Cu}$ (II) $<\mathrm{Zn}$ (II) $<\mathrm{Mn}$ (II). The adsorption of the metal cations studied increased with the temperature due to the increase in the negative surface charge of the oxidized activated carbon. In the case of divalent cation adsorption, the increase in temperature changed the adsorption mechanism from outer sphere to inner sphere. However, the adsorption mechanism of $\mathrm{Cr}$ (III) was outer sphere and independent of temperature. The adsorption capacity was found to augment with the increase in the charge-to-size ratio of the hexa-aquo cations. In addition, the adsorption capacity of divalent cations increased with the rise in stability of the surface metal complex formed.

Anions. Although in limited extent, adsorption of some inorganic anions onto activated carbon cloths has also been explored. Afkhami et al. [131, 132] investigated the adsorption of molybdate (Mo[VI]), tungstate (W[VI]), nitrate, and nitrite ions from single solute solutions at $\mathrm{pH} \sim 7$ onto the same commercial ACC (Spectracarb 2225) used in the studies concerning metal cations uptake, already mentioned. To examine the effect of surface functional groups, modification of the ACC in these cases involved treatment of the samples with $\mathrm{H}_{2} \mathrm{SO}_{4}$ acid solution $(4 \mathrm{M})$. The acid treatment was found to increase the adsorption capacity of the resulting ACC and the adsorption rate for all the investigated anions with respect to distilled water-treated samples. Nevertheless, the capacity and the rate of adsorption of nitrate ions onto both the water- and acid-treated samples were higher for nitrate than for nitrite [131]. Similarly, for both cloths, better results were found for molybdate than for tungstate ions [132]. Adsorption of the four anions on the water-treated samples was explained by the displacement of the adsorbed water molecules, whereas the acid treatment could produce positive sites on the resulting ACC by protonation of surface $-\mathrm{OH}$ groups, causing an increase in electrostatic adsorption of the anions.

Competitive Adsorption. A small minority of studies have been devoted to examine adsorption competition either between metal ions or between metal ions and organic matter (Table 1). Among these studies, adsorption competition between $\mathrm{Cu}[\mathrm{II}]$ and $\mathrm{Pb}[\mathrm{II}]$ ions onto the aforementioned commercial ACC from Actimex Co. was investigated from assays involving single and binary solutions of the metal ions [126] (Table 1). As expected, a decrease in adsorption 
capacities $(\mathrm{Cu}[\mathrm{II}]>\mathrm{Pb}[\mathrm{II}])$ was determined for coadsorption. It was related to the adsorption rate of the individual metal ions, a faster adsorption velocity leading to a more rapid saturation of the adsorption sites. Besides, the competitive adsorption between $\mathrm{Cu}[\mathrm{II}]$ or $\mathrm{Pb}[\mathrm{II}]$ ions and benzoic acid in solution, the latter as a model compound of organic matter, onto the ACC as well as of each metal ion onto benzoic acid-preloaded ACC was explored. The solution $\mathrm{pH}$ exerted a strong influence on coadsorption. Adsorption of the metal ions was found to increase in both cases when benzoic acid was under benzoate form. This was attributed to the formation of ligands between adsorbed benzoate ions and the metals.

Likewise, adsorption competition between $\mathrm{Cd}(\mathrm{II})$ ions and tannic acid, used as model compound of natural organic matter, was also investigated at $\mathrm{pH} 5$ employing pristine and oxidized ACC samples [127] (Table 1). A decrease in $\mathrm{Cd}(\mathrm{II})$ ion uptake was found for the pristine ACC, whereas the opposite occurred for the oxidized sample, pointing to the relevance of the surface chemistry in the adsorptive competition. More recently, noncompetitive and competitive sorptions of $\mathrm{Co}$ (II) and $\mathrm{Pb}$ (II) ions onto an electrochemically modified viscose rayon-based activated carbon cloth were also investigated [133]. Cobalt and lead noncompetitive sorption capacities for the electrochemically oxidized ACC were around 4 times higher than those for the unoxidized sample. Cobalt and lead competitive sorption capacities for the electrochemically oxidized ACC were 4 and 5 times, respectively, higher in comparison with those for the unoxidized ACC. Sorption of cobalt and lead onto the oxidized sample was by ion exchange, whereas that onto the unoxidized one was explained by surface complex formation. Affinity order of the metals sorbed onto both ACC was $\mathrm{Pb}^{2+}>\mathrm{Co}^{2+}$, with metal uptake onto the oxidized sample increasing with the increase in solution $\mathrm{pH}$.

Dynamic Conditions. Little research concerning adsorption of toxic metals onto activated carbon cloths under dynamic conditions has been reported (Table 1). Metals investigated included $\mathrm{Hg}[\mathrm{II}]$ [128], $\mathrm{Pb}$ [II] [134], and $\mathrm{Zn}$ [II] ions [129]. In these studies, breakthrough curves at different flow rates, bed depth, and feed concentration were determined. Characteristic parameters providing useful information for the design and operation of adsorption units were evaluated and, in some cases, compared with results obtained for conventional granular activated carbons. For instance, the breakthrough time for $\mathrm{Hg}$ (II) ions adsorption onto a commercial viscose rayon-based ACC (HEG Ltd. India) was found to increase with the increase in the bed depth but to decrease as the hydraulic loading rate (HLR) and the feed concentration decreased [128] (Table 1). The adsorption of $\mathrm{Hg}$ (II) ions increased with HLR, attaining a maximum value at around $7 \mathrm{~m}^{3} / \mathrm{h} / \mathrm{m}^{2}$. The behavior was explained considering that at low HLR, laminar flow conditions prevailed, and the resulting high liquid-solid resistance led to low mass transfer and, consequently, to smaller adsorption. As HLR increased, the interface resistance decreased and the adsorption increased. Beyond a certain HLR, the rate of adsorption decreased due to the decrease in the residence time of the liquid within the carbon bed and the lower time available for mass transfer.

On the other hand, the effect of surface oxidation and the presence of dissolved natural organic matter, using tannic acid as model compound, on the adsorption of $\mathrm{Zn}[\mathrm{II}]$ ions in columns packed with an activated carbon cloth (Kynol Europe) was examined [129] (Table 1). The oxidized ACC was found to be more effective than the pristine cloth in $\mathrm{Zn}$ (II) ion removal, in agreement with results obtained in the same study for static conditions. The presence of tannic acid decreased the efficiency of the oxidized ACC bed. An increase in the initial concentration of tannic acid was found to exert a greater influence on its removal than on $\mathrm{Zn}$ (II) ions uptake, because of the larger size of tannic acid molecules and their low affinity for the oxidized carbon surfaces.

\subsubsection{Adsorption of Organic Pollutants onto Activated Carbon} Cloths. Several studies concerned with adsorption of organic pollutants from dilute aqueous solutions onto activated carbon cloths have been reported. The organic pollutants investigated mainly included different dyes, surfactants, pesticides, phenol, phenolic, and other organic compounds, such as aromatic organic acids, aniline, and derivatives, among others. Selected studies are summarized below, whereas representative examples are listed in Table 2. Adsorption of organic solutes onto carbon materials is considered as a complex interplay between electrostatic and nonelectrostatic interactions. Electrostatic interactions depend on the solution $\mathrm{pH}$ and ionic strength and control the charge on the carbon surface and on the adsorptive molecule. The electrostatic interactions are predominant for electrolytes and polyelectrolytes when they are ionized under the experimental conditions used. In turn, non-electrostatic interactions are mainly due to dispersion and hydrophobic interactions [135].

Adsorption of Dyes onto Activated Carbon Cloths. Adsorption of dyes has been subject of special interest because they are pollutants often found in textile wastewater, as a result of unfixed dyes from dying baths that are discharged within common textile effluents. Over $7 \times 10^{5}$ tons and approximately $10^{4}$ different dyes and pigments are produced annually worldwide, around $10 \%$ of which may be found in wastewaters. Recalcitrant nature and nonbiodegradability of dyes are characteristics derived from their complex structures and synthetic origin. They are specifically designed to resist fading upon exposure to light, water, and oxidizing agents, and as such dyes are very stable and difficult to degrade $[159,160]$.

Adsorption of dyes has been intensively investigated using conventional activated carbons, as evidenced in the recent review reported by Mezohegyi et al. [10], focusing on their versatile role in aqueous dye removal processes. However, only some studies have been reported in the last years for dye adsorption onto activated carbon cloths (Table 2). Among them, those reported by Métivier-Pignon et al. [136, 137] contribute to gain insight into dye adsorption on ACC. The adsorption of 22 commercial dyes onto two commercial 
rayon-based activated cloths (Actitex Co., France), with different porous structures was examined (Table 2). One of the ACC samples was almost completely microporous (micropore volume > 96\%), whereas the other one was partially mesoporous (mesopore volume of $\sim 32 \%$ ). The investigated dyes belonged to different chemical classes, with special emphasis on azo- and triarylmethane, anthraquinone, polymethine, and thiazine, with molecular weight ranging from 300 to $700 \mathrm{~g} \mathrm{~mol}^{-1}$. Quantitative structure-activity relationships were developed as a predictive tool using molecular connectivity indices as dyes descriptors. A critical size of the adsorbate was found to play a key role in adsorption velocity, with the compound exhibiting a low initial kinetic coefficient when it reached this size. For the azo dyes, adsorption capacity was found rather sensitive to characteristics of the molecule structure, like type of atoms, substitution of aromatic rings. Besides, continuous experiments coupling ultrafiltration to remove the higher-sized compounds (i.e., macromolecules, colloids, and turbidity), and adsorption onto ACC intended to uptake the lower-sized compounds, were carried out in order to simulate the treatment of industrial textile wastewater.

The adsorption of some acid dyes, Acid Blue 45 (AB45), Acid Blue 92 (AB92), Acid Blue 120 (AB120), and Acid Blue 129 (AB129), from aqueous solutions onto the commercial activated carbon cloth Spectracarb 2225 from Spectra Corp. was investigated [138] (Table 2). Adsorption kinetics and equilibrium isotherms were determined from batch measurements applying in situ UV spectroscopy. Adsorption of the dyes was represented by a second-order kinetic model with the rate constants following the sequence AB129 > AB45 > AB120 > AB92. In turn, adsorption capacities for the dyes, as evaluated by application of both Langmuir and Freundlich isotherm models, followed the order AB45 > AB129 > AB92 $>\mathrm{AB} 120$. This order was found in line with the size of dyes molecules and pore size of the ACC. More recently, the adsorption of a basic dye (Basic Violet 10) from aqueous solutions using activated carbons prepared from different industrial wastes, among them textile waste cloths, was examined [161]. In a nearer approach to real conditions, the recent study by Aber and Sheydadei [139] examined adsorption of Indigo dye from filtered wastewater produced from a dying factory using an activated carbon cloth based on kenaf, which was lab-prepared by these authors by physicochemical activation with $30 \% \mathrm{~K}_{2} \mathrm{HPO}_{4}$ w/v solution (Table 2), as earlier depicted in Section 2. COD, $\mathrm{pH}$, and total dissolved solids of the wastewater used were $360,8.1$, and $970 \mathrm{mg} \mathrm{L}^{-1}$, respectively. From batch assays for different experimental conditions, which were designed by applying response surface methodology, optimum dosage, temperature, $\mathrm{pH}$, and contact time, were determined. It was found that the dosage exerted the highest degree of impact on the treatment process among the investigated variables. Adsorption kinetic data and equilibrium isotherms were well represented by a pseudosecond-order rate model and Freundlich model, respectively.
Adsorption of Surfactants onto Activated Carbon Cloths. Surfactants constitute another important group of organic pollutants. These molecules are amphiphilic, due to their dual hydrophobic/hydrophilic character leading to the accumulation at solid-water interfaces, where both the hydrophobic and the hydrophilic parts participate in favorable intermolecular interactions. Surfactants are widely employed in several industrial and commercial products and processes and constitute the most important component of detergents [135]. Their presence in water may occasion deleterious environmental impact and health hazards and cause foams in water. Since many surfactants are nonbiodegradable, they have to be removed or, at least, reduced to acceptable levels. Although their removal by treatment with conventional carbons has been subject of several studies, only a few works dealing with surfactants adsorption onto activated carbon cloths have been still reported (Table 2).

Adsorption of some cationic and anionic surfactants from aqueous solutions on the commercial activated carbon cloth Spectracarb 2225 (Spectra Corp., USA) was examined [140, 141]. A specially designed V-shaped cell was employed in these studies to perform adsorption assays and simultaneous in situ concentration measurements by in situ UV absorption spectrophotometry. The cationic surfactants investigated were classified into three groups [140]. The first group corresponded to benzyltrialkylammonium chlorides and was composed of benzyltrimethylammonium chloride (BTMACl), benzyltriethylammonium chloride (BTEACl), and benzyltributylammonium chloride (BTBACl). The second group belonged to benzyldimethylalkylammonium chlorides and included benzyldimethyldecylammonium chloride (BDMDACl), benzyldimethyltetradecylammonium chloride (BDMTDACl), and benzyldimethylhexadecylammonium chloride (BDMH$\mathrm{DACl}$ ), whereas the third group consisted of alkylpyridinium chlorides and comprised $\mathrm{N}$-dodecylpyridinium chloride $(\mathrm{N}$ $\mathrm{DPCl}$ ) and $\mathrm{N}$-cetylpyridinium chloride ( $\mathrm{CPCl})$. Most of the surfactants investigated were almost completely removed from aqueous solutions under the same experimental conditions. A smaller adsorption extent was determined for the surfactants BTMACl and BTEACl. It was attributed to their lower hydrophobicity in comparison with the other investigated cationic surfactants. Hydrophobic interactions were considered as mainly responsible for the adsorption of the cationic surfactants, the effects of electrostatic interactions, and size factors being less important. A fair linear correlation was obtained between some adsorption parameters and the apparent molar volume at infinite dilution of the surfactants belonging to the first group. With regard to the anionic surfactants, adsorption of benzene sulfonate (BS), ptoluene sulfonate (TS), 4-octylbenzene sulfonate (OBS), and 4-dodecylbenzene sulfonate (DBS), from water and slightly acidic solutions were examined [141]. The rate and extent of adsorption of these surfactants onto the ACC was found to increase in the order $\mathrm{BS}<\mathrm{TS}<\mathrm{OBS} \sim \mathrm{DBS}$. The main type of interaction between the ACC surface and the surfactants was also considered of hydrophobic origin in neutral aqueous solutions. Enhanced surfactants adsorption from the acidic solutions was found and explained by electrostatic attractions 
TABLE 2: Some selected studies involving activated carbon cloths for adsorption of organic pollutants in aqueous phase.

\begin{tabular}{|c|c|c|c|c|}
\hline Sample & ACC characteristics & Pollutant species & Adsorption assays & Reference \\
\hline $\begin{array}{l}\text { Commercial } \\
\text { rayon-based ACC } \\
\text { CS 1501; RS } 1301 \\
\text { Actitex Co., France }\end{array}$ & $\begin{array}{l}\text { CS 1501: } \\
A_{\mathrm{BET}}=1689 \mathrm{~m}^{2} \mathrm{~g}^{-1} ; V_{T}=0.665 \mathrm{~cm}^{3} \mathrm{~g}^{-1} ; \\
V_{m}=96 \% ; \mathrm{pH}_{\mathrm{PZC}}=7.6 \\
\mathrm{RS} 1301: \\
A_{\mathrm{BET}}=1460 \mathrm{~m}^{2} \mathrm{~g}^{-1} ; V_{T}=0.506 \mathrm{~cm}^{3} \mathrm{~g}^{-1} ; \\
V_{m}=68.2 \% ; \mathrm{pH}_{\mathrm{PZC}}=9.5\end{array}$ & $\begin{array}{l}22 \text { commercial dyes } \\
\text { Molecular weight: } \\
300-700 \mathrm{~g} \mathrm{~mol}^{-1}\end{array}$ & $\begin{array}{l}\text { Batch and continuous modes } \\
\text { Single solute sol. } \\
T=15^{\circ} \mathrm{C}-35^{\circ} \mathrm{C} \\
C_{0}=0-5 \times 10^{-5} \mathrm{M} \\
\mathrm{pH}=3.5-6.1\end{array}$ & {$[136,137]$} \\
\hline $\begin{array}{l}\text { Commercial ACC } \\
\text { Spectracarb } 2225 \\
\text { Spectra Corp., USA }\end{array}$ & $\begin{array}{l}\text { ACC washed: } \\
A_{\mathrm{BET}}=1870 \mathrm{~m}^{2} \mathrm{~g}^{-1} ; V_{T}=0.827 \mathrm{~cm}^{3} \mathrm{~g}^{-1} ; \\
V_{m}=0.709 \mathrm{~cm}^{3} \mathrm{~g}^{-1} ; V_{M}=0.082 \mathrm{~cm}^{3} \mathrm{~g}^{-1} \\
\mathrm{pH} H_{\mathrm{PZC}}=7.4\end{array}$ & $\begin{array}{l}\text { Acid dyes: } \\
\text { acid blue } 45 \\
\text { acid blue } 92 \\
\text { acid blue } 120 \\
\text { acid blue } 129\end{array}$ & $\begin{array}{l}\text { Batch mode } \\
\text { Single solute sol. } \\
T=25^{\circ} \mathrm{C} \\
\mathrm{pH}_{0}=5.3-6.7 \\
C_{0}=1-4 \times 10^{-2} \mathrm{mM} \\
\end{array}$ & [138] \\
\hline $\begin{array}{l}\text { Lab prepared } \\
\text { kenaf-based ACC by } \\
\mathrm{K}_{2} \mathrm{HPO}_{4} \\
\text { physicochemical } \\
\text { activation }\end{array}$ & $\begin{array}{l}A_{\mathrm{BET}}=1842 \mathrm{~m}^{2} \mathrm{~g}^{-1} \\
V_{T}=0.850 \mathrm{~cm}^{3} \mathrm{~g}^{-1} \\
\mathrm{pH}_{\mathrm{PZC}}=7.3\end{array}$ & Indigo dye & $\begin{array}{l}\text { Batch mode } \\
T=12.5,20,27.5,35 \text {, and } \\
42.5^{\circ} \mathrm{C} \\
\mathrm{pH}=2,4,6,8 \text {, and } 10 \\
C_{0}=0.1-1.4 \mathrm{mM}\end{array}$ & [139] \\
\hline
\end{tabular}

\begin{tabular}{ll}
\hline & \\
& \\
& ACC washed: \\
& $A_{\mathrm{BET}}=1870 \mathrm{~m}^{2} \mathrm{~g}^{-1}$; \\
Commercial ACC & $V_{T}=0.827 \mathrm{~cm}^{3} \mathrm{~g}^{-1} ;$ \\
Spectracarb 2225 & $V_{m}=0.709 \mathrm{~cm}^{3} \mathrm{~g}^{-1}$; \\
Spectra Corp., USA & $V_{M}=0.082 \mathrm{~cm}^{3} \mathrm{~g}^{-1}$; \\
& $\mathrm{pH}_{\mathrm{PZC}}=7.4$
\end{tabular}

Cationic surfactants:

benzyltrimethylammonium

chloride

benzyltriethylammonium

chloride

benzyltributylammonium

chloride

benzyldimethyldecylammo- Single solute sol.

nium chloride

benzyldimethyltetradecylam-

monium chloride

benzyldimethylhexadecylam-

monium chloride

$\mathrm{N}$-dodecylpyridinium

chloride

N-cetylpyridinium chloride

Commercial ACC

Spectracarb 2225

Spectra Corp., USA

ACC washed:

$A_{\mathrm{BET}}=1870 \mathrm{~m}^{2} \mathrm{~g}^{-1} ; V_{T}=0.827 \mathrm{~cm}^{3} \mathrm{~g}^{-1}$;

$V_{m}=0.709 \mathrm{~cm}^{3} \mathrm{~g}^{-1} ; V_{M}=0.082 \mathrm{~cm}^{3} \mathrm{~g}^{-1}$;

$\mathrm{pH}_{\mathrm{PZC}}=7.4$
Anionic surfactants:

benzene sulfonate;

p-toluene sulfonate;

4-octylbenzene sulfonate

4-dodecylbenzene sulfonate

Pesticides:

ametryn (AM)

[2-(ethylamino)-4-

isopropylamino

$A_{\mathrm{BET}}=2500 \mathrm{~m}^{2} \mathrm{~g}^{-1}$

Commercial ACC

Spectracarb 2225

Spectra Corp., USA

-6-methyl-thio-s-triazine],

Aldicarb (AL) [2-methyl-2-

o-methylcarbamoyloxime];
ACC washed:

$A_{\mathrm{BET}}=1870 \mathrm{~m}^{2} \mathrm{~g}^{-1}$

$V_{T}=0.827 \mathrm{~cm}^{3} \mathrm{~g}^{-1}$;

$V_{m}=0.709 \mathrm{~cm}^{3} \mathrm{~g}^{-1}$;

$V_{M}=0.082 \mathrm{~cm}^{3} \mathrm{~g}^{-1}$;

$\mathrm{pH}_{\text {PZC }}=7.4$ (methylthio)propionaldehyde

diuron (DR)

[N-(3,4-dichlorophenyl)-N;

$\mathrm{N}$-dimethylurea];

Dinoseb (DN) [2-(sec-butyl)-

4,6-dinitrophenol]

Commercial

PAN-based ACC

AW1102

KoTHmex
$A_{\mathrm{BET}}=1140 \mathrm{~m}^{2} \mathrm{~g}^{-1} ; V_{T}=0.45 \mathrm{~cm}^{3} \mathrm{~g}^{-1} ;$

$\mathrm{dp}=1.93 \mathrm{nmp} ; \mathrm{pH}_{\mathrm{PZC}}=3.8$
Pentachlorophenol

\section{Batch mode}

Single solute sol.

$\mathrm{T}=30^{\circ} \mathrm{C}$

$\mathrm{pH}=7.4,2$

$C_{0}=0.1 \mathrm{mM}$

Batch mode

Single solute sol.

$\mathrm{T}=25^{\circ} \mathrm{C}$

$C_{0}=0.065 \mathrm{mM}$ for kinetic

studies

$C_{0 \mathrm{AM}}=0.46 \mathrm{mM}$;

$C_{0 \mathrm{AL}}=0.55 \mathrm{mM}$

$C_{\text {ODN }}=0.09 \mathrm{mM}$

$C_{\text {ODR }}=0.14 \mathrm{mM}$

for isotherms determination

Batch mode

$T=15,25$, and $35^{\circ} \mathrm{C}$

$\mathrm{pH}=6-12$

[143]

$C_{0}=0.15-0.81 \mathrm{mM}$ 
TABLe 2: Continued.

\begin{tabular}{|c|c|c|c|c|}
\hline Sample & ACC characteristics & Pollutant species & Adsorption assays & Reference \\
\hline $\begin{array}{l}\text { Commercial ACC } \\
\text { Kynol Europe }\end{array}$ & $\begin{array}{l}A_{\mathrm{BET}}=2128 \mathrm{~m}^{2} \mathrm{~g}^{-1} \\
V_{m}=0.913 \mathrm{~cm}^{3} \mathrm{~g}^{-1} \\
V_{M}=0.028 \mathrm{~cm}^{3} \mathrm{~g}^{-1} \\
L_{0}=1.69 \mathrm{~nm} \\
\mathrm{pH}_{\mathrm{PZC}}=8.0\end{array}$ & $\begin{array}{l}\text { Herbicides: } \\
\text { amitrole } \\
\text { (3-amino-1,2,4-triazole); } \\
\text { diuron } \\
\text { 3-(3,4-dichlorophenyl)-1,1- } \\
\text { dimethylurea) }\end{array}$ & $\begin{array}{l}\text { Batch and continuous modes } \\
\text { Single solute sol. } \\
T=25^{\circ} \mathrm{C} ; \mathrm{pH}=7 \\
C_{0}(\text { diuron })=0.13 \mathrm{mM} \\
C_{0}(\text { amitrole })=0.12 \mathrm{mM} \\
\text { Column }(9 \mathrm{mM} \text { ID) packed } \\
\text { with ACC circles: } \\
\text { flow rate }=2 \mathrm{~mL} \mathrm{~min}^{-1} \\
\text { bed depth }=1-4 \mathrm{~cm}\end{array}$ & {$[144]$} \\
\hline $\begin{array}{l}\text { Commercial ACC } \\
\text { Kynol Europe }\end{array}$ & $\begin{array}{l}A_{\mathrm{BET}}=2128 \mathrm{~m}^{2} \mathrm{~g}^{-1} \\
V_{m}=0.913 \mathrm{~cm}^{3} \mathrm{~g}^{-1} \\
V_{M}=0.020 \mathrm{~cm}^{3} \mathrm{~g}^{-1} \\
L_{0}=1.69 \mathrm{~nm} \\
\mathrm{pH}_{\mathrm{PZC}}=8.0\end{array}$ & $\begin{array}{l}\text { Herbicide: } \\
\text { fluroxypyr (FLX) } \\
\text { (4-amino-3,5-dichloro-6- } \\
\text { fluoro-2-pyridyloxyacetic } \\
\text { acid) }\end{array}$ & $\begin{array}{l}\text { Batch and continuous modes } \\
\text { Single solute sol. } \\
\text { Binary sol. } \\
\text { FLX + tannic acid (TA) } \\
T=25,40^{\circ} \mathrm{C} ; \mathrm{pH}=2-10 \\
\text { Column }(9 \mathrm{mM} \text { inner diam.) } \\
\text { packed with ACC circles: } \\
\text { flow rate }=2 \mathrm{~mL} \mathrm{m^{-1 }} \text {; } \\
\text { bed depth }=1-4 \mathrm{~cm} ; \\
C_{0}(\mathrm{FLX})=0.12 \mathrm{mM} ; \\
C_{0}(\mathrm{TA})=2 \times 10^{-3} \mathrm{mM} \\
\end{array}$ & [145-147] \\
\hline $\begin{array}{l}\text { Commercial ACC } \\
\text { Kynol Europe }\end{array}$ & $\begin{array}{l}\text { As-received ACC: } \\
A_{\mathrm{BET}}=2128 \mathrm{~m}^{2} \mathrm{~g}^{-1} ; V_{m}=0.913 \mathrm{~cm}^{3} \mathrm{~g}^{-1} \\
L_{0}=1.69 \mathrm{~nm} ; \mathrm{pH}_{\mathrm{PZC}}=8.0 \\
\text { ACC heat-treated at } 900^{\circ} \mathrm{C}: \\
A_{\mathrm{BET}}=1876 \mathrm{~m}^{2} \mathrm{~g}^{-1} ; V_{m}=0.77 \mathrm{~cm}^{3} \mathrm{~g}^{-1} \\
L_{0}=1.80 \mathrm{~nm} ; \mathrm{pH}_{\mathrm{PZC}}=9.0\end{array}$ & $\begin{array}{l}\text { Herbicide: } \\
\text { amitrole } \\
\text { [3-amino-1,2,4-triazole] }\end{array}$ & $\begin{array}{l}\text { Batch mode } \\
\text { Single solute sol. } \\
T=15-35^{\circ} \mathrm{C} \\
\mathrm{pH}=3,5,7 \text {, and } 9 \\
C_{0}=\text { from } 0.02 \text { to } 1.07 \mathrm{mM}\end{array}$ & [148] \\
\hline $\begin{array}{l}\text { Lab-prepared viscose } \\
\text { rayon-based ACC by } \\
\mathrm{CO}_{2} \text { activation }\end{array}$ & $\begin{array}{l}\text { Untreated ACC: } \\
A_{\text {BET }}=740 \mathrm{~m}^{2} \mathrm{~g}^{-1} ; V_{m}=0.18 \mathrm{~cm}^{3} \mathrm{~g}^{-1} ; \\
L_{0}=0.78 \mathrm{~nm} ; \mathrm{pH}_{\mathrm{PZC}}=7.14 \\
\text { ACC posttreated with NaOH sol.: } \\
A_{\mathrm{BET}}=755 \mathrm{~m}^{2} \mathrm{~g}^{-1} ; V_{m}=0.18 \mathrm{~cm}^{3} \mathrm{~g}^{-1} ; \\
L_{0}=0.78 \mathrm{~nm} ; \mathrm{pH}_{\mathrm{PZC}}=10.12 \\
\text { ACC posttreated with urea sol.: } \\
A_{\mathrm{BET}}=1060 \mathrm{~m}^{2} \mathrm{~g}^{-1} ; V_{m}=0.25 \mathrm{~cm}^{3} \mathrm{~g}^{-1} ; \\
L_{0}=0.93 \mathrm{~nm} ; \mathrm{pH}_{\mathrm{PZC}}=8.79\end{array}$ & $\begin{array}{l}\text { Phenolic compounds: } \\
\text { phenol, 4-nitrophenol }\end{array}$ & $\begin{array}{l}\text { Batch mode } \\
\text { Single solute sol. } \\
T=25^{\circ} \mathrm{C} \\
\text { Acid pH medium } \\
C_{0}=\text { n.a. }\end{array}$ & [149] \\
\hline $\begin{array}{l}\text { Commercial ACC } \\
\text { Spectracarb } 2225 \\
\text { Spectra Corp. }\end{array}$ & $\begin{array}{l}\text { ACC washed: } \\
A_{\mathrm{BET}}=1870 \mathrm{~m}^{2} \mathrm{~g}^{-1} ; V_{T}=0.827 \mathrm{~cm}^{3} \mathrm{~g}^{-1} ; \\
V_{m}=0.709 \mathrm{~cm}^{3} \mathrm{~g}^{-1} ; V_{M}=0.082 \mathrm{~cm}^{3} \mathrm{~g}^{-1} \\
\mathrm{pH}_{\mathrm{PZC}}=7.4\end{array}$ & Catechol, resorcinol & $\begin{array}{l}\text { Batch and continuous modes } \\
\text { Single solute sol. } \\
T=25^{\circ} \mathrm{C} \\
\mathrm{pH} \sim 6 \\
C_{0}=0.57-0.76 \mathrm{mM}\end{array}$ & {$[150]$} \\
\hline $\begin{array}{l}\text { Commercial ACC } \\
\text { Spectracarb } 2225 \\
\text { Spectra Corp., USA }\end{array}$ & $\begin{array}{l}\text { ACC washed: } \\
A_{\mathrm{BET}}=1870 \mathrm{~m}^{2} \mathrm{~g}^{-1} ; V_{T}=0.827 \mathrm{~cm}^{3} \mathrm{~g}^{-1} ; \\
V_{m}=0.709 \mathrm{~cm}^{3} \mathrm{~g}^{-1} ; V_{M}=0.082 \mathrm{~cm}^{3} \mathrm{~g}^{-1} \\
\mathrm{pH} \mathrm{P}_{\mathrm{PZC}}=7.4\end{array}$ & $\begin{array}{l}\text { Aromatic acids: } \\
\text { benzoic acid; } \\
\text { salicylic acid; } \\
\text { p-aminobenzoic acid; } \\
\text { nicotinic acid }\end{array}$ & $\begin{array}{l}\text { Batch mode } \\
\text { Single solute sol. } \\
T=30^{\circ} \mathrm{C} \\
\mathrm{pH}=7 \text {; natural } \mathrm{pH} \text {; acid } \\
\left(0.4 \mathrm{M} \mathrm{H}_{2} \mathrm{SO}_{4}\right) ; \text { basic }(0.1 \mathrm{M} \\
\mathrm{NaOH}) \text { media } \\
C_{0}=0.17-0.18 \mathrm{mM} \\
\text { for kinetic studies }\end{array}$ & {$[151]$} \\
\hline $\begin{array}{l}\text { Commercial ACC } \\
\text { Spectracarb } 2225 \\
\text { Spectra Corp., USA }\end{array}$ & $\begin{array}{l}\text { ACC washed: } \\
A_{\mathrm{BET}}=1870 \mathrm{~m}^{2} \mathrm{~g}^{-1} ; V_{T}=0.827 \mathrm{~cm}^{3} \mathrm{~g}^{-1} ; \\
V_{m}=0.709 \mathrm{~cm}^{3} \mathrm{~g}^{-1} ; V_{M}=0.082 \mathrm{~cm}^{3} \mathrm{~g}^{-1} \\
\mathrm{pH}_{\mathrm{PZC}}=7.4\end{array}$ & $\begin{array}{l}\text { Anilinic compounds: } \\
\text { aniline, } \\
\text { p-toluidine, } \\
\text { 1-naphthylamine, } \\
\text { sodium salt of } \\
\text { diphenylamine-4-sulfonic } \\
\text { acid }\end{array}$ & $\begin{array}{l}\text { Batch mode } \\
\text { Single solute sol. } \\
T=30^{\circ} \mathrm{C} \\
\mathrm{pH} \sim 6,0,13 \\
C_{0}=0.10 \mathrm{mM} \text { for kinetic } \\
\text { studies }\end{array}$ & [152] \\
\hline
\end{tabular}


TABle 2: Continued.

\begin{tabular}{llll}
\hline Sample & ACC characteristics & Pollutant species & Adsorption assays \\
& & & Batch mode \\
& As received ACC: & Single solute sol. \\
Commercial ACC & $A_{\text {BET }}=2500 \mathrm{~m}^{2} \mathrm{~g}^{-1}$ & Phthalic acid and esters: & $\mathrm{T}=30^{\circ} \mathrm{C}$ \\
Spectracarb 2225 & ACC washed: & dimethyl phthalate; & Phthalic acid: \\
Spectra Corp., USA & $A_{\text {BET }}=1870 \mathrm{~m}^{2} \mathrm{~g}^{-1} ; V_{T}=0.827 \mathrm{~cm}^{3} \mathrm{~g}^{-1} ;$ & diethyl phthalate; & $\mathrm{pH} \sim 4\left(\right.$ in $\left.\mathrm{H}_{2} 0\right) ;$ acid $(1 \mathrm{M}$ \\
& $V_{m}=0.709 \mathrm{~cm}^{3} \mathrm{~g}^{-1} ; V_{M}=0.082 \mathrm{~cm}^{3} \mathrm{~g}^{-1} ;$ & diallyl phthalate & $\left.\mathrm{H}_{2} \mathrm{SO}_{4}\right) ;$ basic $(0.005 \mathrm{M}$ \\
& $\mathrm{pH}_{\mathrm{PZC}}=7.4$ & & $\mathrm{NaOH}^{2}$ media \\
& & & $C_{0}=0.24 \mathrm{mM}$ \\
\hline
\end{tabular}

\section{Benzene and}

naphthalene sulfonates: sodium salt of benzene sulfonic acid;

Commercial ACC Spectracarb 2225 Spectra Corp., USA
ACC washed:

$A_{\text {BET }}=1870 \mathrm{~m}^{2} \mathrm{~g}^{-1} ; V_{T}=0.827 \mathrm{~cm}^{3} \mathrm{~g}^{-1}$; $V_{m}=0.709 \mathrm{~cm}^{3} \mathrm{~g}^{-1} ; V_{M}=0.082 \mathrm{~cm}^{3} \mathrm{~g}^{-1}$; $\mathrm{pH}_{\mathrm{PZC}}=7.4$ disodium salt of 1,3-benzene

disulfonic acid;

sodium salt of 1-naphthalene

sulfonic acid;

disodium salt of

1,5-naphthalene disulfonic

acid; trisodium salt of 1,3,(6

or 7)-naphthalene trisulfonic acid

Phenol (Ph); pyridine (Py); naphthalene sulfonic acid (NSA); pentachlorophenol (PCP); methylene blue (MB)

$\begin{array}{ll}\text { Commercial } & A_{\mathrm{BET}}=988 \mathrm{~m}^{2} \mathrm{~g}^{-1} ; \\ \text { PAN-based ACC } & V_{T}=0.482 \mathrm{~cm}^{3} \mathrm{~g}^{-1} ; \\ \text { AW1104 } & \mathrm{dp}=1.95 \mathrm{~nm} \\ \text { KoTHmex } & \mathrm{pm}\end{array}$

KoTHmex

\section{Batch mode}

Single solute sol.

$\mathrm{T}=25^{\circ} \mathrm{C}$

$\mathrm{pH}_{\mathrm{Ph}}=7 ; \mathrm{pH}_{\mathrm{Py}}=10$

$\mathrm{pH}_{\mathrm{NSA}}=3 ; \mathrm{pH}_{\mathrm{PCP}}=7$

$\mathrm{pH}_{\mathrm{MB}}=3$

$C_{0}=0.25-6.33 \mathrm{mM}$

Batch mode

Single solute sol.

Commercial

PAN-based ACC $\quad A_{\text {BET }}=1138 \mathrm{~m}^{2} \mathrm{~g}^{-1}$

AW1104 $V_{T}=0.59 \mathrm{~cm}^{3} \mathrm{~g}^{-1}$;

KoTHmex

$\mathrm{dp}=1.96 \mathrm{~nm}$

Pyridine

$T=15,25$, and $35^{\circ} \mathrm{C}$

$\mathrm{pH}=3-10$
$C_{0}=0.25$ to $10.11 \mathrm{mM}$

Batch mode;

Single solute sol.

$T=25^{\circ} \mathrm{C}$

$\mathrm{pH}_{\mathrm{BA}}=3.8$

$\mathrm{pH}_{\mathrm{PH}}=5.6$

$\mathrm{pH}_{\mathrm{PC}}=5.3$

$C_{0}=0.008-1 \mathrm{mM}$

Binary solutions:

equimolar

$C_{0}=0.008-1 \mathrm{mM}$

Batch mode

Single solute sol.

$T=25^{\circ} \mathrm{C} ; \mathrm{pH}=7$;

$C_{0}(\mathrm{MIB}, \mathrm{GEO})=1 \times 10^{-3} \mathrm{mM}$

Multisolute solutions:

$A_{\text {BET }}=1137 \mathrm{~m}^{2} \mathrm{~g}^{-1}$

Commercial phenolic resin-based ACC with increasing degrees of activation Nippon Kynol, Japan
$V_{T}=0.598 \mathrm{~cm}^{3} \mathrm{~g}^{-1}$

ACC-20:

$A_{\mathrm{BET}}=1456 \mathrm{~m}^{2} \mathrm{~g}^{-1}$

$V_{T}=0.766 \mathrm{~cm}^{3} \mathrm{~g}^{-1}$

ACC-25:

$A_{\text {BET }}=2014 \mathrm{~m}^{2} \mathrm{~g}^{-1} ; V_{T}=0.842 \mathrm{~cm}^{3} \mathrm{~g}^{-1}$
Taste- and odor-causing compounds:

2-methyl isoborneol (MIB), geosmin (GEO)

[trans-1,

10-dimethyl-trans-9-decalol]
$\mathrm{MIB}+\mathrm{GEO}$;

MIB or GEO + humic acid

(HA);

$\mathrm{MIB}+\mathrm{GEO}+\mathrm{HA}$

$C_{0}(\mathrm{HA})=10 \mathrm{mg} \mathrm{L}^{-1}$

$\mathrm{C}_{0}(\mathrm{MIB})=$

$6 \times 10^{-4} \mathrm{mM}-2.33 \mathrm{mM}$

$\mathrm{C}_{0}(\mathrm{GEO})=$

$1 \times 10^{-3} \mathrm{mM}-1.10 \mathrm{mM}$
$A_{\mathrm{BET}}: \mathrm{BET}$ surface area; $V_{T}=$ total pore volume; $V_{M}=$ mesopore volume; $V_{m}:$ micropore volume; $L_{0}:$ mean micropore width; dp = average pore diameter $\left(4 V_{T} / A_{\mathrm{BET}}\right) ; \mathrm{pH}_{\mathrm{PZC}}: \mathrm{pH}$ at the point of zero charge; $C_{0}$ : initial concentration. 
between the negatively charged surfactant molecules and the ACC surface which acquired a net positive charge in acidic medium. Results also showed that an inert electrolyte $(\mathrm{NaCl})$ decreased the adsorption capacity of the ACC for the anionic surfactants. For all the surfactants, kinetic data were fitted to the pseudosecond-order rate model, and adsorption equilibrium isotherms were satisfactorily described by the Freundlich model.

Pesticides. Adsorption of pesticides from water onto activated carbon has gained increasing attention due to their growing consumption, adversely impacting on aquatic ecosystems. Pesticides are commonly used in agriculture to protect crops from pest organisms including insects, plants, fungi, rodents, and nematodes. In their cycle, pesticides may appear as pollutants in water sources threatening human health because of their toxicity, carcinogenicity, and mutagenicity [162]. Kyriakopoulos and Doulia [163] reviewed studies reported in the literature for the period 1990-2004 dealing with the adsorption of pesticides from aqueous solutions onto polymeric and carbonaceous materials, including cloths as adsorbent.

In a series of articles, Ayranci and Hoda [142, 162, 164] reported the adsorption of several pesticides, aldicarb, ametryn, atrazine, bentazon, bromacil, dinoseb, diuron, metribuzin, propanil, and 2,4-dichlorophenoxyacetic acid (24 D) onto the same activated carbon cloth Spectracarb 2225 from Spectra Corp (Table 2). The kinetics and equilibrium isotherms for the adsorption of the pesticides mostly from single solute aqueous solutions onto the ACC were determined by in situ UV spectroscopy. Kinetic parameters were evaluated by comparatively applying first-order rate, secondorder rate, or intraparticle diffusion models, whereas the adsorption isotherms were in general satisfactorily described by the Langmuir and Freundlich models. The structure of the pesticide was found to play a crucial role in the order of extents of adsorption. In one of these studies involving aldicarb, ametryn, dinoseb, and diuron [142], the rate constants, as evaluated by both the first-order and second-order models, and the extent of adsorption were found to follow the order dinoseb $>$ ametryn $>$ diuron $>$ aldicarb. The extent of adsorption onto the ACC could not be explained by a direct relation with the solubility of these pesticides. Results were interpreted in terms of the interactions between the surface of the ACC used and the pesticides molecules. Adsorption of the pesticides was considered to take place mainly by dispersion forces between $\pi$ electrons in the pesticide structure and $\pi$ electrons in the carbon cloth surface. The presence of aromatic rings in the structure of the pesticide increased the possibility of interactions, attributable to delocalization of $\pi$ electrons over the ring. The lowest rate and extent of adsorption for aldicarb were explained by the lack of an aromatic ring in its structure, whereas the branched alkyl substituent of the aromatic ring of dinoseb, providing hydrophobicity to the structure, was ascribed as responsible for the highest rate and adsorption extent attained for this pesticide. In the case of bentazon and propanil, adsorption kinetic measurements from equimolar binary solutions were additionally conducted [162]. It was found that the adsorption of propanil from the binary solution was almost the same as that from the single solute solution. Instead, at the initial stages of adsorption, bentazon was adsorbed faster from the binary solution than from the single solute solution, even though it slowed down in the later stages. The estimated characteristic parameters of the Langmuir and Freundlich models for the adsorption isotherms determined for each pesticide from single solute solutions showed that adsorption of bentazon was higher than that of propanil. It was concluded that although the activated carbon cloth used was quite effective for the individual adsorption of both pesticides from aqueous solutions, selectivity was rather low.

The effect of the solution $\mathrm{pH}$ and temperature on the adsorption of another versatile, very persistent pesticide, pentachlorophenol, onto activated carbon in the form of felt ( surface area $=1220 \mathrm{~m}^{2} \mathrm{~g}^{-1}$; total pore volume $=0.60 \mathrm{~cm}^{3} \mathrm{~g}^{-1}$ ) and cloth (surface area $=1140 \mathrm{~m}^{2} \mathrm{~g}^{-1}$; total pore volume $=$ $0.45 \mathrm{~cm}^{3} \mathrm{~g}^{-1}$ ) was comparatively examined [143]. Adsorption equilibrium isotherms were determined in the $\mathrm{pH}$ range of 6-12 and at temperatures between 15 and $35^{\circ} \mathrm{C}$ (Table 2). The speciation diagram of the pesticide showed that pentachlorophenolate anion was the predominant species at $\mathrm{pH}$ above 6 . The adsorption capacity was found to decrease with the $\mathrm{pH}$ increase, whereas it slightly diminished with the temperature increase. The effect of the solution $\mathrm{pH}$ on the adsorption capacity of the felt was explained by the electrostatic repulsion between the pentachlorophenolate anions in solution and the negatively charged surface of the carbon. Dispersion forces caused by $\pi-\pi$ interactions between the aromatic ring of pentachlorophenol and of the aromatic rings of graphitic layers of the carbons were found responsible for the adsorption of pentachlorophenol and for reversibility. Besides, the adsorption capacity of the felt nearly duplicated that of the cloth. The trend was attributed to the higher concentration of basic sites of the felt $\left(\sim 0.4 \mathrm{meq} \mathrm{g}^{-1}\right)$ in comparison with the cloth $\left(\sim 0.3 \mathrm{meqg}^{-1}\right)$ leading to stronger $\pi-\pi$ interactions. Desorption results enabled to demonstrate that the adsorption of the pesticide on the felt was reversible, providing additional evidence that adsorption took place by $\pi-\pi$ interactions.

As summarized in Table 2, a series of comprehensive studies on the adsorption of herbicides onto activated carbon cloths for batch and continuous modes has been reported by Moreno-Castilla and coworkers [135, 144-148]. The herbicides investigated included amitrole, diuron, and fluroxypyr. In one of these studies, adsorption of diuron and amitrole from water under static and dynamic conditions was comparatively investigated using activated carbons in the form of fibers, cloth, and grains [144]. In all cases, adsorption of diuron was found to be higher than the corresponding to amitrole. The results were attributed to the lower solubility, greater hydrophobicity, and larger dipolar moment of the former. Under dynamic conditions, the ACC showed the best performance in diuron adsorption. The behavior was explained by the largest mesopore volume, water accessible pore volume, and surface area of the ACC compared to the other forms investigated, whereas the granular activated carbon was found to behave as the best adsorbent for amitrole 
owing to its higher surface basicity. In another study [148], both the adsorption of amitrole from water on an activated carbon cloth and the oxidation with hydrogen peroxide using the same ACC as catalyst were examined. The effects of the solution $\mathrm{pH}$, ionic strength, and temperature on amitrole adsorption as well as the influence of the solution $\mathrm{pH}$ and the surface chemistry of the ACC on the oxidation were investigated. Adsorption of amitrole onto the ACC was found to attain levels of only $20-25 \%$ at the best adsorption conditions. This was explained by the high solubility and low aromaticity of amitrole, leading to a reduced adsorption of the herbicide on the ACC. A higher amitrole removal rate was obtained for the activated carbon $/ \mathrm{H}_{2} \mathrm{O}_{2}$ system. The best results were achieved for basic activated carbon surfaces at $\mathrm{pH} 7-10$. They were explained by the fact that these conditions favored hydroxyl radical formation, leading to higher levels of amitrole removal (35-45\%). It was also concluded that it was necessary to remove the oxygen fixed on the carbon surface during amitrole oxidation by heat treatment, in order to regenerate the surface basicity of the carbon prior to its reutilization in another oxidation cycle.

On the other hand, the effect of the solution $\mathrm{pH}$ and temperature on the adsorption of fluroxypyr from diluted aqueous solutions on activated carbon fibers and cloth and on the thermal desorption of fluroxypyr up to $800^{\circ} \mathrm{C}$ was investigated [145]. Adsorption of fluroxypyr was studied at $\mathrm{pH}$ values in the range of $2-10$ and temperatures of $25^{\circ} \mathrm{C}$ and $40^{\circ} \mathrm{C}$ using an activated carbon fiber $(9 \mu \mathrm{m}$ diameter and $3 \mathrm{~mm}$ length) and an activated carbon cloth of $0.45 \mathrm{~mm}$ thickness, both supplied by Kynol Europe (Table 2). The adsorption capacity was found to decrease as the solution $\mathrm{pH}$ increased. The trend was explained by changes in fluroxypyr solubility and in dispersive and electrostatic adsorbentadsorbate interactions with $\mathrm{pH}$ increase. The highest adsorption was achieved at $\mathrm{pH} 2$. As pointed out in the study, at this condition, the adsorbate was not dissociated and showed the lowest solubility, adsorbent-adsorbate dispersive interactions predominated, and no repulsive interactions among adsorbed fluroxypyr molecules took place. An increase in temperature led to a decrease in the adsorption capacity. The behavior of fluroxypyr as a function of adsorption temperature was found different from that for the herbicide diuron, but similar to that for amitrole. Interestingly, this was explained by considering that neither fluroxypyr nor amitrole change their molecular size with temperature, whereas diuron molecules increase their planarity with higher temperature, increasing the dipolar moment and the diffusion of diuron molecules into the microporosity of the adsorbent. Besides, a residue on the carbon surface, which increased as the $\mathrm{pH}$ increased, was found for the thermal desorption of fluroxypyr up to $800^{\circ} \mathrm{C}$. Differential thermogravimetry profiles showed two desorption peaks at $\mathrm{pH}$ values of 2 and 4 , and only one peak at $\mathrm{pH}$ of 7 and 10 . These results were related to the type of adsorbateadsorbent interactions established during adsorption and the predominance of electrostatic interactions favoring the strongly bound or chemisorbed fluroxypyr. It was concluded that the highest amounts of fluroxypyr were adsorbed and thermally desorbed when only nonelectrostatic interactions between fluroxypyr molecules and carbon surface occurred.
The effect of water alkalinity and hardness on fluroxypyr adsorption from distilled and tap water was further examined using the activated carbon fiber and cloth aforementioned (Table 2) and, additionally, conventional granular activated carbons [146]. At low fluroxypyr surface concentrations, the amount adsorbed from distilled water was related to the surface hydrophobicity. Around $60-65 \%$ of the surface area of the carbons was found to be covered by fluroxypyr molecules. Variations in fluroxypyr solubility with water characteristics showed a salting-in effect. Calcium, magnesium, and bicarbonate ions were adsorbed in different extents on the activated carbons. The presence of fluroxypyr in the solution decreased their adsorption, attributed to a competition effect. A nearly linear increasing relationship between the affinity characteristic parameter of the Freundlich model and water hardness was obtained. It was explained by saltscreened electrostatic repulsions between the charged fluroxypyr molecules. The amount adsorbed from distilled water was the largest at high fluroxypyr solution concentrations. This was attributed to the absence of competition between inorganic ions and fluroxypyr molecules. For dynamic conditions, it was found that the column breakthrough volume and the amount adsorbed at breakthrough were smaller in tap water than in distilled water. Furthermore, carbon consumption was found lower for the activated carbon cloth than for the granular activated carbon. In a closer approach to a real scenario, competitive adsorption of the herbicide fluroxypyr and tannic acid, as model of natural organic matter, from both distilled and tap water on activated carbon cloth and granular activated carbon was recently investigated in batch and continuous modes (Table 2), including thermal desorption of the adsorbates from the spent cloth [147]. At low equilibrium concentrations of fluroxypyr, the results showed that fluroxypyr adsorption was higher from tap water than from distilled water, whereas the opposite occurred at high concentrations. The presence of tannic acid led to a decrease in the amount of fluroxypyr adsorbed from tap and distilled water, that was attributed to partial blocking of microporosity. Nevertheless, the same trends aforementioned were held at low and high concentrations of the herbicide. Under dynamic conditions, the presence of tannic acid led to increase carbon consumption, as obtained from the breakthrough curves. This was related to microporosity of the samples. Besides, from thermal desorption profiles of the spent ACC at different heating rates, apparent activation energies and preexponential factors of the desorption process were determined.

Phenol, Phenolic, and Other Organic Compounds. Adsorption of phenol and phenolic compounds from aqueous solutions is one of the most investigated of all liquid-phase applications of carbon adsorbents. This is because phenol is considered a priority pollutant due to its toxicity even at low concentrations, and it is used as a model aromatic molecule [135]. Phenols discharged into the environment cause unpleasant taste and odour. Phenolic compounds present in liquid effluents are generated from paper and pulp, chemical, paint, resin, pesticides, gas, and coke manufacture and dyeing industries. Degradation of phenolic compounds leads to the appearance 
of phenol and its derivatives in the environment, and therefore their removal from wastewater is an important issue for protection. Among the processes applied for the removal of phenol from waste effluents, adsorption remains as the most versatile method, and activated carbon materials are widely used as adsorbents [75, 149]. The $\mathrm{pH}$ of the solution, the adsorbent real surface area, and the surface functional groups play a major role in the adsorption of phenolic compounds. Besides, the impact of the functional groups of a phenolic molecule on its adsorption is important and has been subject of intense research for conventional activated carbons [165]. These aspects have been also investigated for activated carbon cloths.

Apart from the works earlier depicted for dyes, surfactants, and pesticides, Ayranci and coworkers have also carried out intensive research on the adsorption of various other organic compounds using Spectracarb 2225 ACC [150$154,166,167]$. These studies comprised phenolic compounds $[150,166]$, some aromatic organic acids [151, 167], anilinic compounds [152], phthalic acid and its esters [153], and benzene and naphthalene sulfonates [154] (Table 2). With regard to phenolic compounds, the effect of ionization on the adsorption of phenol, hydroquinone, m-cresol, $\mathrm{p}$ cresol, and p-nitrophenol from acidic, basic, and natural $\mathrm{pH}$ aqueous solutions was examined [166]. Adsorption kinetics was represented by a first-order rate model. The highest rate constants were obtained for the adsorption of the compounds from solutions at natural $\mathrm{pH}$, whereas the lowest ones were estimated for the data from the basic solutions. The rate constants decreased in the order p-nitrophenol $\sim \mathrm{m}$-cresol $>$ p-cresol $>$ hydroquinone $\sim$ phenol. The extent and rate of adsorption were found dependent on the charge of the ACC surface, as determined by the point of zero charge, and on the predominating phenolic species, ionic or molecular, in turn depending on the solution $\mathrm{pH}$. The adsorption isotherms were well represented by the Freundlich model. The substituents on the phenolic ring were found to present positive or negative effects on both the adsorption rate and the extent of adsorption depending on their hydrophobicity and contribution to the $\pi$ electron delocalization over the ring. The higher adsorption capacity for p-nitrophenol compared to the other compounds was explained by the strong electronwithdrawing effect of the $-\mathrm{NO}_{2}$ group, reducing the overall electron density in the $\pi$ system of the ring and enhancing the attraction with the carbon surface in comparison with the interaction of the other compounds with the surface. In a further study, adsorption of catechol and resorcinol (two of the three isomers of dihydroxybenzene) from aqueous solutions onto the same ACC was investigated and additionally compared with results obtained for electrosorption [150] (Table 2). More than $82 \%$ of the pores of ACC were found to be available for the adsorption of catechol and resorcinol on the basis of their sizes. Kinetic data for both adsorption and electrosorption were represented by a pseudosecondorder model. Adsorption and electrosorption of catechol and resorcinol were mainly attributed to dispersion interactions between surface charges and $\pi$ electrons on adsorbate molecules. The adsorption capacity, as judged by the affinity characteristic parameter of the Freundlich model applied to the experimental isotherms, was found to be higher for catechol than for resorcinol. In addition, comparison of these values with the ones previously obtained for the adsorption of phenol onto the same ACC for neutral solutions showed a higher adsorption capacity for phenol than for catechol and resorcinol due to the smaller size of phenol.

The influence of the surface acidity of activated carbon cloths and of the solution $\mathrm{pH}$ on the adsorption of phenol and 2,4-dinitrophenol, as model compounds with very different $\mathrm{pKa}$ values, was also investigated [168]. Phenol adsorption was found to be favored by low solution $\mathrm{pH}$ values and high point of zero charge of the samples. The adsorption of 2,4dinitrophenol was promoted at very low $\mathrm{pH}$ values, and it was less influenced by the surface acidity of the ACC. More recently, the adsorption of phenol and p-nitrophenol from aqueous solutions $(\mathrm{pH}=6)$ onto activated carbon cloths labprepared from kenaf at optimized conditions was examined [112]. In agreement with the results reported for commercial ACC [166], it was also found that adsorption kinetics followed a pseudofirst-order rate model. Instead, adsorption of phenol was slightly faster than that of p-nitrophenol, and the Langmuir model fitted better the experimental equilibrium data, with quite similar maximum adsorption capacities for phenol and p-nitrophenol. Differences in the surface characteristics among the ACC and in values of the solution $\mathrm{pH}$ used in the studies, pronouncedly affecting the results attained, could explain the found trends. Furthermore, a strong correlation between the amount of adsorbed phenol and the micropore volume of activated carbon fibers, obtained from a phenolic textile fiber by carbonization and activation with water and $\mathrm{CO}_{2}$ under atmospheric and supercritical state, was found [75]. The relationship between surface oxygen concentration and the amount of physisorbed and chemisorbed phenol was assessed. The results showed that higher amounts of surface oxygen groups decreased the phenol chemisorption capacity of the activated carbon fibers.

On the other hand, structural and ionization effects on the adsorption of anilinic compounds, aniline, p-toluidine, 1naphthylamine, and sodium salt of diphenylamine-4-sulfonic acid, onto Spectracarb 2225 activated carbon cloth was investigated [152]. Solutions of these compounds in water, as well as in acidic $\left(1 \mathrm{M} \mathrm{H}_{2} \mathrm{SO}_{4}\right)$ or basic solutions $(0.1 \mathrm{M} \mathrm{NaOH})$ were employed (Table 2). Adsorption of the compounds was found to follow first-order kinetics. The point of zero charge of the carbon cloth surface was 7.4. For aniline, p-toluidine, and 1-naphthylamine, the highest rates and extents of adsorption were attained from the solutions of the compounds in water, while the best results were obtained from the acidic solutions for the sodium salt of diphenylamine-4-sulfonic acid. The adsorption behavior of the four compounds in the three types of solutions was explained in terms of electrostatic and dispersion interactions between the ACC surface and the anilinic species. The adsorption isotherm data for the anilinic compounds were determined and modeled. It was found that the Freundlich model better represented the experimental isotherms than the Langmuir model.

The effect of the solution $\mathrm{pH}$ in the range of $2-11$ on the adsorption of benzoic acid from aqueous solutions onto Spectracarb 2225 ACC was also studied [167]. Both the 
adsorption rate and the extent of adsorption attained the highest values at $\mathrm{pH} 3.7$ and decreased at higher or lower $\mathrm{pH}$ values. The types of interactions governing the adsorption of benzoic acid were interpreted by considering the surface charge of the cloth and the dissociation of the acid at different $\mathrm{pH}$ values. The very small rates and extents of adsorption determined at high $\mathrm{pH}$ values (9.0 and 11.0) were explained by increased electrostatic repulsions between benzoate anion and the negative surface charge at these $\mathrm{pH}$ values. This study was further extended to examine the adsorption of benzoic acid, salicylic acid, p-aminobenzoic acid, and nicotinic acid from solutions of the organics in water at natural $\mathrm{pH}$, from acid $\left(0.4 \mathrm{M} \mathrm{H}_{2} \mathrm{SO}_{4}\right)$ and basic $(0.1 \mathrm{M} \mathrm{NaOH})$ solutions, and also from solutions with $\mathrm{pH} 7.0$ [151] (Table 2). Adsorption kinetic data were represented by a first-order rate model. The rates and extents of adsorption of the compounds in water or acidic solutions attained the highest values, whereas the lowest ones were determined for the compounds in the basic solutions. Likewise, the rates and extents of adsorption of the organic acids in each of the four solutions were found to follow the order salicylic acid $>$ benzoic acid $>$ nicotinic acid $\sim$ p-aminobenzoic acid. Results were explained in terms of electrostatic, dispersion, and hydrogen bonding interactions between the surface and the adsorbate species, accounting for the charge of the carbon surface and the adsorbate in each solution. Benzoic acid in water was found to be adsorbed mainly in benzoate form leaving some neutral benzoic acid molecules in solution. The adsorption isotherms for the investigated systems were equally well represented by both the Langmuir and Freundlich models. In addition, the adsorption of phthalic acid and of the derived esters dimethyl phthalate, diethyl phthalate, and diallyl phthalate onto the same activated carbon cloth was investigated [153] (Table 2). The effect of ionization of phthalic acid on the adsorption was examined by carrying out adsorption assays in water, $1 \mathrm{M} \mathrm{H}_{2} \mathrm{SO}_{4}$ and $0.005 \mathrm{M} \mathrm{NaOH}$. Maximum adsorption was attained from the compounds in the acidic solutions, while almost no adsorption of the compounds from the basic media was found. The results were discussed in terms of electrostatic and dispersion interactions between the adsorbate species and the carbon cloth surface accounting for the point of zero charge (7.4) of the ACC. As for other compounds, the adsorption of the phthalate species was found to follow a firstorder rate expression, and the experimental isotherm data for the adsorption of phthalic acid and its esters were equally well represented by both the Langmuir and Freundlich models.

In a recent contribution, the effect of the molecular size of organic compounds on the overall rate of adsorption on a commercial PAN-based ACC (AW1104 manufactured by KoTHmex) was examined [155]. For this purpose, pyridine $(0.49 \mathrm{~nm})$, phenol $(0.53 \mathrm{~nm})$, naphthalene sulfonic acid (NAS) $(0.85 \mathrm{~nm})$, pentachlorophenol (PCP) $(0.87 \mathrm{~nm})$, and methylene blue $(\mathrm{MB})(1.03 \mathrm{~nm})$ were used (Table 2). Adsorption equilibrium and kinetics were studied for each organic compound at $\mathrm{pH}$ values for which maximum adsorption capacity occurred. These values were $\mathrm{pH} 10$ for pyridine, $\mathrm{pH} 7$ for phenol and PCP, and $\mathrm{pH} 3$ for NSA and MB. Adsorption isotherms for each compound were reasonably well represented by the Prausnitz-Radke model. The adsorption capacity was found to decrease in the order $\mathrm{MB}>$ $\mathrm{PCP} \approx$ phenol $>\mathrm{NSA}>$ pyridine. Interestingly, the overall rate of adsorption was interpreted by a diffusional model which accounted for the external mass transfer and intrafiber diffusion as important mass transfer mechanisms in the rate of adsorption on ACC. It was found that the molecular size of the organic compounds affected considerably the overall rate of adsorption on the ACC and the controlling mass transfer mechanism. It was demonstrated that the overall adsorption rate of pyridine and phenol was controlled by the external mass transfer, while intrafiber diffusion was the controlling mechanism in the adsorption rate of NSA, PCP, and $\mathrm{MB}$. In turn, it was found that intrafiber diffusion of the three latter compounds in ACC was reduced by hindered diffusion, which was explained by steric exclusion, drag effects, and obstruction due to molecules adsorbed on the pore walls. Furthermore, the effect of the solution $\mathrm{pH}$ and of the temperature on the adsorption of pyridine onto the same commercial PAN-based ACC was also recently examined [156]. The adsorption capacity of the ACC was found to increase by increasing the solution $\mathrm{pH}$ from 3 to 6 , but it was almost independent of the temperature in the range investigated $\left(15-35^{\circ} \mathrm{C}\right)$. The effect of the solution $\mathrm{pH}$ was explained by $\pi-\pi$ dispersive and electrostatic interactions between the pyridine species in solution and the surface complexes of ACC. A proper representation for the influence of the $\mathrm{pH}$ on the adsorption capacity was attained by a modified Langmuir model, assuming that both neutral pyridine and pyridinium were simultaneously adsorbed onto the ACC. Reversibility studies showed that $75 \%$ of pyridine was desorbed from ACC. This was considered as an indication that part of the pyridine was irreversibly adsorbed, and possibly chemisorbed.

Other studies have been devoted to examine the adsorption of some organic compounds onto ACC from binary solutions and in the presence of another compound mimicking natural organic matter (Table 2), including modeling. For example, Monneyron et al. [157] determined adsorption equilibrium of phenol, benzoic acid, and p-chlorophenol, from single solute solutions and binary solutions of initial equimolar concentrations of the two compounds, onto the commercial rayon-based activated carbon cloths (CS-1501 and RS1301 from Actitex Co.) for a wide range of concentrations (Table 2). The initial solution $\mathrm{pH}$ was 5.6 for phenol, 3.8 for benzoic acid, and 5.3 for p-chlorophenol. From single solute isotherms, physisorption of phenol and p-chlorophenol onto the cloths was inferred, while the adsorption of benzoic acid was ascribed to a combination of physisorption and chemisorption. The adsorption capacity parameter of the Langmuir and Freundlich models indicated the following order for the three compounds investigated: benzoic acid $>\mathrm{p}$ chlorophenol $>$ phenol, whereas a different order was found for the adsorption energy parameter ( $\mathrm{p}$-chlorophenol $>$ benzoic acid $>$ phenol). The results were enabled to confirm the influence of the adsorbent's microporosity on the adsorption capacity of the ACC. The CS-1501 sample possessing a higher pore volume $\left(0.665 \mathrm{~cm}^{3} \mathrm{~g}^{-1}\right)$ with pronounced predominance of micropores $(\sim 96 \%)$ showed higher adsorption capacity 
compared to RS-1301 cloth $\left(0.506 \mathrm{~cm}^{3} \mathrm{~g}^{-1} ; \sim 68 \%\right)$. Besides, the hydrophobicity and solubility of the adsorbates were found to have a significant influence on the adsorption energy and capacity, respectively. These findings were also confirmed from the binary solute isotherms. The experimental data for binary adsorption were used to investigate two approaches to competitive modeling. They involved a deterministic model, the ideal adsorbed solution theory (IAST), and a statistical model, neural networks. For both models, good agreement between the experimental and predicted data was in some cases attained.

The influence of the adsorbent pore size distribution on the adsorption of two taste- and odor-causing compounds, namely, 2-methyl isoborneol- $\mathrm{C}_{11} \mathrm{H}_{20} \mathrm{O}$ (MIB) and geosmin $\left(\mathrm{C}_{12} \mathrm{H}_{22} \mathrm{O}\right)$, from single solute and binary solutions using three different activated carbon cloths and a granularactivated carbon was investigated [158] (Table 2). The ACC obtained with different degrees of activation had narrow pore size distributions and specific critical pore diameters. The effect of the presence of natural organic matter (NOM) on compounds adsorption was also studied for the single solute and binary systems by using humic acid as model compound. The Myers equation was found to represent well the single solute isotherms, and the pore size distribution significantly influenced the adsorption for all the samples. Binary adsorption of MIB and geosmin was properly predicted by the IAST. No significant differences in binary adsorption isotherms conducted in the presence and absence of oxygen were found. It was inferred that physical adsorption and no oligomerization took place. Likewise, the presence of NOM led to deviation from IAST behavior for two of the adsorbents tested.

3.2. Adsorption of Air Pollutants. The emissions of volatile organic compounds (VOCs) and hazardous air pollutants (HAPs) are serious environmental issues. Regulations pertaining to HAPs/VOCs emissions have encouraged the development of new air pollution control technologies for a more effective removal of HAPs/VOCs from gas streams. Adsorption with regeneration is a convenient route to capture and control the emissions of organic vapors, recovery, and reuse of those compounds $[169,170]$. Owing to their properties, activated carbon cloths may contribute to solve air quality problems in a more environmentally sustainable way. Some selected studies concerned with the removal of air pollutants using ACC are summarized below, and a list with examples is shown in Table 3.

3.2.1. Inorganic Gaseous Pollutants. Use of activated carbon cloths for the removal of $\mathrm{H}_{2} \mathrm{~S}$, a major odorous compound from some industrial activities and other emission sources, has received special attention (Table 3). Le Leuch et al. [171] showed their good efficiency for $\mathrm{H}_{2} \mathrm{~S}$ adsorption/oxidation in different atmosphere conditions at room temperature. Batch measurements were performed using three different commercial rayon-based activated carbon cloths, produced by steam or $\mathrm{CO}_{2}$ physical activation at different carbonization and activation temperatures and a granular coconut-derived carbon. The humidity level, the presence of oxygen in the gas phase, and the structural and chemical surface properties of the adsorbents on $\mathrm{H}_{2} \mathrm{~S}$ removal were examined (Table 3). The removal of $\mathrm{H}_{2} \mathrm{~S}$ was found to take place mainly by oxidation reactions on specific surfaces. An approach of the oxidation pathway, which was found to depend on the operating conditions and surface functional groups, was determined. The catalytic role in $\mathrm{H}_{2} \mathrm{~S}$ removal played by the elemental sulfur $\left(\mathrm{S}_{0}\right)$ byproduct from the oxidation reaction was demonstrated.

The effect of modifying the surface chemistry on the performance of ACC in the removal of $\mathrm{H}_{2} \mathrm{~S}$ and $\mathrm{SO}_{2}$ from air streams was also studied (Table 3). The influence of ammonia treatments of a commercial viscose rayon-based ACC (WKL20, Actitex Co.) on the oxidative retention of $\mathrm{H}_{2} \mathrm{~S}$ and $\mathrm{SO}_{2}$ in humid air at room temperature was investigated $[172,173]$. Surface basic nitrogen groups were introduced either by treatment with ammonia/air at $300^{\circ} \mathrm{C}$ or with ammonia/steam at $800^{\circ} \mathrm{C}$. Changes in the surface chemistry were assessed by several complementary techniques. The ammonia treatments were found to markedly change the desulfurization ability of the activated carbon cloth. The ammonia/steam treatment led to a better improvement in ACC performance, that was explained by the nitrogen surface groups introduced as well as by changes in the extension of microporosity and in the distribution of surface oxygen groups. Important differences between oxidative retention of $\mathrm{H}_{2} \mathrm{~S}$ and $\mathrm{SO}_{2}$ and the subsequent catalyst/support regeneration process in successive adsorption-regeneration cycles were found.

A comprehensive review about the removal of inorganic gases and volatile organic compounds onto activated carbon was reported by Bandosz in 2008 [59]. Although it mostly deals with adsorption on conventional activated carbons, studies involving activated carbon fibers and cloths for the removal of gaseous pollutants, such as hydrogen cyanide, hydrogen sulfide, and sulfur dioxide, have also been included. Among recent studies, Sullivan et al. [174] examined physicochemical, adsorptive, and adsorption kinetic properties of PAN-derived activated carbon nanofibers produced by electrospinning and subsequent carbonization and activation, in order to assess their potentialities as adsorbent of toxic industrial chemicals. Properties of the nanofibers were compared with those of a commercially available activated carbon fiber cloth (ACC), as detailed in Table 3, and Calgon BPL granular activated carbon as reference. Adsorption/desorption isotherms for $\mathrm{H}_{2} \mathrm{O}, \mathrm{SO}_{2}, \mathrm{HCN}$, and butane were obtained gravimetrically. The nitrogen content in the nanofibers (9.6 wt\%) led to a basic surface that enhanced acid-gas adsorption. The nanofibers showed 4-20 times greater HCN adsorption capacities and 2-5 times greater $\mathrm{SO}_{2}$ adsorption capacities in dry nitrogen than the activated carbons in granular and cloth forms. Although the nanofibers had 50\% of the micropore volume $\left(0.30 \mathrm{~cm}^{3} \mathrm{~g}^{-1}\right)$ of the adsorbents used as reference, which limited their adsorption capacity at high concentrations for VOCs ( $>500 \mathrm{ppmv})$, it was found that they had similar adsorption capacity to the cloth and about 3 times that of the granular carbon at low concentrations 
TABLE 3: Some selected studies involving activated carbon cloths for removal of gaseous pollutants.

\begin{tabular}{|c|c|c|c|c|}
\hline Sample & ACC characteristics & Pollutant species & Adsorption assays & Reference \\
\hline $\begin{array}{l}\text { Commercial phenolic } \\
\text { novolac resin-based } \\
\text { ACC } \\
\text { ACC-5092-20 } \\
\text { American Kynol Inc. }\end{array}$ & $\begin{array}{l}A_{\mathrm{BET}}=1604 \mathrm{~m}^{2} \mathrm{~g}^{-1} \\
V_{m}=0.726 \mathrm{~cm}^{3} \mathrm{~g}^{-1}\end{array}$ & $\begin{array}{l}\text { Acetone, } \\
\text { benzene }\end{array}$ & $\begin{array}{l}\text { Gravimetric method } \\
T=20-60^{\circ} \mathrm{C} ; \\
P=101 \mathrm{kPa} \\
\text { Acetone: } \\
C_{0}=0-196000 \mathrm{ppmv} \\
\text { Benzene: } \\
C_{0}=0-94000 \mathrm{ppmv}\end{array}$ & {$[170]$} \\
\hline
\end{tabular}

\begin{tabular}{|c|c|c|c|c|}
\hline $\begin{array}{l}\text { Commercial } \\
\text { rayon-based ACC } \\
\text { WWP3, WWP3-V, } \\
\text { VS15 Actitex }\end{array}$ & $\begin{array}{l}\text { WWP3: } \\
A_{\mathrm{BET}}=976 \mathrm{~m}^{2} \mathrm{~g}^{-1} ; V_{m}=0.335 \mathrm{~cm}^{3} \mathrm{~g}^{-1} ; \\
V_{M}=0.024 \mathrm{~cm}^{3} \mathrm{~g}^{-1} ; \mathrm{pH}_{\mathrm{PZC}}=9.23 \\
\text { WWP3-V: } \\
A_{\mathrm{BET}}=871 \mathrm{~m}^{2} \mathrm{~g}^{-1} ; V_{m}=0.171 \mathrm{~cm}^{3} \mathrm{~g}^{-1} \\
V_{M}=0.303 \mathrm{~cm}^{3} \mathrm{~g}^{-1} ; \mathrm{pH} \text { PZC }=9.52 \\
\text { VS15: } \\
A_{\mathrm{BET}}=1480 \mathrm{~m}^{2} \mathrm{~g}^{-1} ; V_{m}=0.665 \mathrm{~cm}^{3} \mathrm{~g}^{-1} ; \\
V_{M}=0.025 \mathrm{~cm}^{3} \mathrm{~g}^{-1} ; \mathrm{pH}_{\mathrm{PZC}}=8.65\end{array}$ & $\mathrm{H}_{2} \mathrm{~S}$ & $\begin{array}{l}\text { Batch unit } \\
T=25^{\circ} \mathrm{C} \\
C_{0}=\text { n.a. } \\
\text { Atmospheres: } \mathrm{N}_{2} \text {, dry air, and } \\
\text { humid air }(\mathrm{RH}=30 \%)\end{array}$ & [171] \\
\hline $\begin{array}{l}\text { Commercial viscose } \\
\text { rayon-based ACC } \\
\text { WKL } 20 \text { Actitex }\end{array}$ & 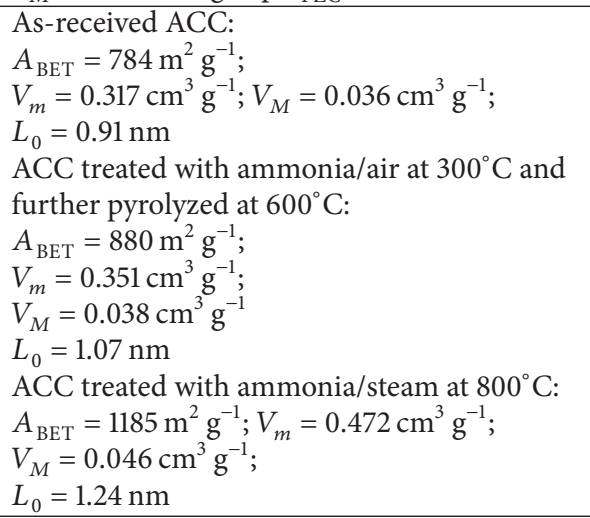 & $\mathrm{H}_{2} \mathrm{~S}, \mathrm{SO}_{2}$ & $\begin{array}{l}\text { Fixed bed, dynamic conditions } \\
T=25^{\circ} \mathrm{C} \\
C_{0}\left(\mathrm{H}_{2} \mathrm{~S}\right)=5000 \mathrm{ppmv} \\
C_{0}\left(\mathrm{SO}_{2}\right)=3000 \mathrm{ppmv}\end{array}$ & {$[172,173]$} \\
\hline $\begin{array}{l}\text { Commercial ACC } \\
\text { ACC-5092-15 } \\
\text { American Technical } \\
\text { Trading, Inc. }\end{array}$ & $\begin{array}{l}A_{\mathrm{BET}}=1262 \mathrm{~m}^{2} \mathrm{~g}^{-1} ; V_{T}=0.64 \mathrm{~cm}^{3} \mathrm{~g}^{-1} ; \\
V_{m}=0.62 \mathrm{~cm}^{3} \mathrm{~g}^{-1} ; L_{0}=0.77 \mathrm{~nm}\end{array}$ & $\begin{array}{l}\text { n-butane, } \mathrm{HCN}, \\
\mathrm{SO}_{2}\end{array}$ & $\begin{array}{l}\text { Gravimetric method } \\
T=25^{\circ} \mathrm{C}\end{array}$ & {$[174]$} \\
\hline $\begin{array}{l}\text { Commercial ACC } \\
\text { ACC-5092-20 } \\
\text { American Kynol }\end{array}$ & $\begin{array}{l}A_{\mathrm{BET}}=1604 \mathrm{~m}^{2} \mathrm{~g}^{-1} ; V_{T}=0.803 \mathrm{~cm}^{3} \mathrm{~g}^{-1} \\
V_{m}=0.746 \mathrm{~cm}^{3} \mathrm{~g}^{-1}\end{array}$ & $\begin{array}{l}\text { Methyl-ethyl } \\
\text { ketone }\end{array}$ & $\begin{array}{l}\text { Electrothermal swing adsorption } \\
\text { Adsorber vessel ( } 125 \mathrm{~mm} \text { O.D.) } \\
\text { with ACC rolled into } 4 \text { hollow } \\
\text { cylinders ( } 19 \mathrm{~mm} \text { I.D., } 200 \mathrm{~mm} \\
\text { length) } \\
C_{0}=250-1000 \text { ppmv } \\
\text { Flow rate }=25-60 \mathrm{~L} \mathrm{~min}^{-1}\end{array}$ & [175] \\
\hline $\begin{array}{l}\text { Commercial PAN-based } \\
\text { ACC } \\
\text { AW1108 Taicarbon Inc. }\end{array}$ & $\begin{array}{l}\text { As-received: } \\
A_{\mathrm{BET}}=1100 \mathrm{~m}^{2} \mathrm{~g}^{-1} \\
\text { Thermally posttreated at different } \\
\text { temperatures: } \\
\text { ACC }\left(T=600^{\circ} \mathrm{C}\right): A_{\mathrm{BET}}=1100 \mathrm{~m}^{2} \mathrm{~g}^{-1} \\
\text { ACC }\left(T=850^{\circ} \mathrm{C}\right): A_{\mathrm{BET}}=1209 \mathrm{~m}^{2} \mathrm{~g}^{-1} \\
\text { ACC }\left(T=1100^{\circ} \mathrm{C}\right): A_{\mathrm{BET}}=1227 \mathrm{~m}^{2} \mathrm{~g}^{-1}\end{array}$ & Benzene, $\mathrm{Cl}_{4} \mathrm{C}$ & $\begin{array}{l}\text { Gravimetric method } \\
\text { Single component } \\
T=25^{\circ} \mathrm{C} \\
C_{0}\left(\mathrm{C}_{6} \mathrm{H}_{6}\right)=5000 \mathrm{ppmv} \\
C_{0}\left(\mathrm{Cl}_{4} \mathrm{C}\right)=8500 \mathrm{ppmv}\end{array}$ & [176] \\
\hline $\begin{array}{l}\text { Lab-prepared lyocell } \\
\text { (Tencel)-based } \\
\text { ACC by } \mathrm{H}_{3} \mathrm{PO}_{4} \\
\text { activation at different } \\
\text { temperatures }\end{array}$ & $\begin{array}{l}\text { ACC }\left(T=864^{\circ} \mathrm{C}, 10 \mathrm{wt} \% \text { acid conc. }\right): \\
A_{\text {BET }}=1229 \mathrm{~m}^{2} \mathrm{~g}^{-1} ; V_{T}=0.52 \mathrm{~cm}^{3} \mathrm{~g}^{-1} ; \\
V_{m}=0.48 \mathrm{~cm}^{3} \mathrm{~g}^{-1} ; L_{0}=0.84 \mathrm{~nm} \\
\text { ACC }\left(T=963^{\circ} \mathrm{C}, 10 \text { wt } \% \text { acid conc. }\right): \\
A_{\text {BET }}=1705 \mathrm{~m}^{2} \mathrm{~g}^{-1} ; V_{T}=0.67 \mathrm{~cm}^{3} \mathrm{~g}^{-1} ; \\
V_{m}=0.64 \mathrm{~cm}^{3} \mathrm{~g}^{-1} ; L_{0}=1.09 \mathrm{~nm}\end{array}$ & $\begin{array}{l}\text { n-hexane, } \\
\text { Benzene, } \\
\text { Toluene }\end{array}$ & $\begin{array}{l}\text { Gravimetric method } \\
\text { Single component } \\
T=25^{\circ} \mathrm{C} \\
C_{0}\left(\mathrm{C}_{6} \mathrm{H}_{14}\right)=0-173000 \mathrm{ppmv} \\
C_{0}\left(\mathrm{C}_{6} \mathrm{H}_{6}\right)=0-112000 \mathrm{ppmv} \\
C_{0}\left(\mathrm{C}_{7} \mathrm{H}_{8}\right)=0-33000 \mathrm{ppmv}\end{array}$ & [177] \\
\hline $\begin{array}{l}\text { Commercial } \\
\text { rayon-based ACC } \\
\text { Zorflex Woven ACC } \\
\text { FM } 10\end{array}$ & $\begin{array}{l}A_{\mathrm{BET}}=1084 \mathrm{~m}^{2} \mathrm{~g}^{-1} ; V_{T}=0.41 \mathrm{~cm}^{3} \mathrm{~g}^{-1} \\
V_{m}=0.48 \mathrm{~cm}^{3} \mathrm{~g}^{-1} ; \text { minimum pore diameter }= \\
0.53 \mathrm{~nm} \\
\text { Total basic groups }=0.79 \mu \mathrm{eq} \mathrm{m} \mathrm{e}^{-2} \\
\text { Total acidic groups }=0.83 \mu \mathrm{eq} \mathrm{m}{ }^{-2}\end{array}$ & Formaldehyde & $\begin{array}{l}\text { Gravimetric method } \\
T=26^{\circ} \mathrm{C} \\
C_{0}=0-32.5 \mathrm{ppmv}\end{array}$ & [178] \\
\hline
\end{tabular}

$A_{\mathrm{BET}}$ : BET surface area; $V_{T}$ : total pore volume; $V_{M}$ : mesopore volume; $V_{m}$ : micropore volume; $L_{0}$ : mean micropore width; $\mathrm{pH}$ PZC: $\mathrm{pH}$ at the point of zero charge; $C_{0}$ : initial concentration. 
( $<500$ ppmv). Besides, the small fiber diameters $(0.2-1.5 \mu \mathrm{m})$ allowed for higher mass transfer coefficients, resulting in adsorption kinetics nearly twice as fast as ACC and eight times as fast as the granular sample. Hydrophilicity and reduced structural strength were pointed out as drawbacks for the PAN-derived activated carbon nanofibers.

Other studies have been devoted to examine the removal of elemental mercury vapor $\left(\mathrm{Hg}^{0}\right)$. For instance, the $\mathrm{Hg}^{0}$ removal ability of activated carbon fiber impregnated with cerium dioxide $\left(\mathrm{CeO}_{2}\right)$ was examined [179]. The effects of loading values, calcination temperatures, reaction temperatures, and acid gases, such as $\mathrm{NO}$ and $\mathrm{SO}_{2}$, on the $\mathrm{Hg}^{0}$ removal rates were investigated. The impregnation with $\mathrm{CeO}_{2}$ was found to significantly enhance the $\mathrm{Hg}^{0}$ removal ability of the fiber, particularly with the loading value of $6 \%$. The samples at different calcination temperatures had a similar $\mathrm{Hg}^{0}$ removal performance. For temperatures below $150^{\circ} \mathrm{C}$, the $\mathrm{CeO}_{2} /$ fiber removal ability for $\mathrm{Hg}^{0}$ increased with the increase of temperature and then decreased after $150^{\circ} \mathrm{C}$. $\mathrm{NO}$ and $\mathrm{SO}_{2}$ showed a promoted effect on $\mathrm{Hg}^{0}$ oxidation.

3.2.2. Organic Gaseous Pollutants and Regeneration of Activated Carbon Cloths. The vapor-phase adsorption of $\mathrm{n}-$ hexane and benzene in single component and binary systems onto a commercial activated carbon cloth from HEG Limited was investigated by conducting batch studies [180]. Adsorption capacities were evaluated by applying Freundlich and Langmuir adsorption isotherm models. The adsorption of n-hexane was found to be higher compared to that of benzene. At low concentration levels, the adsorption of hexane did not change due to presence of benzene, but the amount of hexane adsorbed decreased in the presence of benzene at high concentrations. In the case of benzene, the adsorption decreased both at low and high concentration levels in the presence of hexane. Depending upon the design of the experiment, internal diffusion was found to control the adsorption of benzene and n-hexane on the ACC.

Equilibrium adsorption isotherms for acetone and benzene onto another commercial activated carbon cloth (ACFC-5092-20, American Kynol Inc.) were determined (Table 3 ) and compared with results for a coal-derived activated carbon (CDAC, BPL, Calgon Carbon Corp.) [170]. The ACC had a $\mathrm{N}_{2}$-BET surface area of $\sim 1600 \mathrm{~m}^{2} \mathrm{~g}^{-1}$ and a narrow pore size distribution, whereas the BET area for the coal-derived activated carbon was $965 \mathrm{~m}^{2} \mathrm{~g}^{-1}$. Benzene was found to be adsorbed more effectively than acetone onto both adsorbents. This was attributed to its lower saturation vapor pressure and its higher boiling point. The DubininAshtakov (DA) equation was used to describe the adsorption isotherms. The DA parameters were found to be independent of the temperature. The resulting DA equations together with the Clausius-Clapeyron equation were used to analytically determine the isosteric heat of adsorption $(\Delta \mathrm{Hs})$ of the adsorbate-adsorbent systems investigated. The ACC showed higher adsorption capacities for both organic vapors than the conventional carbon. $\Delta H$ s values for the adsorbates were found independent of the temperature for the conditions evaluated and comparable with values reported in the literature.

The capture and recovery of HAPs and VOCs from gas streams using physical adsorption onto activated carbon fiber cloth on the bench scale was demonstrated by Sullivan et al. [175]. Adsorption of methyl ethyl ketone (MEK) vapor from air streams onto the same aforementioned ACC from American Kynol Inc. was particularly investigated (Table 3). The system was regenerated electrothermally, by passing an electric current directly through the ACC. MEK desorbed from the adsorbent rapidly condensed on the inside walls of the adsorber and then drained from the adsorber as a pure liquid. Characteristics found for rapid electrothermal desorption included extremely low purge gas flow rate, rapid rate of ACC heating, rapid mass transfer kinetics inherent to ACC, and in-vessel condensation. Furthermore, the capture of toluene vapor onto the same ACC in a bench-scale system using electrothermal swing adsorption was examined [181] in the framework of a comparative study which also included activated carbon in the form of monolith and beads. In particular, the adsorption unit involving the ACC contained four annular cartridges, each one with eight layers of cloth, in order to adsorb the organic vapor from air stream. Pressure drop, permeability, adsorption capacity, breakthrough curve, throughput ratio, length of unused bed, electrical resistivity, concentration factor during regeneration, and cost were determined. The ACC was found to possess the largest adsorption capacity for toluene that was explained by the larger specific surface area and micropore volume of the ACC compared to the two other activated carbon forms. The electrical resistivity of the ACC was $6 \times 10^{-3} \Omega \mathrm{m}$ at $22^{\circ} \mathrm{C}$. Electrothermal regeneration of the ACC was also faster and had a larger concentration factor than those for the monolith and the beads.

Toluene adsorption onto $300 \mathrm{~nm}$ average diameter activated carbon nanofibers, which were obtained by electrospinning of PAN fibers and further activated with steam at various temperatures, was studied by $\mathrm{Oh}$ et at. [182]. Toluene adsorption capacity for the activated carbon nanofibers obtained at $1000^{\circ} \mathrm{C}$ attained $7 \mathrm{mmol}$ toluene per gram of sample, that was attributed to the high specific surface area $\left(\sim 1400 \mathrm{~m}^{2} \mathrm{~g}^{-1}\right)$, large micropore volume $\left(\sim 0.50 \mathrm{~cm}^{3} \mathrm{~g}^{-1}\right)$, and narrow average pore diameter $(0.6 \mathrm{~nm})$ of the sample. Besides, as pointed out in the study, its low oxygen-to-carbon ratio could induce a higher toluene adsorption capacity, as a result of nonpolar interactions between the adsorbent surface and toluene.

Studies involving modifications of the surface chemistry on gaseous pollutants adsorption have been also conducted (Table 3). For example, the effect of heat treatment of commercial PAN-based activated carbon fabric and rayon-based activated carbon felt on their performance in the adsorption of benzene, carbon tetrachloride, and water vapor at preestablished conditions was investigated [176], to examine the role of surface chemistry. The samples were thermally treated at different temperatures $\left(600^{\circ} \mathrm{C}, 850^{\circ} \mathrm{C}\right.$, or $\left.1000^{\circ} \mathrm{C}\right)$ for $1 \mathrm{~h}$ in nitrogen atmosphere. Differences in the ACC precursors resulted in various elemental compositions and imposed diverse influence upon surface functionalities after heat treatment. It was found that the surface of the heat-treated samples 
became more graphitic and hydrophobic. Among the several surface functionalities identified, the presence of nitride-like species, aromatic $\mathrm{N}$-imines, or chemisorbed nitrogen oxides was found to be favorable for the adsorption of water vapor or benzene, but not for pyridine. Unstable complexes on the surface would hinder the fibers from adsorption of $\mathrm{CCl}_{4}$. The rise in total ash content or hydrogen composition positively impacted the access of water vapor. Modifications of the samples by heat treatment were found effective in improving their adsorption performance.

More recently, Ramos et al. [177] determined gravimetrically the adsorption isotherms of $n$-hexane, benzene, and toluene onto lyocell-based ACC lab-prepared by phosphoric acid activation at final thermal treatment temperatures of $864^{\circ} \mathrm{C}$ and $963^{\circ} \mathrm{C}$ (Table 3). The isotherms of the three VOCs exhibited a classical Type-I shape. Experimental adsorption data were satisfactorily fitted to the Freundlich model over the whole equilibrium pressure range. The DubininRadushkevich equation also represented properly the adsorption isotherms in the range of relative pressures between 0.01 and 0.1 . Among the three compounds investigated, the highest relative adsorption capacity was found for benzene ( $\sim 6 \mathrm{mmol} \mathrm{g}^{-1}$, according to the Freundlich model), while the minimum value was obtained for $\mathrm{n}$-hexane. The trend was attributed to dispersive $\pi-\pi$ interactions between the aromatic compounds and the $\pi$ system of pseudographitic planes of the ACC. The shape and size of benzene could also allow an easier diffusion in the narrow ultramicropores of the ACC. In turn, the adsorption capacity of the ACC obtained at $963^{\circ} \mathrm{C}$ was 1.5 times higher than those developed at $864^{\circ} \mathrm{C}$. This was explained by the higher specific surface area, average pore diameter, and large micropore volume characterizing the former. To evaluate the feasibility of in situ electrothermal regeneration of the saturated lyocell-based ACC, their electrical resistivity before and after exposure to n-hexane, as model compound, was determined from macroscopic electrical measurements. The adsorption of $n$-hexane onto both ACC reduced the electrical resistivity and the thermal coefficient of the samples. The ACC obtained at $963^{\circ} \mathrm{C}$ showed a greater reduction of the electrical parameters, probably due to the higher amount of $n$-hexane adsorbed on this sample. Additionally, all the samples were heated by the Joule effect, the range of measured temperatures being comprised between $\sim 30$ and $130^{\circ} \mathrm{C}$ for voltages between 10 and $20 \mathrm{~V}$. The ACC showed a rapid heating rate. Different central surface temperatures were achieved in less than $30 \mathrm{~s}$. The samples presented a high level of regeneration, between $\sim 96 \%$ and $98 \%$, without appreciable changes in their surface properties. Accordingly, it was concluded that the heat generated had potential for in situ regeneration of the ACC loaded with VOCs and for recovery of these compounds.

Adsorption of benzene and toluene at low concentration (200 ppmv) using activated carbon fibers lab-prepared by physical activation with steam or carbon dioxide was recently reported [183]. Activated carbon fibers showed high adsorption capacities for benzene and toluene at the low concentration examined. Adsorption capacities were $4 \mathrm{mmol} \mathrm{g}^{-1}$ for benzene and $6 \mathrm{mmolg}^{-1}$ for toluene. The behavior was explained by the large volume of narrow micropores
$(<0.7 \mathrm{~nm})$ developed upon activation and low content in surface oxygen groups of the fibers. Good agreement between the results from dynamic adsorption experiments and from adsorption isotherms was found. As the relative pressure of the organic compound increased, the corresponding fraction of narrow micropore volumes filled by benzene and toluene also increased. For a given low and comparable relative pressure, toluene was found to occupy a larger fraction of narrow micropores than benzene in all cases.

Carter et al. [178] determined for the first time adsorption isotherms of formaldehyde onto a commercial rayon-based activated carbon cloth (Zorflex Woven ACC, FM10) and two granular activated carbon samples (Table 3). Formaldehyde adsorption was examined in the low ppmv range, from 0 to $32.5 \mathrm{ppmv}$. Single-component isotherms of water vapor at relative pressures from 0.1 to 0.9 and at $26^{\circ} \mathrm{C}$ were also determined. HCHO adsorption isotherms exhibited a sigmoidal curve characteristic of Type $\mathrm{V}$ isotherms, according to the IUPAC isotherm classification. A four-parameter model was applied to fit the $\mathrm{HCHO}$ and water vapor adsorption isotherms. Physicochemical characteristics of the activated carbon surfaces were determined, and relationships between the characteristics and adsorption capacities of the two adsorbates were investigated. It was found that at low concentrations, $\mathrm{HCHO}$ adsorption capacity was most strongly related to the density of basic surface functional groups, while water vapor adsorption was most strongly influenced by the density of acidic surface functionalities.

The effect of the operating variables on the performance of an activated carbon cloth in the adsorption-regeneration of limonene, toluene, and MEK was assessed by Yao et al. [184]. A single layer of the sample exhibited remarkable adsorption and regenerative properties using 100 parts per billion by volume (ppbv) toluene as indoor contaminant. Joule heating regeneration showed that the adsorbent was rapid and efficient in removing the low initial loading of toluene. Even after continuous adsorption/regeneration cycles, it showed very good performance. After over 300 heating and cooling cycles, the cloth presented excellent durability and adsorption capacity.

Le Cloirec and collaborators have extensively investigated adsorption of HAPs, some of them already mentioned in Section 3.2.1, and VOCs onto commercial activated carbon cloths, as well as desorption and regeneration of saturated ACC by electrothermal heating $[25,26,185]$. Their contributions also including research on relevant engineering aspects, such as modeling of fluid pressure drops through ACC by a neural network approach [186] and 3D simulations of cylindrical pleated filter packed with ACC [30], deserve to be highlighted. A specific review on adsorption onto activated carbon cloths and electrothermal desorption of VOCs has been recently reported by Le Cloirec [20]. Among other recent studies, Boulinguiez and Le Cloirec [187] investigated the adsorption capacity and kinetics of five selected VOCs, toluene, dichloromethane, isopropanol, ethyl mercaptan, and D4 siloxane (octamethylcyclotetrasiloxane), commonly found in biogas, onto two commercial granular activated carbons and two commercial ACC (FM30 K from CCI, U K and THC515 from Dacarb, France) in batch mode. A synthetic 
biogas matrix of methane and carbon dioxide was employed to approach field conditions. Adsorptions of the VOCs were satisfactorily represented by the Langmuir-Freundlich model and related to the inherent porosity characteristics of the adsorbents. The most porous adsorbents showed the best compromise in adsorption capacities for the five compounds, but the adsorption kinetics confirmed the importance of the fiber cloth morphology in activated carbon materials. The early step of thermal regeneration was investigated and suggested an optimal temperature of regeneration higher than $200^{\circ} \mathrm{C}$ for any carbon, despite being partially hampered by the formation of nonvolatile compounds. In another study, the adsorption and thermal regeneration of commercial activated carbons, including two fiber cloths based on viscose and PAN, and two granular samples, for three organosulfur compounds (ethyl mercaptan, isopropyl mercaptan, and tetrahydrothiophene), that are purposefully added as odorous markers in gases related to energy applications for leaks detection, were investigated. Experimental isotherms at $25^{\circ} \mathrm{C}$ were determined and satisfactorily represented by the LangmuirFreundlich model. Performance of the activated carbons in the removal of the organosulfurs was explained accounting for their inherent porosity and surface functional groups characteristics. At low organosulfur concentration, the cloths were found to exhibit greater adsorption than the granular carbons, confirming their potential for desulfurization. Thermal desorption of the carbons loaded at 50\% of their adsorption maximum capacity was performed in nitrogen and air atmospheres. Analyses of the desorbed byproducts arising from both atmospheres enabled to demonstrate the major role of oxygen in the degradation process of the organosulfurs. Mercaptans were found to oxidize to their respective sulfide, disulfide, sulfur dioxide, minor carbonyl compounds, and elemental sulfur, while tetrahydrothiophene by-products were limited to thiophene, sulfur dioxide, elemental sulfur, and traces of sulfone compound. Based on the several detected by-products, the oxidative degradation pathways for the three organosulfurs were proposed in this study.

In order to improve desorption energy efficiency through control of adsorbent heating, allowing for cost-effective separation and concentration of organic gases for reuse, Johnsen et al. [188] performed experiments to evaluate regeneration energy consumption. Electrothermal swing adsorption of isobutene from an air stream containing $2000 \mathrm{ppmv}$ of this compound onto an ACC was examined. Control logic based on temperature feedback was found to achieve select temperature and power profiles during regeneration cycles while maintaining the cloth's mean regeneration temperature $\left(200^{\circ} \mathrm{C}\right)$. Besides, energy requirements for regeneration were independent of differences in temperature/power oscillations (1186-1237 kJ/mol of isobutane). Among other results, additional logic that increased the maximum power application at lower ACC temperatures was found to decrease 36\% in energy consumption. It was concluded that implementation of such control logic improved energy efficiency for separating and concentrating organic gases for postdesorption liquefaction of the organic gas for reuse. In another recent study, Johnsen and Rood [189] proposed a new method to control electrothermal heating of an adsorbent based on rapid remote electrical resistance measurements, eliminating the need for direct contact temperature sensors. Consistent resistance values after repeated electrothermal heating cycles were demonstrated, showing that this cost-effective and simple regeneration method may be used for extended durations for practical applications.

The feasibility of using microwaves as the source of energy to regenerate ACC as part of a process for the capture and the recovery of organic vapors from gas streams was investigated [169]. A bench-scale fixed-bed microwave-swing adsorption (MSA) system was built and tested for the adsorption of water vapor, methyl ethyl ketone (MEK), and tetrachloroethylene from an airstream, to recover the vapors by microwave regeneration. The electromagnetic heating behavior of dry and vapor-saturated ACC was also characterized. The MSA system was found to successfully adsorb organic vapors from the airstreams, allowing for rapid regeneration of the ACC cartridge, and for the recovery of water and organic vapors as liquids. Emamipour et al. [190] developed and tested a method to achieve steady-state and dynamic-tracking desorption of organic compounds from activated carbon in a bench-scale system, also exploring use of microwaves for regeneration. Activated carbon fiber cloth was used to adsorb methyl ethyl ketone (MEK) from air streams. Direct electrothermal heating was used for desorption of the vapor to generate select vapor concentrations at $500 \mathrm{ppmv}$ and 5000 ppmv in air. Dynamic-tracking desorption was also achieved with carefully controlled variable vapor concentrations between $250 \mathrm{ppmv}$ and $5000 \mathrm{ppmv}$, allowing the flow carrier gas rate to change by $100 \%$. The results were also compared to conditions when recovering MEK as a liquid, and using microwaves as the energy source to regenerate the adsorbent and to provide MEK as a vapor or a liquid. Advantages and disadvantages of electrothermal swing adsorption (ESA) and MSA systems were comparatively discussed. The amounts of energy consumed for the ESA and MSA systems were of the same order of magnitude. Nevertheless, depending on the type of application, one system could be favorable over the other. As pointed out in the study, the MSA has the potential for selective desorption based on the microwave properties of the adsorbent and adsorbate which can enhance the energy efficiency of the system. In contrast, the ESA system is considered to be less complex than the MSA system, allowing for direct application of energy to the adsorbent. Moreover, the impact of chemical functional groups on the microwave attenuation and electrical resistivity properties of activated carbon fiber cloths was also examined [191]. These properties are important because of their influence on the direct electrothermal and microwave regeneration properties of the cloths. Increasing the oxygen content was found to reduce their ability to absorb microwaves, likely complicating their further heating with microwaves. However, decreasing the oxygen content allowed the ACC to heat more readily by resistive heating. It was concluded that since microwave and resistive heating techniques depend on the microwave attenuation constant and electric resistivity, respectively, controlling the density of functional groups of the ACC 
could significantly affect the thermal regeneration of the ACC depending on the method used for heating.

On the other hand, some studies have been concerned with proposals for predictive modeling of multicomponent VOCs adsorption equilibrium. For instance, modeling of multicomponent adsorption equilibria of VOCs based on equilibrium data of only one similar component was reported [192]. Single and binary adsorption equilibria of acetone and benzene vapors in ACC (ACFC-5092-20, Kynol) were predicted by models formulation and compared with modeled and measured characterization data available in the literature.

\section{Concluding Remarks}

Despite significant advances attained on the development of activated carbon cloths and their demonstrated advantageous potentialities for environmental applications, as summarized in the present overview, massive adoption of activated carbon cloths for full-scale treatment of liquid and gaseous effluents still requires to overcome some issues. In order to contribute to lower costs associated with the manufacture of high quality activated carbon cloths, more research toward optimization of cost-effective processes using inexpensive fabrics as precursors is needed. It is also important to conduct adsorption studies involving multicomponent systems for a closer approach to real conditions. Likewise, studies in dynamic conditions are still necessary to achieve reliable information for the proper design and operation of largescale treatment units for the removal of liquid and gaseous pollutants. On the other hand, another aspect to be further explored concerns the mechanical and electrical characterization of lab-prepared activated carbon cloths. The latter is particularly relevant to take full advantage of the benefits related to electrothermal regeneration of activated carbon cloths saturated with organic vapors. In addition, integral research studies devoted to the tailoring of activated carbon cloths from a given precursor in terms of desired properties and/or specific end uses, through the strategic selection of main variables involved in the activation process applied, may help their high performance without further posttreatments.

\section{Conflict of Interests}

The author affirms that she has no direct or indirect financial relation or other relations with the commercial identities mentioned in the paper entitled "Development and Environmental Applications of Activated Carbon Cloths" of her authorship.

\section{Acknowledgments}

The author gratefully acknowledges the financial support from Universidad de Buenos Aires, Consejo Nacional de Investigaciones Científicas y Técnicas (CONICET), and FONCYT-MINCYT from Argentina.

\section{References}

[1] R. C. Bansal and M. Goyal, Activated Carbon Adsorption, CRC Press, Boca Raton, Fla, USA, 2005.

[2] M. C. Basso and A. L. Cukierman, "Arundo donax-based activated carbons for aqueous-phase adsorption of volatile organic compounds," Industrial and Engineering Chemistry Research, vol. 44, no. 7, pp. 2091-2100, 2005.

[3] H. Marsh and F. R. Reinoso, Activated Carbon, Elsevier, Oxford, UK, 2006.

[4] T. J. Bandosz, Activated Carbon Surfaces in Environmental Remediation, Academic Press, 2006.

[5] R. V. Ramanujan, S. Purushotham, and M. H. Chia, "Processing and characterization of activated carbon coated magnetic particles for biomedical applications," Materials Science and Engineering C, vol. 27, no. 4, pp. 659-664, 2007.

[6] P. Le Cloirec and C. Faur-Brasquet, "Adsorption of inorganic species from aqueous solutions," in Adsorption By Carbons, E. J. Bottani and J. M. D. Tascón, Eds., Chapter 24, pp. 631-651, Elsevier, Oxford, UK, 2008.

[7] J. de Celis, N. E. Amadeo, and A. L. Cukierman, "In situ modification of activated carbons developed from a native invasive wood on removal of trace toxic metals from wastewater," Journal of Hazardous Materials, vol. 161, no. 1, pp. 217-223, 2009.

[8] J. Rivera-Utrilla, M. Sanchez-Polo, V. Gomez-Serrano, P. M. Alvarez, M. C. M. Alvim-Ferraz, and J. M. Dias, "Activated carbon modifications to enhance its water treatment applications. An overview," Journal of Hazardous Materials, vol. 187, pp. 1-23, 2011.

[9] J. F. Kwiatkowski, Ed., Activated Carbon: Classifications, Properties and Applications, Nova Science Publishers, New York, NY, USA, 2012.

[10] G. Mezohegyi, F. P. Van Der Zee, J. Font, A. Fortuny, and A. Fabregat, "Towards advanced aqueous dye removal processes: a short review on the versatile role of activated carbon," Journal of Environmental Management, vol. 102, pp. 148-164, 2012.

[11] J. Wang and S. Kaskel, "KOH activation of carbon-based materials for energy storage," Journal of Materials Chemistry, vol. 22, pp. 23710-23725, 2012.

[12] G. V. Nunell, M. E. Fernández, P. R. Bonelli, and A. L. Cukierman, "Removal of nitrate from wastewater by activated carbons developed from sawdust of an invasive wood," Biomass and Bioenergy, vol. 44, pp. 87-95, 2012.

[13] Roskill Report, 2008, http://www.roskill.com/reports/industrial-minerals/activated-carbon.

[14] S. Román, J. M. V. Nabais, B. Ledesma, J. F. González, C. Laginhas, and M. M. Titirici, "Production of low-cost adsorbents with tunable surface chemistry by conjunction of hydrothermal carbonization and activation processes," Microporous and Mesoporous Materials, vol. 165, pp. 127-133, 2013.

[15] J. L. Peñalver, J. L. Linares-Fernández, V. de Araujo Farías et al., "Activated carbon cloth as support for mesenchymal stem cell growth and differentiation to osteocytes," Carbon, vol. 47, no. 15, pp. 3574-3577, 2009.

[16] S. Y. Lee and S. J. Park, "Determination of the optimal pore size for improved $\mathrm{CO}_{2}$ adsorption in activated carbon fibers," Journal of Colloid and Interface Science, vol. 389, pp. 230-235, 2013.

[17] F. Rodríguez-Reinoso, "Production and applications of activated carbons," in Handbook of Porous Solids, F. Schüth, K. S. W. Sing, and J. Weitkamp, Eds., Chapter 4, 8, 1, pp. 1766-1827, Wiley-VCH, Weinheim, Germany, 2002. 
[18] J. M. D. Tascón, "Overview of carbon materials in relation to adsorption," in Adsorption By Carbons, E. J. Bottani and J. M. D. Tascón, Eds., pp. 15-49, Elsevier, Oxford, UK, 2008.

[19] A. Linares-Solano and D. Cazorla-Amorós, "Adsorption on activated carbon fibers," in Adsorption By Carbons, E. J. Bottani and J. M. D. Tascón, Eds., Chapter 17, pp. 431-449, Elsevier, Oxford, UK, 2008.

[20] P. Le Cloirec, "Adsorption of activated carbon fiber cloth and electrothermal desorption of volatile organic compounds (VOCs): a specific review," Chinese Journal of Chemical Engineering, vol. 20, no. 3, pp. 461-468, 2012.

[21] C. O. Ania and F. Béguin, "Mechanism of adsorption and electrosorption of bentazone on activated carbon cloth in aqueous solutions," Water Research, vol. 41, pp. 3372-3380, 2007.

[22] C. O. Ania and F. Béguin, "Electrochemical regeneration of activated carbon cloth exhausted with bentazone," Environmental Science \& Technology, vol. 42, pp. 4500-4506, 2008.

[23] G. Milczarek, A. Ciszewski, and I. Stepniak, "Oxygen-doped activated carbon fiber cloth as electrode material for electrochemical capacitor," Journal of Power Sources, vol. 196, no. 18, pp. 7882-7885, 2011.

[24] I. Villar, D. J. S. De la Calle, Z. González et al., "Carbon materials as electrodes for electrosorption of $\mathrm{NaCl}$ in aqueous solutions," Adsorption, vol. 17, pp. 467-471, 2011.

[25] A. Subrenat, J. N. Baléo, P. Le Cloirec, and P. E. Blanc, "Electrical behaviour of activated carbon cloth heated by the joule effect: desorption application," Carbon, vol. 39, no. 5, pp. 707-716, 2001.

[26] A. Subrenat and P. Le Cloirec, "Thermal behavior of activated carbon cloths heated by Joule effect," Journal of Environmental Engineering, vol. 129, no. 12, pp. 1077-1084, 2003.

[27] A. Badalyan, R. Bromball, P. Pendleton, and W. Skinner, "An assessment of activated carbon cloth microporosity change due to chemical activation," Carbon, vol. 48, no. 4, pp. 1004-1011, 2010.

[28] M. E. Ramos, P. R. Bonelli, and A. L. Cukierman, "Strategies for optimizing the development of cellulose-based activated carbon cloths by the chemical activation process," in Activated Carbon: Classifications, Properties and Applications, J. F. Kwiatkowski, Ed., Chapter 15, pp. 475-507, Nova Science Publishers, New York, NY, USA, 2011.

[29] D. L. Johnsen and M. J. Rood, "Temperature control during regeneration of activated carbon fiber cloth with resistancefeedback," Environmental Science \& Technology, vol. 46, pp. 11305-11312, 2012.

[30] A. Subrenat, J. Bellettre, and P. Le Cloirec, "3-D numerical simulations of flows in a cylindrical pleated filter packed with activated carbon cloth," Chemical Engineering Science, vol. 58, no. 22, pp. 4965-4973, 2003.

[31] L. Kiwi-Minsker, M. Ruta, T. Eslanloo-Pereira, and B. Bromley, "Structured catalytic wall microreactor for efficient performance of exothermic reactions," Chemical Engineering and Processing, vol. 49, no. 9, pp. 973-978, 2010.

[32] D. Bremner and I. Johnson, "In vogue," Chemical Engineer, vol. 836, pp. 40-41, 2011.

[33] Y. Matatov-Meytal and M. Sheintuch, "Catalytic fibers and cloths," Applied Catalysis A, vol. 231, no. 1-2, pp. 1-16, 2002.

[34] U. I. Matatov-Meytal, "Radial-flow reactor packed with a catalytic cloth: nitrate reduction in hydrogen-saturated water," Industrial and Engineering Chemistry Research, vol. 44, no. 25, pp. 9575-9580, 2005.
[35] U. Matatov-Meytal and M. Sheintuch, "Activated carbon clothsupported Pd-Cu catalyst: application for continuous water denitrification," Catalysis Today, vol. 102-103, pp. 121-127, 2005.

[36] V. Gaur, A. Sharma, and N. Verma, "Catalytic oxidation of toluene and $\mathrm{m}$-xylene by activated carbon fiber impregnated with transition metals," Carbon, vol. 43, no. 15, pp. 3041-3053, 2005.

[37] P. Korovchenko, A. Renken, and L. Kiwi-Minsker, "Microwave plasma assisted preparation of Pd-nanoparticles with controlled dispersion on woven activated carbon fibres," Catalysis Today, vol. 102-103, pp. 133-141, 2005.

[38] A. Perrard, P. Gallezot, J. P. Joly et al., "Highly efficient metal catalysts supported on activated carbon cloths: a catalytic application for the hydrogenation of d-glucose to d-sorbitol," Applied Catalysis A, vol. 331, no. 1, pp. 100-104, 2007.

[39] R. B. Biniwale and M. Ichikawa, "Thermal imaging of catalyst surface during catalytic dehydrogenation of cyclohexane under spray-pulsed conditions," Chemical Engineering Science, vol. 62, no. 24, pp. 7370-7377, 2007.

[40] P. D. Tien, T. Satoh, M. Miura, and M. Nomura, "Continuous hydrogen evolution from cyclohexanes over platinum catalysts supported on activated carbon fibers," Fuel Processing Technology, vol. 89, no. 4, pp. 415-418, 2008.

[41] D. Xu, Z. H. Huang, F. Kang, M. Inagaki, and T. H. Ko, "Effect of heat treatment on adsorption performance and photocatalytic activity of $\mathrm{TiO}_{2}$-mounted activated carbon cloths," Catalysis Today, vol. 139, no. 1-2, pp. 64-68, 2008.

[42] J. C. Naranjo, A. Córdoba, L. Giraldo, V. S. García, and J. C. Moreno-Piraján, "Lipase supported on granular activated carbon and activated carbon cloth as a catalyst in the synthesis of biodiesel fuel," Journal of Molecular Catalysis B, vol. 66, pp. 166-171, 2010.

[43] M. A. Fontecha-Cámara, M. A. Álvarez-Merino, F. CarrascoMarín, M. V. López-Ramón, and C. Moreno-Castilla, "Heterogeneous and homogeneous Fenton processes using activated carbon for the removal of the herbicide amitrole from water," Applied Catalysis B, vol. 101, pp. 425-430, 2011.

[44] J. V. Pande, A. Shukla, and R. B. Biniwale, "Catalytic dehydrogenation of cyclohexane over Ag-M/ACC catalysts for hydrogen supply," International Journal of Hydrogen Energy, vol. 37, no. 8, pp. 6756-6763, 2012.

[45] I. Isaev, G. Salitra, A. Soffer, Y. S. Cohen, D. Aurbach, and J. Fischer, "A new approach for the preparation of anodes for Liion batteries based on activated hard carbon cloth with pore design," Journal of Power Sources, vol. 119-121, pp. 28-33, 2003.

[46] K. Babel and K. Jurewicz, "KOH activated carbon fabrics as supercapacitor material," Journal of Physics and Chemistry of Solids, vol. 65, no. 2-3, pp. 275-280, 2004.

[47] C. Sivakumar, J. N. Nian, and H. Teng, "Poly(o-toluidine) for carbon fabric electrode modification to enhance the electrochemical capacitance and conductivity," Journal of Power Sources, vol. 144, no. 1, pp. 295-301, 2005.

[48] C. M. Chuang, C. W. Huang, H. Teng, and J. M. Ting, "Effects of carbon nanotube grafting on the performance of electric double layer capacitors," Energy and Fuels, vol. 24, no. 12, pp. 64766482, 2010.

[49] A. Lewandowski, A. Olejniczak, M. Galinski, and I. Stepniak, "Performance of carbon-carbon supercapacitors based on organic, aqueous and ionic liquid electrolytes," Journal of Power Sources, vol. 195, no. 17, pp. 5814-5819, 2010.

[50] Y. Geng, Y. Song, M. Zhong, J. Shi, Q. Guo, and L. Liu, "Influence of the pitch fluoride on the electrical conductivity of 
the activated carbon cloth as electrodes of the supercapacitor," Materials Letters, vol. 64, no. 24, pp. 2673-2675, 2010.

[51] R. Elazari, G. Salitra, A. Garsuch, A. Panchenko, and D. Aurbach, "Sulfur-impregnated activated carbon fiber cloth as a binder-free cathode for rechargeable Li-S batteries," Advanced Materials, vol. 23, no. 47, pp. 5641-5644, 2011.

[52] I. Stepniak and A. Ciszewski, "Electrochemical characteristics of a new electric double layer capacitor with acidic polymer hydrogel electrolyte," Electrochimica Acta, vol. 56, no. 5, pp. 2477-2482, 2011.

[53] N. Zhu, X. Chen, T. Zhang, P. Wu, P. Li, and J. Wu, "Improved performance of membrane free single-chamber air-cathode microbial fuel cells with nitric acid and ethylenediamine surface modified activated carbon fiber felt anodes," Bioresource Technology, vol. 102, no. 1, pp. 422-426, 2011.

[54] M. T. Z. Myint and J. Dutta, "Fabrication of zinc oxide nanorods modified activated carbon cloth electrode for desalination of brackish water using capacitive deionization approach," Desalination, vol. 305, pp. 24-30, 2012.

[55] H. Xia, "Study on the treatment of high concentration dye wastewater on modified active carbon cloth electrode," Advanced Materials Research, vol. 347-353, pp. 1869-1873, 2012.

[56] M. Zhong, Y. Song, Y. Li et al., "Effect of reduced graphene oxide on the properties of an activated carbon cloth/polyaniline flexible electrode for supercapacitor application," Journal of Power Sources, vol. 217, pp. 6-12, 2012.

[57] B. V. Kaludjerović, M. S. Trtica, B. B. Radak, J. M. Stăsić, S. S. K. Mŭsović, and V. M. Dodevski, "Analysis of the interaction of pulsed laser with nanoporous activated carbon cloth," Journal of Materials Science \& Technology, vol. 27, no. 11, pp. 979-984, 2011.

[58] J. H. Tsai, H. M. Chiang, G. Y. Huang, and H. L. Chiang, "Adsorption characteristics of acetone, chloroform and acetonitrile on sludge-derived adsorbent, commercial granular activated carbon and activated carbon fibers," Journal of Hazardous Materials, vol. 154, no. 1-3, pp. 1183-1191, 2008.

[59] T. J. Bandosz, "Removal of inorganic gases and VOCs on activated carbons," in Adsorption By Carbons, E. J. Bottani and J. M. D. Tascón, Eds., Chapter 21, pp. 533-556, Elsevier, Oxford, UK, 2008.

[60] M. Yao, Q. Zhang, D. W. Hand, D. L. Perram, and R. Taylor, "Investigation of the treatability of the primary indoor volatile organic compounds on activated carbon fiber cloths at typical indoor concentrations," Journal of the Air and Waste Management Association, vol. 59, no. 7, pp. 882-890, 2009.

[61] R. Chand, R. Molina, I. Johnson, A. Hans, and D. H. Bremner, "Activated carbon cloth: a potential adsorbing/oxidizing catalyst for phenolic wastewater," Water Science and Technology, vol. 61, no. 11, pp. 2817-2823, 2010.

[62] C. C. Huang and Y. J. Su, "Removal of copper ions from wastewater by adsorption/electrosorption on modified activated carbon cloths," Journal of Hazardous Materials, vol. 175, no. 1-3, pp. 477-483, 2010.

[63] C. Moreno-Castilla, M. A. Álvarez-Merino, L. M. PastranaMartínez, and M. V. López-Ramón, "Adsorption mechanisms of metal cations from water on an oxidized carbon surface," Journal of Colloid and Interface Science, vol. 345, pp. 461-466, 2010.

[64] S. Azizian, Z. Niknam, and E. Rombi, "Adsorption of pentafluorophenol onto powdered, granular, and cloth activated carbons," Journal of Dispersion Science and Technology, vol. 33, no. 2, pp. 206-212, 2012.
[65] A. Hajian and S. Azizian, "On the adsorption of some catechol derivatives from aqueous solutions onto activated carbon cloth: equilibrium and kinetic studies," Journal of Dispersion Science and Technology, vol. 33, no. 11, pp. 629-1634, 2012.

[66] W. Shen, H. Wang, R. Guan, and Z. Li, "Surface modification of activated carbon fiber and its adsorption for vitamin B1 and folic acid," Colloids and Surfaces A, vol. 331, no. 3, pp. 263-267, 2008.

[67] P. J. M. Carrott, J. M. V. Nabais, M. M. L. R. Carrott, and J. A. Menéndez, "Microwave heating as a novel method for introducing molecular sieve properties into activated carbon fibres," Carbon, vol. 42, no. 1, pp. 227-229, 2004.

[68] X. Shao, W. Wang, and X. Zhang, "Experimental measurements and computer simulation of methane adsorption on previous activated carbon fibers," Carbon, vol. 45, no. 1, pp. 188-195, 2007.

[69] J. Zhang, W. Luan, H. Huang, Y. Qi, and S. T. Tu, “Preparation and characteristics of Pt/ACC catalyst for thermoelectric thin film hydrogen sensor," Sensors and Actuators B, vol. 128, no. 1, pp. 266-272, 2007.

[70] M. Kunowsky, B. Weinberger, F. L. Darkrim, F. Suárez-García, D. Cazorla-Amorós, and A. Linares-Solano, "Impact of the carbonisation temperature on the activation of carbon fibres and their application for hydrogen storage," International Journal of Hydrogen Energy, vol. 33, no. 12, pp. 3091-3095, 2008.

[71] L. Zubizarreta, A. Arenillas, and J. J. Pis, "Carbon materials for $\mathrm{H}_{2}$ storage," International Journal of Hydrogen Energy, vol. 34, pp. 4575-4581, 2009.

[72] G. Rodríguez-Blanco, L. Giraldo, and J. C. Moreno-Piraján, "Carbon molecular sieves from carbon cloth: influence of the chemical impregnant on gas separation properties," Applied Surface Science, vol. 256, pp. 5221-5225, 2010.

[73] F. Salvador, M. J. Sánchez-Montero, J. Montero, and C. Izquierdo, "Activated carbon fibers prepared from a phenolic fiber by supercritical water and steam activation," Journal of Physical Chemistry C, vol. 112, pp. 20057-20064, 2008.

[74] M. J. Sánchez-Montero, F. Salvador, and C. Izquierdo, "Reactivity and porosity of a carbon fiber activated with supercritical $\mathrm{CO}_{2}$," Journal of Physical Chemistry C, vol. 112, no. 13, pp. 49914999, 2008.

[75] J. L. Figueiredo, N. Mahata, M. F. R. Pereira, M. J. S. Montero, J. Montero, and F. Salvador, "Adsorption of phenol on supercritically activated carbon fibres: effect of texture and surface chemistry," Journal of Colloid and Interface Science, vol. 357, no. 1, pp. 210-214, 2011.

[76] P. T. Williams and A. R. Reed, "High grade activated carbon matting derived from the chemical activation and pyrolysis of natural fibre textile waste," Journal of Analytical and Applied Pyrolysis, vol. 71, no. 2, pp. 971-986, 2004.

[77] A. C. Pastor, F. Rodríguez-Reinoso, H. Marsh, and M. A. Martínez, "Preparation of activated carbon cloths from viscous rayon. Part I. Carbonization procedures," Carbon, vol. 37, pp. 1275-1283, 1999.

[78] F. Rodriguez-Reinoso, A. C. Pastor, H. Marsh, and M. A. Martínez, "Preparation of activated carbon cloths from viscous rayon. Part II: physical activation processes," Carbon, vol. 38, pp. 379-395, 2000.

[79] F. Rodríguez-Reinoso, A. C. Pastor, H. Marsh, and A. Huidobro, "Preparation of activated carbon cloths from viscous rayon. Part III. Effect of carbonization on $\mathrm{CO}_{2}$ activation," Carbon, vol. 38, no. 3, pp. 397-406, 2000. 
[80] A. Huidobro, A. C. Pastor, and F. R. Reinoso, "Preparation of activated carbon cloth from viscous rayon. Part IV: chemical activation," Carbon, vol. 38, pp. 389-398, 2001.

[81] M. C. B. López, A. Martínez-Alonso, and J. M. D. Tascón, "Microporous texture of activated carbon fibres prepared from Nomex aramid fibres," Microporous and Mesoporous Materials, vol. 34, no. 2, pp. 171-179, 2000.

[82] F. Suárez-García, A. Martínez-Alonso, and J. M. D. Tascón, "Beneficial effects of phosphoric acid as an additive in the preparation of activated carbon fibers from Nomex aramid fibers by physical activation," Fuel Processing Technology, vol. 7778, pp. 237-244, 2002.

[83] F. Suárez-García, A. Martínez-Alonso, and J. M. D. Tascón, "Activated carbon fibers from Nomex by chemical activation with phosphoric acid," Carbon, vol. 42, pp. 1419-1426, 2004.

[84] M. Wu, Q. Zha, J. Qiu, Y. Guo, H. Shang, and A. Yuan, "Preparation and characterization of porous carbons from PAN-based preoxidized cloth by $\mathrm{KOH}$ activation," Carbon, vol. 42, no. 1, pp. 205-210, 2004.

[85] Y. V. Basova, D. D. Edie, P. Y. Badheka, and H. C. Bellam, "The effect of precursor chemistry and preparation conditions on the formation of pore structure in metal-containing carbon fibers," Carbon, vol. 43, no. 7, pp. 1533-1545, 2005.

[86] S. Villar-Rodil, R. Navarrete, R. Denoyel et al., "Carbon molecular sieve cloths prepared by chemical vapour deposition of methane for separation of gas mixtures," Microporous and Mesoporous Materials, vol. 77, no. 2-3, pp. 109-118, 2005.

[87] J. P. Boudou, P. Parent, F. Suarez-García, S. Villar-Rodil, A. Martínez-Alonso, and J. M. D. Tascón, "Nitrogen in aramidbased activated carbon fibers by TPD, XPS and XANES," Carbon, vol. 44, pp. 2452-2462, 2006.

[88] C. Liu, W. Dong, J. Song, and L. Liu, "Evolution of microstructure and properties of phenolic fibers during carbonization," Materials Science and Engineering A, vol. 459, pp. 347-354, 2007.

[89] S. J. Zhang, H. M. Feng, J. P. Wang, and H. Q. Yu, "Structure evolution and optimization in the fabrication of PVA-based activated carbon fibres," Journal of Colloid and Interface Science, vol. 321, pp. 96-102, 2008.

[90] H. M. Feng, S. J. Zhang, Y. Z. Chen, Y. W. Ding, H. Q. Yu, and M. H. W. Lam, "Fabrication and evaluation of mesoporous poly(vinyl alcohol)-based activated carbon fibers," Industrial and Engineering Chemistry Research, vol. 48, no. 7, pp. 33983402, 2009.

[91] A. Castro-Muñiz, A. Martínez-Alonso, and J. M. D. Tascón, "Effect of PPTA pre-impregnation with phosphoric acid on the porous texture of carbons prepared by $\mathrm{CO}_{2}$ activation of PPTA chars," Microporous and Mesoporous Materials, vol. 119, no. 1-3, pp. 284-289, 2009.

[92] Y. Geng, Y. Song, M. Zhong, P. Li, Q. G. Guo, and L. Liu, "Investigation of preparation and electrochemical performance of phenolic resin based activated carbon cloth," Journal of Materials Engineering, vol. 10, pp. 1-4, 2011.

[93] M. B. Vázquez-Santos, A. Martínez-Alonso, and J. M. D. Tascón, "Activated carbon fibers from poly(p-phenylene benzobisoxazole)," Carbon, vol. 46, pp. 818-832, 2008.

[94] M. B. Vázquez-Santos, F. Suárez-García, A. Martínez-Alonso, and J. M. D. Tascón, "Activated carbon fibers with a high heteroatom content by chemical activation of $\mathrm{PBO}$ with phosphoric acid," Langmuir, vol. 28, pp. 5850-5860, 2012.

[95] K. Babeł, "Porous structure evolution of cellulose carbon fibres during heating in the initial activation stage," Fuel Processing Technology, vol. 85, pp. 75-89, 2003.
[96] J. A. Maciá-Agulló, B. C. Moore, D. Cazorla-Amorós, and A. Linares-Solano, "Influence of carbon fibres crystallinities on their chemical activation by $\mathrm{KOH}$ and $\mathrm{NaOH}$," Microporous and Mesoporous Materials, vol. 101, no. 3, pp. 397-405, 2007.

[97] P. J. M. Carrott, J. M. V. Nabais, M. M. L. R. Carrott, and J. A. Pajares, "Preparation of activated carbon fibres from acrylic textile fibres," Carbon, vol. 39, no. 10, pp. 1543-1555, 2001.

[98] P. J. M. Carrott, J. M. V. Nabais, M. M. L. R. Carrott, and J. A. Menéndez, "Thermal treatments of activated carbon fibres using a microwave furnace," Microporous and Mesoporous Materials, vol. 47, no. 2-3, pp. 243-252, 2001.

[99] J. M. V. Nabais, P. J. M. Carrott, and M. M. L. R. Carrott, "From commercial textile fibres to activated carbon fibres: chemical transformations," Materials Chemistry and Physics, vol. 93, no. 1, pp. 100-108, 2005.

[100] J. M. V. Nabais, T. Canário, P. J. M. Carrott, and M. M. L. R. Carrott, "Production of activated carbon cloth with controlled structure and porosity from a new precursor," Journal of Porous Materials, vol. 14, no. 2, pp. 181-190, 2007.

[101] J. M. V. Nabais, P. J. M. Carrott, M. M. L. R. Carrott, and J. A. Menéndez, "Preparation and modification of activated carbon fibres by microwave heating," Carbon, vol. 42, pp. 1315-1320, 2004.

[102] S. Y. You, Y. H. Park, and C. R. Park, "Preparation and properties of activated carbon fabric from acrylic fabric waste," Carbon, vol. 38, no. 10, pp. 1453-1460, 2000.

[103] P. T. Williams and A. R. Reed, "Pre-formed activated carbon matting derived from the pyrolysis of biomass natural fibre textile waste," Journal of Analytical and Applied Pyrolysis, vol. 70, no. 2, pp. 563-577, 2003.

[104] P. T. Williams and A. R. Reed, "Development of activated carbon pore structure via physical and chemical activation of biomass fibre waste," Biomass and Bioenergy, vol. 30, no. 2, pp. 144-152, 2006.

[105] M. A. Nahil and P. T. Williams, "Activated carbons from acrylic textile waste," Journal of Analytical and Applied Pyrolysis, vol. 89, no. 1, pp. 51-59, 2010.

[106] M. A. Nahil and P. T. Williams, "Surface chemistry and porosity of nitrogen-containing activated carbons produced from acrylic textile waste," Chemical Engineering Journal, vol. 184, pp. 228237, 2012.

[107] M. Olivares-Marín, S. García, C. Pevida, M. S. Wong, and M. Maroto-Valer, "The influence of the precursor and synthesis method on the $\mathrm{CO}_{2}$ capture capacity of carpet waste-based sorbents," Journal of Environmental Management, vol. 92, no. 10, pp. 2810-2817, 2011.

[108] R. Yang, H. Yu, L. Luo et al., "Pore structure of hemp clothderived carbon fibers activated by zinc chloride," Journal of Beijing University of Chemical Technology, vol. 37, no. 5, pp. 4450, 2010.

[109] M. E. Ramos, J. D. Gonzalez, P. R. Bonelli, and A. L. Cukierman, "Effect of process conditions on physicochemical and electrical characteristics of denim-based activated carbon cloths," Industrial and Engineering Chemistry Research, vol. 46, no. 4, pp. 11671173, 2007.

[110] M. E. Ramos, P. R. Bonelli, and A. L. Cukierman, "Physicochemical and electrical properties of activated carbon cloths. Effect of inherent nature of the fabric precursor," Colloids and Surfaces A, vol. 324, no. 1-3, pp. 86-92, 2008.

[111] M. E. Ramos, P. R. Bonelli, A. L. Cukierman, M. M. L. R. Carrott, and P. J. M. Carrott, "Influence of thermal treatment 
conditions on porosity development and mechanical properties of activated carbon cloths from a novel nanofibre-made fabric," Materials Chemistry and Physics, vol. 116, no. 2-3, pp. 310-314, 2009.

[112] S. Aber, A. Khataee, and M. Sheydaei, "Optimization of activated carbon fiber preparation from Kenaf using $\mathrm{K}_{2} \mathrm{HPO}_{4}$ as chemical activator for adsorption of phenolic compounds," Bioresource Technology, vol. 100, no. 24, pp. 6586-6591, 2009.

[113] M. E. Ramos, P. R. Bonelli, S. Blacher, M. M. L. R. Carrott, P. J. M. Carrott, and A. L. Cukierman, "Effect of the activating agent on physico-chemical and electrical properties of activated carbon cloths developed from a novel cellulosic precursor," Colloids and Surfaces A, vol. 378, no. 1-3, pp. 87-93, 2011.

[114] M. C. Basso, E. G. Cerrella, and A. L. Cukierman, "Activated carbons developed from a rapidly renewable biosource for removal of cadmium(II) and nickel(II) ions from dilute aqueous solutions," Industrial and Engineering Chemistry Research, vol. 41, no. 2, pp. 180-189, 2002.

[115] M. C. Basso, E. G. Cerrella, and A. L. Cukierman, "Lignocellulosic materials as potential biosorbents of trace toxic metals from wastewater," Industrial and Engineering Chemistry Research, vol. 41, no. 15, pp. 3580-3585, 2002.

[116] A. L. Cukierman, "Metal ion biosorption potential of lignocellulosic biomasses and marine algae for wastewater treatment," Adsorption Science and Technology, vol. 25, no. 3-4, pp. 227-244, 2007.

[117] M. Betancur, P. R. Bonelli, J. Velásquez, and A. L. Cukierman, "Potentiality of lignin from the Kraft pulping process for removal of trace nickel from wastewater: effect of demineralisation," Bioresource Technology, vol. 100, no. 3, pp. 1130-1137, 2009.

[118] D. A. Nabarlatz, J. de Celis, P. Bonelli, and A. L. Cukierman, "Batch and dynamic sorption of $\mathrm{Ni}$ (II) ions by activated carbon based on a native lignocellulosic precursor," Journal of Environmental Management, vol. 97, pp. 109-115, 2012.

[119] K. Kadirvelu, C. Faur-Brasquet, and P. Le Cloirec, "Removal of $\mathrm{Cu}(\mathrm{II}), \mathrm{Pb}$ (II), and $\mathrm{Ni}$ (II) by adsorption onto activated carbon cloths," Langmuir, vol. 16, no. 22, pp. 8404-8409, 2000.

[120] J. R. Rangel-Mendez and M. Streat, "Adsorption of cadmium by activated carbon cloth: influence of surface oxidation and solution pH," Water Research, vol. 36, no. 5, pp. 1244-1252, 2002.

[121] A. Afkhami, T. Madrakian, Z. Karimi, and A. Amini, "Effect of treatment of carbon cloth with sodium hydroxide solution on its adsorption capacity for the adsorption of some cations," Colloids and Surfaces A, vol. 304, no. 1-3, pp. 36-40, 2007.

[122] A. Afkhami, T. Madrakian, A. Amini, and Z. Karimi, "Effect of the impregnation of carbon cloth with ethylenediaminetetraacetic acid on its adsorption capacity for the adsorption of several metal ions," Journal of Hazardous Materials, vol. 150, no. 2, pp. 408-412, 2008.

[123] O. Duman and E. Ayranci, "Attachment of benzo-crown ethers onto activated carbon cloth to enhance the removal of chromium, cobalt and nickel ions from aqueous solutions by adsorption," Journal of Hazardous Materials, vol. 176, no. 1-3, pp. 231-238, 2010.

[124] I. D. Harry, B. Saha, and I. W. Cumming, "Effect of electrochemical reduction and oxidation of a viscose rayon based activated carbon cloth for $\mathrm{Cr}(\mathrm{VI})$ sorption from aqueous solution," Industrial and Engineering Chemistry Research, vol. 47, no. 17, pp. 6734-6741, 2008.

[125] D. Mohan, K. P. Singh, and V. K. Singh, "Removal of hexavalent chromium from aqueous solution using low-cost activated carbons derived from agricultural waste materials and activated carbon fabric cloth," Industrial and Engineering Chemistry Research, vol. 44, no. 4, pp. 1027-1042, 2005.

[126] C. Faur-Brasquet, K. Kadirvelu, and P. Le Cloirec, "Removal of metal ions from aqueous solution by adsorption onto activated carbon cloths: adsorption competition with organic matter," Carbon, vol. 40, no. 13, pp. 2387-2392, 2002.

[127] C. Moreno-Castilla, M. A. Alvarez-Merino, M. V. LópezRamón, and J. Rivera-Utrilla, "Cadmium ion adsorption on different carbon adsorbents from aqueous solutions. effect of surface chemistry, pore texture, ionic strength, and dissolved natural organic matter," Langmuir, vol. 20, pp. 8142-8148, 2004.

[128] M. Goyal, M. Bhagat, and R. Dhawan, "Removal of mercury from water by fixed bed activated carbon columns," Journal of Hazardous Materials, vol. 171, no. 1-3, pp. 1009-1015, 2009.

[129] M. A. Álvarez-Merino, V. López-Ramón, and C. MorenoCastilla, "A study of the static and dynamic adsorption of $\mathrm{Zn}$ (II) ions on carbon materials from aqueous solutions," Journal of Colloid and Interface Science, vol. 288, pp. 335-341, 2005.

[130] R. Leyva-Ramos, P. E. Diaz-Flores, A. Aragon-Piña, J. Mendoza-Barron, and R. M. Guerrero-Coronado, "Adsorption of cadmium(II) from an aqueous solution onto activated carbon cloth," Separation Science and Technology, vol. 40, no. 10, pp. 2079-2094, 2005.

[131] A. Afkhami, T. Madrakian, and Z. Karimi, "The effect of acid treatment of carbon cloth on the adsorption of nitrite and nitrate ions," Journal of Hazardous Materials, vol. 144, no. 1-2, pp. 427-431, 2007.

[132] A. Afkhami, T. Madrakian, and A. Amini, "Mo(VI) and W(VI) removal from water samples by acid-treated high area carbon cloth," Desalination, vol. 243, no. 1-3, pp. 258-264, 2009.

[133] B. Saha, I. D. Harry, and U. Siddiqui, "Electrochemically modified viscose-rayon-based activated carbon cloth for competitive and noncompetitive sorption of trace cobalt and lead ions from aqueous solution," Separation Science and Technology, vol. 44, no. 16, pp. 3950-3972, 2009.

[134] M. Goyal and M. Bhagat, "Dynamic adsorption of $\mathrm{Pb}$ (II) ions from aqueous solution using activated carbon beds," Indian Journal of Engineering and Materials Sciences, vol. 17, no. 5, pp. 367-372, 2010.

[135] C. Moreno-Castilla, "Adsorption of organic solutes from dilute aqueous solutions," in Adsorption By Carbons, E. J. Bottani and J. M. D. Tascón, Eds., Chapter 25, pp. 653-678, Elsevier, Oxford, UK, 2008.

[136] H. Métivier-Pignon, C. Faur-Brasquet, and P. Le Cloirec, "Adsorption of dyes onto activated carbon cloths: approach of adsorption mechanisms and coupling of ACC with ultrafiltration to treat coloured wastewaters," Separation and Purification Technology, vol. 31, no. 1, pp. 3-11, 2003.

[137] H. Métivier-Pignon, C. Faur, and P. L. Cloirec, "Adsorption of dyes onto activated carbon cloth: using QSPRs as tools to approach adsorption mechanisms," Chemosphere, vol. 66, no. 5, pp. 887-893, 2007.

[138] N. Hoda, E. Bayram, and E. Ayranci, "Kinetic and equilibrium studies on the removal of acid dyes from aqueous solutions by adsorption onto activated carbon cloth," Journal of Hazardous Materials, vol. 137, no. 1, pp. 344-351, 2006.

[139] S. Aber and M. Sheydaei, "Removal of COD from industrial effluent containing Indigo dye using adsorption method by activated carbon cloth: optimization, kinetic, and isotherm studies," Clean-Soil, Air, Water, vol. 40, no. 1, pp. 87-94, 2012. 
[140] O. Duman and E. Ayranci, "Adsorptive removal of cationic surfactants from aqueous solutions onto high-area activated carbon cloth monitored by in situ UV spectroscopy," Journal of Hazardous Materials, vol. 174, no. 1-3, pp. 359-367, 2010.

[141] E. Ayranci and O. Duman, "Removal of anionic surfactants from aqueous solutions by adsorption onto high area activated carbon cloth studied by in situ UV spectroscopy," Journal of Hazardous Materials, vol. 148, no. 1-2, pp. 75-82, 2007.

[142] E. Ayranci and N. Hoda, "Adsorption kinetics and isotherms of pesticides onto activated carbon-cloth," Chemosphere, vol. 60, no. 11, pp. 1600-1607, 2005.

[143] P. E. Diaz-Flores, R. Leyva-Ramos, R. M. Guerrero-Coronado, and J. Mendoza-Barron, "Adsorption of pentachlorophenol from aqueous solution onto activated carbon fiber," Industrial and Engineering Chemistry Research, vol. 45, no. 1, pp. 330-336, 2006.

[144] M. V. López-Ramón, M. A. Fontecha-Cámara, M. A. AlvarezMerino, and C. Moreno-Castilla, "Removal of diuron and amitrole from water under static and dynamic conditions using activated carbons in form of fibers, cloth, and grains," Water Research, vol. 41, pp. 2865-2870, 2007.

[145] L. M. Pastrana-Martínez, M. V. López-Ramón, and C. MorenoCastilla, "Adsorption and thermal desorption of the herbicide fluroxypyr on activated carbon fibers and cloth at different $\mathrm{pH}$ values," Journal of Colloid and Interface Science, vol. 331, no. 1, pp. 2-7, 2009.

[146] L. M. Pastrana-Martínez, M. V. López-Ramón, M. A. FontechaCámara, and C. Moreno-Castilla, "Batch and column adsorption of herbicide fluroxypyr on different types of activated carbons from water with varied degrees of hardness and alkalinity," Water Research, vol. 44, pp. 879-885, 2010.

[147] C. Moreno-Castilla, M. V. López-Ramón, L. M. PastranaMartínez, M. A. Álvarez-Merino, and M. A. Fontecha-Cámara, "Competitive adsorption of the herbicide fluroxypyr and tannic acid from distilled and tap water on activated carbons and their thermal desorption," Adsorption, vol. 18, pp. 173-179, 2012.

[148] C. Moreno-Castilla, M. A. Fontecha-Cámara, M. A. ÁlvarezMerino, M. V. López-Ramón, and F. Carrasco-Marín, "Activated carbon cloth as adsorbent and oxidation catalyst for the removal of amitrole from aqueous solution," Adsorption, vol. 17, pp. 413419, 2011.

[149] I. P. P. Cansado, P. A. M. Mourão, A. I. Falcão, M. M. L. R. Carrott, and P. J. M. Carrott, "The influence of the activated carbon post-treatment on the phenolic compounds removal," Processing Technology, vol. 103, pp. 64-70, 2012.

[150] E. Bayram, N. Hoda, and E. Ayranci, "Adsorption/electrosorption of catechol and resorcinol onto high area activated carbon cloth," Journal of Hazardous Materials, vol. 168, no. 2-3, pp. 1459-1466, 2009.

[151] E. Ayranci and O. Duman, "Adsorption of aromatic organic acids onto high area activated carbon cloth in relation to wastewater purification," Journal of Hazardous Materials, vol. 136, no. 3, pp. 542-552, 2006.

[152] O. Duman and E. Ayranci, "Structural and ionization effects on the adsorption behaviors of some anilinic compounds from aqueous solution onto high-area carbon-cloth," Journal of Hazardous Materials, vol. 120, no. 1-3, pp. 173-181, 2005.

[153] E. Ayranci and E. Bayram, "Adsorption of phthalic acid and its esters onto high-area activated carbon-cloth studied by in situ UV-spectroscopy," Journal of Hazardous Materials, vol. 122, no. 1-2, pp. 147-153, 2005.
[154] E. Ayranci and O. Duman, "Structural effects on the interactions of benzene and naphthalene sulfonates with activated carbon cloth during adsorption from aqueous solutions," Chemical Engineering Journal, vol. 156, no. 1, pp. 70-76, 2010.

[155] R. Leyva-Ramos, R. Ocampo-Perez, and J. Mendoza-Barron, "External mass transfer and hindered diffusion of organic compounds in the adsorption on activated carbon cloth," Chemical Engineering Journal, vol. 183, pp. 141-151, 2012.

[156] P. Alonso-Davila, O. L. Torres-Rivera, R. Leyva-Ramos, and R. Ocampo-Perez, "Removal of pyridine from aqueous solution by adsorption on an activated carbon cloth," Clean-Soil, Air, Water, vol. 40, no. 1, pp. 45-53, 2012.

[157] P. Monneyron, C. Faur-Brasquet, A. Sakoda, M. Suzuki, and P. Le Cloirec, "Competitive adsorption of organic micropollutants in the aqueous phase onto activated carbon cloth: comparison of the IAS model and neural networks in modeling data," Langmuir, vol. 18, no. 13, pp. 5163-5169, 2002.

[158] R. Srinivasan and G. A. Sorial, "Adsorption of geosmin and MIB on activated carbon fibers-single and binary solute system," Water, Air, and Soil Pollution, vol. 9, no. 3, pp. 223-235, 2009.

[159] M. E. Fernandez, G. V. Nunell, P. R. Bonelli, and A. L. Cukierman, "Effectiveness of Cupressus sempervirens cones as biosorbent for the removal of basic dyes from aqueous solutions in batch and dynamic modes," Bioresource Technology, vol. 101, no. 24, pp. 9500-9507, 2010.

[160] M. E. Fernandez, G. V. Nunell, P. R. Bonelli, and A. L. Cukierman, "Batch and dynamic biosorption of basic dyes from binary solutions by alkaline-treated cypress cone chips," Bioresource Technology, vol. 106, pp. 55-62, 2012.

[161] P. Ravichandran, A. Sowmya, and S. Meenakshi, "Equilibrium and kinetic studies on the removal of basic violet 10 from aqueous solutions using activated carbons prepared from industrial wastes," Bioremediation Journal, vol. 16, no. 2, pp. 86-96, 2012.

[162] E. Ayranci and N. Hoda, "Adsorption of bentazon and propanil from aqueous solutions at the high area activated carbon-cloth," Chemosphere, vol. 57, no. 8, pp. 755-762, 2004.

[163] G. Kyriakopoulos and D. Doulia, "Adsorption of pesticides on carbonaceous and polymeric materials from aqueous solutions: a review," Separation and Purification Reviews, vol. 35, no. 3, pp. 97-191, 2006.

[164] E. Ayranci and N. Hoda, "Studies on removal of metribuzin, bromacil, 2,4-D and atrazine from water by adsorption on high area carbon cloth," Journal of Hazardous Materials, vol. 112, no. 1-2, pp. 163-168, 2004.

[165] A. Dąbrowski, P. Podkościelny, Z. Hubicki, and M. Barczak, "Adsorption of phenolic compounds by activated carbon-a critical review," Chemosphere, vol. 58, pp. 1049-1070, 2005.

[166] E. Ayranci and O. Duman, "Adsorption behaviors of some phenolic compounds onto high specific area activated carbon cloth," Journal of Hazardous Materials, vol. 124, no. 1-3, pp. 125132, 2005.

[167] E. Ayranci, N. Hoda, and E. Bayram, "Adsorption of benzoic acid onto high specific area activated carbon cloth," Journal of Colloid and Interface Science, vol. 284, no. 1, pp. 83-88, 2005.

[168] T. Vasiljević, J. Spasojević, M. Baćić, A. Onjia, and M. Laušević, "Adsorption of phenol and 2, 4-dinitrophenol on activated carbon cloth: the influence of sorbent surface acidity and $\mathrm{pH}$," Separation Science and Technology, vol. 41, pp. 1061-1075, 2006.

[169] Z. Hashisho, M. Rood, and L. Botich, "Microwave-swing adsorption to capture and recover vapors from air streams with activated carbon fiber cloth," Environmental Science and Technology, vol. 39, no. 17, pp. 6851-6859, 2005. 
[170] D. Ramirez, S. Qi, M. J. Rood, and K. J. Hay, "Equilibrium and heat of adsorption for organic vapors and activated carbons," Environmental Science \& Technology, vol. 39, pp. 5864-5871, 2005.

[171] L. M. Le Leuch, A. Subrenat, and P. Le Cloirec, "Hydrogen sulfide adsorption and oxidation onto activated carbon cloths: applications to odorous gaseous emission treatments," Langmuir, vol. 19, no. 26, pp. 10869-10877, 2003.

[172] J. P. Boudou, "Surface chemistry of a viscose-based activated carbon cloth modified by treatment with ammonia and steam," Carbon, vol. 41, no. 10, pp. 1955-1963, 2003.

[173] J. P. Boudou, M. Chehimi, E. Broniek, T. Siemieniewska, and J. Bimer, "Adsorption of $\mathrm{H}_{2} \mathrm{~S}$ or $\mathrm{SO}_{2}$ on an activated carbon cloth modified by ammonia treatment," Carbon, vol. 41, no. 10, pp. 1999-2007, 2003.

[174] P. Sullivan, J. Moate, B. Stone, J. D. Atkinson, Z. Hashisho, and M. J. Rood, "Physical and chemical properties of PAN-derived electrospun activated carbon nanofibers and their potential for use as an adsorbent for toxic industrial chemicals," Adsorption, vol. 18, pp. 265-274, 2012.

[175] P. D. Sullivan, M. J. Rood, G. Grevillot, J. D. Wander, and K. J. Hay, "Activated carbon fiber cloth electrothermal swing adsorption system," Environmental Science and Technology, vol. 38, no. 18, pp. 4865-4877, 2004.

[176] Y. C. Chiang, C. Y. Lee, and H. C. Lee, "Surface chemistry of polyacrylonitrile- and rayon-based activated carbon fibers after post-heat treatment," Materials Chemistry and Physics, vol. 101, no. 1, pp. 199-210, 2007.

[177] M. E. Ramos, P. R. Bonelli, A. L. Cukierman, M. M. L. R. Carrott, and P. J. M. Carrott, "Adsorption of volatile organic compounds onto activated carbon cloths derived from a novel regenerated cellulosic precursor," Journal of Hazardous Materials, vol. 177, no. 1-3, pp. 175-182, 2010.

[178] E. M. Carter, L. E. Katz, G. E. Speitel Jr., and D. Ramirez, "Gasphase formaldehyde adsorption isotherm studies on activated carbon: correlations of adsorption capacity to surface functional group density," Environmental Science and Technology, vol. 45, no. 15, pp. 6498-6503, 2011.

[179] X. Fan, C. Li, G. Zeng et al., "Removal of gas-phase element mercury by activated carbon fiber impregnated with $\mathrm{CeO}_{2}$," Energy and Fuels, vol. 24, no. 8, pp. 4250-4254, 2010.

[180] K. P. Singh, D. Mohan, G. S. Tandon, and G. S. D. Gupta, "Vapor-phase adsorption of hexane and benzene on activated carbon fabric cloth: equilibria and rate studies," Industrial and Engineering Chemistry Research, vol. 41, no. 10, pp. 2480-2486, 2002.

[181] L. Luo, D. Ramirez, M. J. Rood, G. Grevillot, K. J. Hay, and D. L. Thurston, "Adsorption and electrothermal desorption of organic vapors using activated carbon adsorbents with novel morphologies," Carbon, vol. 44, no. 13, pp. 2715-2723, 2006.

[182] G. Y. Oh, Y. W. Ju, M. Y. Kim, H. R. Jung, H. J. Kim, and W. J. Lee, "Adsorption of toluene on carbon nanofibers prepared by electrospinning," The Science of the Total Environment, vol. 393, pp. 341-347, 2008.

[183] M. A. Lillo-Ródenas, D. Cazorla-Amorós, and A. LinaresSolano, "Benzene and toluene adsorption at low concentration on activated carbon fibres," Adsorption, vol. 17, no. 3, pp. 473481, 2011.

[184] M. Yao, Q. Zhang, D. W. Hand, D. Perram, and R. Taylor, "Adsorption and regeneration on activated carbon fiber cloth for volatile organic compounds at indoor concentration levels,"
Journal of the Air and Waste Management Association, vol. 59, no. 1, pp. 31-36, 2009.

[185] A. S. Subrenat and P. A. Le Cloirec, "Volatile organic compound (VOC) removal by adsorption onto activated carbon fiber cloth and electrothermal desorption: an industrial application," Chemical Engineering Communications, vol. 193, no. 4, pp. 478486, 2006.

[186] C. Faur-Brasquet and P. Le Cloirec, "Modelling of the flow behavior of activated carbon cloths using a neural network approach," Chemical Engineering and Processing, vol. 42, no. 8-9, pp. 645-652, 2003.

[187] B. Boulinguiez and P. Le Cloirec, "Adsorption on activated carbons of five selected volatile organic compounds present in biogas: comparison of granular and fiber cloth materials," Energy and Fuels, vol. 24, no. 9, pp. 4756-4765, 2010.

[188] D. L. Johnsen, K. E. Mallouk, and M. J. Rood, "Control of electrothermal heating during regeneration of activated carbon fiber cloth," Environmental Science and Technology, vol. 45, no. 2, pp. 738-743, 2011.

[189] D. L. Johnsen and M. J. Rood, "Temperature control during regeneration of activated carbon fiber cloth with resistancefeedback," Environmental Science \& Technology, vol. 46, pp. 11305-11312, 2012.

[190] H. Emamipour, Z. Hashisho, D. Cevallos et al., "Steady-state and dynamic desorption of organic vapor from activated carbon with electrothermal swing adsorption," Environmental Science and Technology, vol. 41, no. 14, pp. 5063-5069, 2007.

[191] Z. Hashisho, M. J. Rood, S. Barot, and J. Bernhard, "Role of functional groups on the microwave attenuation and electric resistivity of activated carbon fiber cloth," Carbon, vol. 47, no. 7, pp. 1814-1823, 2009.

[192] M. Lordgooei and M. S. Kim, "Modeling volatile organic compound sorption in activated carbon. II: multicomponent equilibrium," Journal of Environmental Engineering, vol. 130, no. 3, pp. 223-230, 2004. 

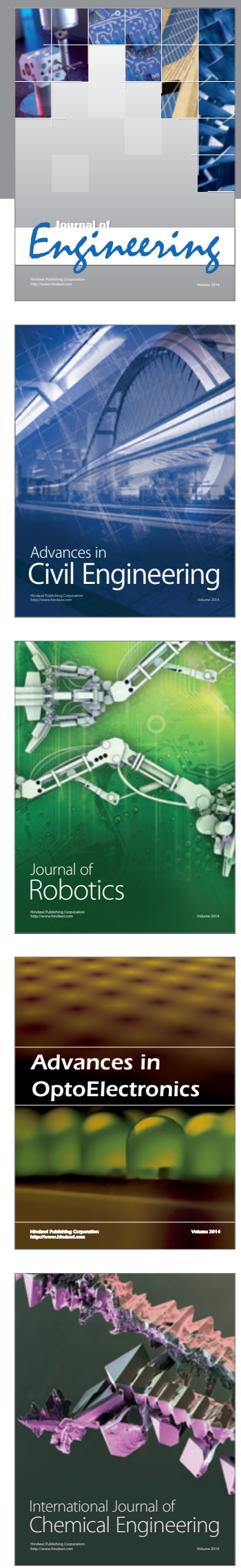



The Scientific World Journal
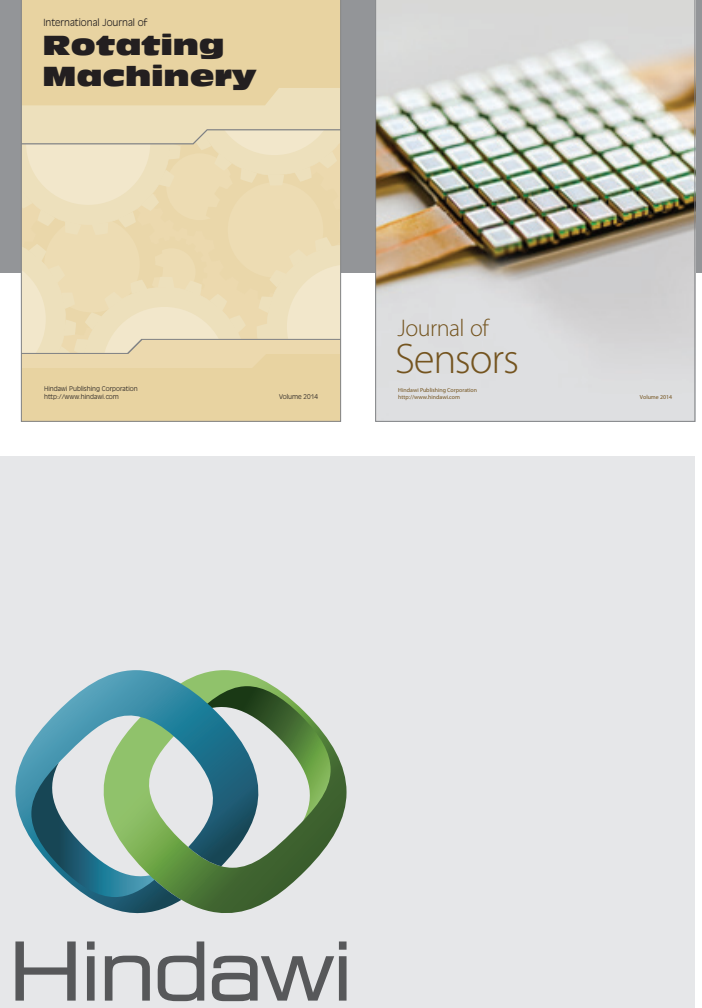

Submit your manuscripts at http://www.hindawi.com
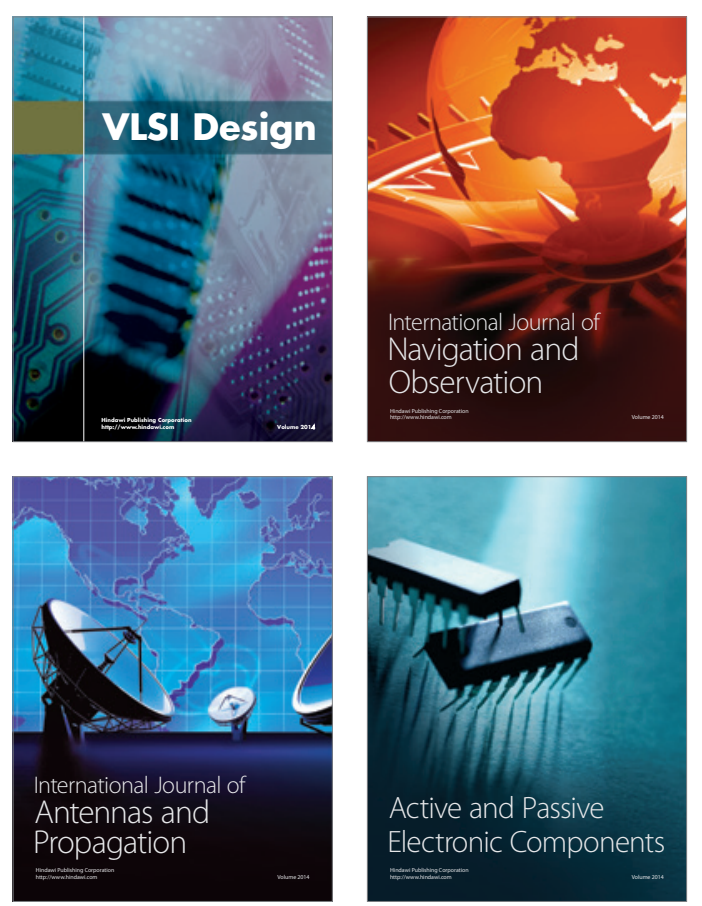


Journal of

Control Science

and Engineering
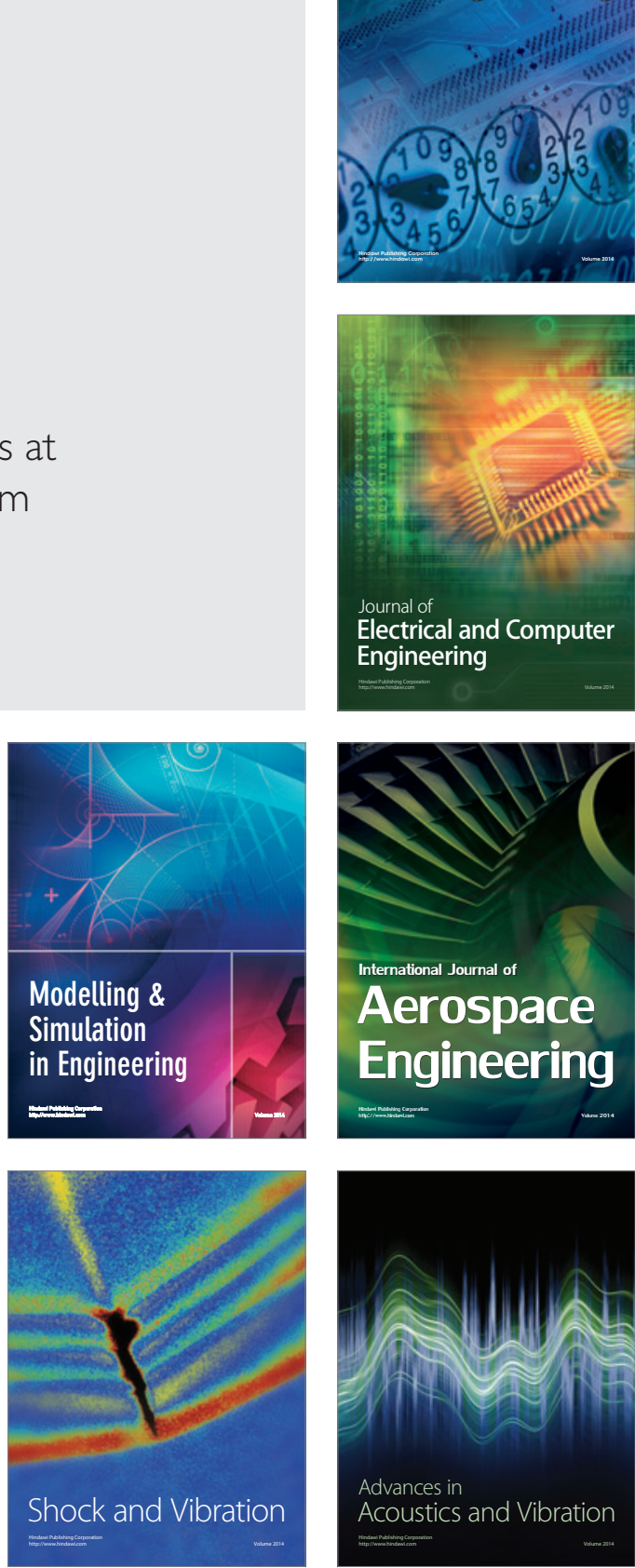